NUREG/CR-4513

ANL-93/22

Rev. 1

\title{
Estimation of Fracture Toughness of Cast Stainless Steels During Thermal Aging in LWR Systems
}

Manuscript Completed: May 1994

Date Published: August 1994

Prepared by

O. K. Chopra

Argonne National Laboratory

9700 South Cass Avenue

Argonne, IL 60439

Prepared for

Division of Engineering

Office of Nuclear Regulatory Research

U.S. Nuclear Regulatory Commission

Washington, DC 20555-0001

NRC FIN A2243

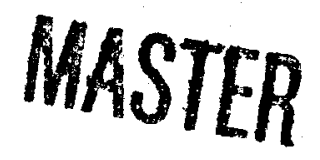




\section{Previous Documents in Series}

Initial Assessment of the Mechanisms and Significance of Low-Temperature Embrittlement of Cast Statnless Steels in LWR Systems, NUREG/CR-5385. ANL-89/17 (August 1990).

Estimation of Fracture Toughness of Cast Statiless Steels During Thermal Aging in LWR Systems, NUREG/CR-4513, ANL-90/42 (June 1991). 


\title{
Estimation of Fracture Toughness of Cast Stainless Steels during Thermal Aging in LWR Systems - Revision 1
}

by

\author{
O. K. Chopra
}

\begin{abstract}
This report presents a revision of the procedure and correlations presented earlier in NUREG/CR-4513, ANL-90/42 (June 1991) for predicting the change in mechanical properties of cast stainless steel components due to thermal aging during service in light water reactors at $280-330^{\circ} \mathrm{C}\left(535-625^{\circ} \mathrm{F}\right)$. The correlations presented in this report are based on an expanded data base and have been optimized with mechanical-property data on cast stainless steels aged up to $\approx 58,000 \mathrm{~h}$ at $290-350^{\circ} \mathrm{C}\left(554-633^{\circ} \mathrm{F}\right)$. The correlations for estimating the change in tenslle stress, including the Ramberg/Osgood parameters for strain hardening, are also described. The fracture toughness J-R curve, tensile stress, and Charpy-impact energy of aged cast stainless steels are estimated from known material information. Mechanical properties of a specific cast stainless steel are estimated from the extent and kdnetics of thermal embrittlement. Embrittlement of cast stainless steels is characterized in terms of room-temperature Charpy-Impact energy. The extent or degree of thermal embrittlement at "saturation," 1.e., the minimum impact energy that can be achieved for a material after long-term aging, is determined from the chemical composition of the steel. Charpy-impact energy as a function of time and temperature of reactor service is estimated from the kinetics of thermal embrittlement. which are also determined from the chemical composition. The initial impact energy of the unaged steel is required for these estimations. Initial tensile flow stress is needed for estimating the flow stress of the aged material. The fracture toughness J-R curve for the material is then obtained by correlating room-temperature Charpy-impact energy with fracture toughness parameters. The values of $J_{I C}$ are determined from the estimated $J-R$ curve and flow stress. A common "predicted lower-bound" J-R curve for cast stainless steels of unknown chemical composition is also defined for a given grade of steel, range of ferrite content, and temperature. Examples of estimating mechanical properties of cast stainless steel components during reactor service are presented.
\end{abstract}




\section{Contents}

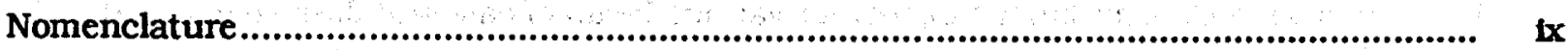

Executive Summary …......................................................................................................

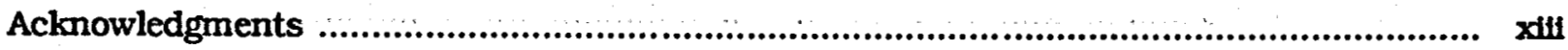

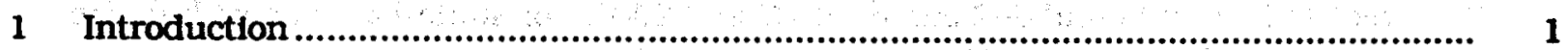

2 Mechanism of Thermal Embrittlement ......................................................................... 3

3 Assessment of Thermal Embrittlement …......................................................... 5

3.1 Estimate for Steels of Unknown Composition: Lower-Bound Values .................. 6

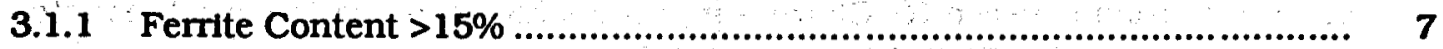

3.1.2 Ferrite Content 10-15\% .......................................................... 10

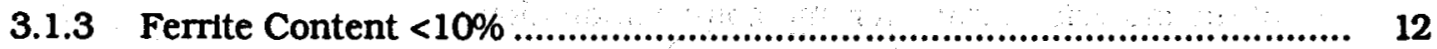

3.2 Estimate for Steels of Known Composition and Unknown Service History:

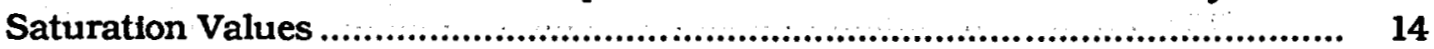

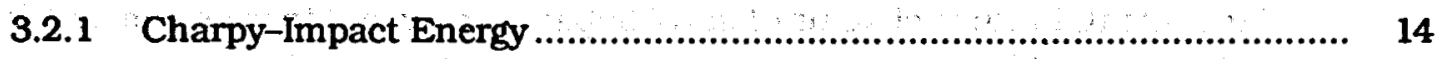

3.2.2 Fracture Toughness J-R Curve....................................................... 19

3.3 Estimate for Steels of Known Composition and Service History:

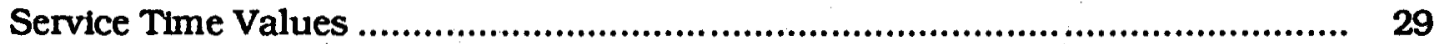

3.3.1 Charpy-Impact Energy …......................................................... 29

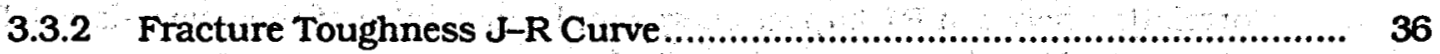

3.4 Estimation of Tensile Properties …................................................................... 38

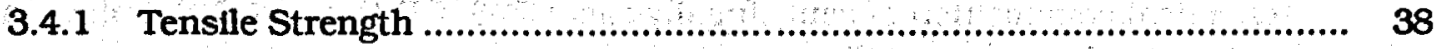

3.4.2 Ramberg-Osgood Parameters ............................................................ 46

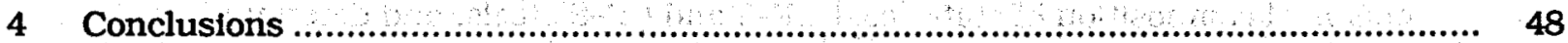

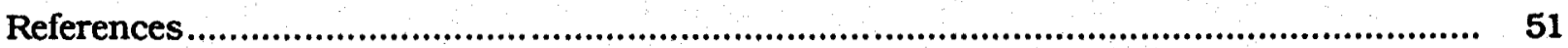

Appendix: Estimation of Fracture Properties of Cast SSs ........................................... A-1 


\section{List of Figures}

1. Decrease in Charpy-Impact energy for various heats of cast stainless steels aged at $400^{\circ} \mathrm{C}$

2. Flow diagram for estimating mechanical properties of aged cast stainless steels in LWR systems

3. Predicted lower-bound J-R curves at RT and $290^{\circ} \mathrm{C}$ for static-cast SSs with ferrite contents $>15,10-15$, or $<10 \%$.

4. Predicted lower-bound J-R curves at RT and $290^{\circ} \mathrm{C}$ for centrifugally cast SSs with ferrite contents $>15,10-15$, or $<10 \%$

5. Measured and calculated ferrite content of various heats of cast stainless steel

6. Correlation between RT Charpy-impact energy at saturation and the material parameter $\phi$ for $C F-3, C F-8$, and CF-8M steels

7. Experimental values of saturation $\mathrm{RT}$ Impact energy and those estimated in terms of the material parameter and composition alone

8. Experimental and lower of the two estimated values of saturation RT impact energy

9. Experimental values of saturation RT Impact energy and those estimated from old and new correlations

10. Estimates of ferrite content obtained from Hull's equivalent factors and ASTM

A 800

11. Correlation between RT Charpy-impact energy and coefficient $\mathrm{C}$ for cast stainless steel at $290-320^{\circ} \mathrm{C}$ and at $\mathrm{RT}$.

12. Correlation between RT impact energy and exponent $n$ of the power-law J-R curve at $\mathrm{RT}$ and $290^{\circ} \mathrm{C}$ for cast stainless steels

13. Saturation fracture toughness J-R curves at $R T$ and $290^{\circ} \mathrm{C}$, estimated from the chemical composition of centrifugally cast $\mathrm{CF}-3, \mathrm{CF}-8$, and $\mathrm{CF}-8 \mathrm{M}$ pipes, and determined experimentally

14. Saturation fracture toughness $J-R$ curves at $R T$ and $290^{\circ} \mathrm{C}$, estimated from the chemical composition of static-cast CF-3 and CF- 8 steels, and determined expertmentally

15. Saturation fracture toughness J-R curves at RT and $290^{\circ} \mathrm{C}$, estimated from the chemical composition of static-cast CF-8M steels, and determined experimentally.... 
16. Saturation fracture toughness $J-R$ curves at $R T$ and $290^{\circ} \mathrm{C}$, estimated from the chemical composition of static-cast $\mathrm{CF}-3$ and $\mathrm{CF}-8 \mathrm{M}$ steels, and determined experimentally

17. Fracture toughness $J-R$ curve for unaged cast stainless steels at $290^{\circ} \mathrm{C}$ and wrought stainless steels at various temperatures

18. Observed and estimated activation energy for thermal embrittlement of cast stainless steels

19. RT Charpy-impact energy for 16 ANL heats and 1 EPRI heat, observed experimentally and estimated from the composition and initial impact energy of the materials

20. RT Charpy-Impact energy for the GF, FRA and EdF heats, observed experimentally and estimated from the composition and initial impact energy of the materials

21. Fracture toughness $\mathrm{J}-\mathrm{R}$ curve at $\mathrm{RT}$ and $290^{\circ} \mathrm{C}$, estimated from the chemical composition and initial Charpy-impact energy and determined experimentally

22. Fracture toughness J-R curves at RT and $290^{\circ} \mathrm{C}$, estimated from the chemical composition and initial Charpy-impact energy and determined experimentally

23. Flow stress ratio of aged cast stainless steels at $\mathrm{RT}$ and $290^{\circ} \mathrm{C}$ as a function of the normalized aging parameter

24. Experimental and estimated flow stress of aged cast stainless steel at $290^{\circ} \mathrm{C}$ and RT.

25. Experimental and estimated values of $\mathrm{J}_{\mathrm{IC}}$ for aged cast stainless steels

26. Experimental and estimated yield stress of aged cast stainless steel at $290^{\circ} \mathrm{C}$ and RT.

27. Correlation between the Ramberg/Osgood parameter $\alpha_{1}$ and flow stress at RT and $290^{\circ} \mathrm{C}$ for cast stainless steels

28. Engineering stress-vs.-strain curve at RT and $290^{\circ} \mathrm{C}$, estimated from the chemical composition and initial tenslle strength and determined experimentally for thermally aged CF-3, CF-8, and CF-8M steels

A-1. Estimation scheme for Example 1

A-2. Estimation scheme for Example 2

A-3. Estimation scheme for Example 3

A-4. Estimation scheme for Example 4 
A-5. Estimation scheme for Example 5

\section{List of Tables}

1. Chemical composition, ferrite content, and kinetics of thermal embrittlement for various heats of cast stainless steels 


\section{Nomenclature}

C Coefficient of the power-law J-R curve.

Creq Chromlum equitvalent for a materlal (wt.\%).

CV Room-temperature "normalized" Charpy-impact energy, 1.e., Charpy-impact energy per unit fracture area, at any given service and aging time $\left(\mathrm{J} / \mathrm{cm}^{2}\right)$. The fracture area for a standard Charpy V-notch specimen (ASTM Specification E 23) is $0.8 \mathrm{~cm}^{2}$. Divide the value of impact energy in $\mathrm{J}$ by 0.8 to obtain "normalized". impact energy.

CVint Initial room-temperature "normalized" Charpy-impact energy of a material, 1.e., unaged material $\left(\mathrm{J} / \mathrm{cm}^{2}\right)$.

CVsat Room-temperature "normalized" Charpy-impact energy of a material at saturation, 1.e., the minimum impact energy that would be achleved for the material after longterm service $\left(\mathrm{J} / \mathrm{cm}^{2}\right)$.

CMTR Certified material test record.

$\mathrm{J}_{\mathrm{d}} \quad$ Deformation $\mathrm{J}$ per ASTM Specification E $813-85$ or E $1152-87\left(\mathrm{~kJ} / \mathrm{m}^{2}\right)$.

$n$ Exponent of the power-law J-R curve.

$n_{1} \quad$ Ramberg/Osgood parameter.

$\mathrm{Ni}_{\mathrm{eq}} \quad$ Nickel equivalent for a material (wt.\%).

P Aging parameter, 1.e., the log of the time of aging at $400^{\circ} \mathrm{C}$.

8 Activation energy for the process of thermal embrittlement $(\mathrm{kJ} / \mathrm{mole})$.

$\mathbf{R}_{\mathrm{f}} \quad$ Ratio of tensile flow stress of aged $\sigma_{f_{\text {aged }}}$ and unaged $\sigma_{f_{\text {unaged }}}$ cast stainless steel.

$R_{\mathbf{y}} \quad$ Ratio of tensile yleld stress of aged $\sigma_{\text {yaged }}$ and unaged $\sigma_{\text {yunaged }}$ cast stainless steel.

t Service or aging time (h).

$\mathrm{T}_{\mathrm{s}} \quad$ Service or aging temperature $\left({ }^{\circ} \mathrm{C}\right)$.

$\alpha \quad$ Shape factor of the curve for the change in room-temperature Charpy-impact energy with time and temperature of aging.

$\alpha_{1} \quad$ Ramberg/Osgood parameter.

$\beta \quad$ Half the maximum change in room-temperature Charpy-impact energy.

$\delta_{c} \quad$ Ferrite content calculated from the chemical composition of a material (\%).

$\Delta \mathrm{a} \quad$ Crack extension (mm).

$\Phi \quad$ Material parameter.

$\theta \quad$ Aging behavior at $400^{\circ} \mathrm{C}$, 1.e., the $\log$ of the time to achieve $\beta$ reduction in impact energy at $400^{\circ} \mathrm{C}$. 
In this report, all values of impact energy are considered to be for a standard Charpy-Vnotch specimen per ASTM Spectfication E 23, 1.e., $10 \times 10-\mathrm{mm}$ cross section and 2-mm $V$ notch. Impact energies obtained on subsize specimens should be normalized with respect to the actual cross-sectional area and appropriate correction factors should be applied to account for size effects. Similarly, impact energy from other standards, e.g., U-notch specimen, should be converted to a Charpy-V-notch value by appropriate correlations.

SI units of measurements have been used in this report. Conversion factors for measurements in British units are as follows:

\begin{tabular}{lll} 
To convert from & to & multiply by \\
In. & $\mathrm{mm}$ & 25.4 \\
$\mathcal{J}^{*}$ & $\mathrm{ft} \cdot \mathrm{lb}$ & 0.7376 \\
$\mathrm{~kJ} / \mathrm{m}^{2}$ & $\mathrm{ln} .-\mathrm{lb} / \mathrm{ln} .^{2}$ & 5.71015 \\
$\mathrm{~kJ} / \mathrm{mole}$ & $\mathrm{kcal} / \mathrm{mole}$ & 0.239 \\
\hline
\end{tabular}

When impact energy is expressed in $\mathrm{J} / \mathrm{cm}^{2}$. first multiply by 0.8 to obtatn impact energy of a standard Charpy V-notch specimen in $\mathrm{J}$. 
Cast statnless steels used in valve bodies, pump casings, piping, and other components in coolant systems of light water reactors (LWRs) suffer a loss in fracture toughness due to thermal aging after many years of service at temperatures in the range of $280-320^{\circ} \mathrm{C}\left(=535-610^{\circ} \mathrm{F}\right)$. Thermal aging of cast stainless steels at these temperatures causes an increase in hardness and tensile strength and a decrease in ductility. Impact strength. and fracture toughness of the material. The Charpy transition curve shifts to higher temperatures. Therefore, an assessment of mechanical-property degradation due to thermal embrittlement is required to evaluate the performance of cast stainless steel components during prolonged exposure to service temperatures.

Investigations at Argonne National Laboratory (ANL) and elsewhere have shown that thermal embrittlement of cast stainless steel components can occur during the reactor design lifetime of $40 \mathrm{yr}$. Various grades and heats of cast stainless steel exhibit varying degrees of thermal embrittlement. In general, the low-C CF-3 steels are the most resistant to thermal embrittlement, and the Mo-bearing, high-C CF- $8 \mathrm{M}$ steels are the least resistant.

Embrittlement of cast stainless steels results in brittle fracture associated with either cleavage of the ferrite or separation of the ferrite/austenite phase boundary. Thermal aging of cast stainless steels at temperatures $<500^{\circ} \mathrm{C}\left(<932^{\circ} \mathrm{F}\right)$ leads to precipitation of additional phases in the ferrite, e.g., formation of a $\mathrm{Cr}$-rich $\alpha^{\prime}$ phase by spinodal decomposition; nucleation and growth of $\alpha^{\prime}$ : precipitation of a $\mathrm{NL}$ - and SI-rich G phase, $\mathrm{M}_{23} \mathrm{C}_{6}$, and $\gamma_{2}$ (austenite): and additional precipitation and/or growth of existing carbides at the ferrite/austenite phase boundaries. Formation of the $\alpha^{\prime}$ phase provides the strengthening mechanisms that increase strain hardening and local tensile stress. Consequently, the critical stress level for brittle fracture is attained at higher temperatures. Predominantly brittle fallure occurs when either the ferrite phase is continuous (e.g.. in cast material with a large ferrite content) or the ferrite/austenite phase boundary provides an easy path for crack propagation (e.g., in high-C grades of cast steel with large phase-boundary carbides). Consequently, the amount, size, and distribution of the ferrite phase in the duplex structure, and the presence of phase-boundary carbides are important parameters in controlling the degree or extent of thermal embrittlement.

A procedure and correlations have been developed at ANL for estimating the Charpy-impact energy and fracture toughness $J-R$ curve of cast stainless steel components under LWR operating conditions from material information readily avallable in certified material test records (CMTRs). The procedure and correlations were published in NUREG/CR-4513, ANL 90/42 (June 1991). This report presents a revision of the procedure and correlations presented earlier. All the correlations have been optimized to provide more accurate estimates. The correlations are based on an expanded data base and mechanical-property results on cast stainless steels that were aged up to $\approx 58,000 \mathrm{~h}$ at $290-350^{\circ} \mathrm{C}\left(554-662^{\circ} \mathrm{F}\right)$. The procedure for estimating the change in tenslle stress. Including the Ramberg/Osgood parameters for strain hardening, is also presented.

Fracture toughness of a specific cast stainless steel is estimated from the extent and kinetics of thermal embrittlement. The extent of thermal embrittlement is characterized by the room-temperature (RT) Charpy-impact energy. A correlation for the extent of thermal embrittlement at "saturation." 1.e., the minimum impact energy that would be achieved for the mate- 
rial after long-term aging, is given in terms of the chemical composition. The extent of thermal embrittlement as a function of time and temperature of reactor service is estimated from the extent of embrittlement at saturation and from the correlations describing the kinetics of embrittlement, which are also given in terms of chemical composition. The fracture toughness $J-R$ curve for the material is then obtained from the correlation between the fracture toughness parameters and the RT Charpy-impact energy used to characterize the extent of thermal embrittlement. Tensile yleld and flow stresses and Ramberg/Osgood parameters for tensile strain hardening are estimated from the flow stress of the unaged material and the ldnetics of embrittlement. Fracture toughness $\mathrm{J}_{I C}$ and tearing modulus can then be determined from the estimated $J-R$ curve and tensile flow stress. A common lower-bound $J-R$ curve for cast materials of unknown chemical composition is also defined for a given material specification, ferrite content, and temperature. Examples of estimating mechanical properties of cast stainless steel components during reactor service are presented. 


\section{Acknowledgments}

This work was supported by the Office of Nuclear Regulatory Research, U.S. Nuclear Regulatory Commission (NRC), under FIN A2243, Program Manager: Joe Muscara. The author thanks W. J. Shack and T. F. Kassner for their helpful discussions. 
Cast duplex stainless steels used in light water reactor (LWR) systems for primary pressure-boundary components, such as valve bodies, pump casings, and primary coolant piping. are susceptible to thermal embrittlement at reactor operating temperatures, 1.e., $280-320^{\circ} \mathrm{C}$ (536-608 ${ }^{\circ}$ ). Thermal aging of cast stainless steels (1.e., ASTM Specification A-351 for Grades $\mathrm{CF}-3, \mathrm{CF}-3 \mathrm{~A}, \mathrm{CF}-8, \mathrm{CF}-8 \mathrm{~A}$, and $\mathrm{CF}-8 \mathrm{M}$ ) at these temperatures causes an increase in hardness and tensile strength and a decrease in ductility, impact strength, and fracture toughness of the material and the Charpy transition curve shifts to higher temperatures. Investigations at Argonne National Laboratory $(A N L)^{1-14}$ and elsewhere ${ }^{15-22}$ have shown that thermal embrittlement of cast stainless steel components occurs during the reactor design lifetime of 40 yr. Various grades and heats of cast stainless steel exhibit varying degrees of thermal embrittlement. In general, the low-C CF-3 steels are the most resistant to thermal embrittlement, and the Mo-bearing, high-C CF-8M steels are the least resistant.

An assessment of mechanical-property degradation due to thermal embrittlement is therefore required to evaluate the performance of cast stainless steel components during prolonged exposure to service temperatures, because rupture of the primary pressure boundary could lead to a loss-of-coolant accident and possible exposure of the public to radiation. A procedure and correlations have been developed at ANL for estimating Charpy-impact energy and fracture toughness J-R curve of cast stainless steel components under LWR operating conditions from material information readily avallable in certified material test records (CMTRs). The procedure and correlations were published previously. ${ }^{9}$

Fracture toughness of a specific cast stainless steel is estimated from the extent and kinetics of thermal embrittlement. The extent of thermal embrittlement is characterized by the room-temperature (RT) "normalized" Charpy-Impact energy (Charpy-impact energy per unit fracture area). A correlation for the extent of thermal embrittlement at "saturation," 1.e., the minimum Charpy-impact energy that would be achieved for the material after long-term aging, is given in terms of chemical composition. The extent of thermal embrittlement as a function of time and temperature of reactor service is estimated from the extent of embrittlement at saturation and from the correlations describing the kinetics of embrittlement, which are also given in terms of chemical composition. The fracture toughness $J-R$ curve for the material is then obtained from the correlation between fracture toughness parameters and RT Charpy-impact energy used to characterize the extent of thermal embrittlement. A common lower-bound $J-R$ curve for cast materials of unknown chemical composition is defined for a given material specification, ferrite content, and temperature.

These correlations have been updated and optimized with an expanded data base and mechanical-property results on cast stainless steels that were aged up to $=58,000 \mathrm{~h}$ at $290-350^{\circ} \mathrm{C}$ $\left(554-662^{\circ} \mathrm{F}\right) \cdot 10,11$ Correlations have also been developed for estimating changes in tensile stress and Ramberg/Osgood parameters for tensile strain hardening. ${ }^{23}$ This report presents a revision of the procedure and correlations presented earlier. 9 The correlations for estimating

\footnotetext{
In this report, Grades CF-3A and CF-8A are considered equivalent to $C F-3$ and $C F-8$, respectively. The $A$ designation represents high tensile strength. The chemical composition of CF-3A and CF- $8 A$ is further restricted within the composition limits of CF-3 and CF-8, respectively, to obtain a ferite/austenite ratio that results in higher ultimate and yield strengths.
} 
the change in tensile stress, Including the Ramberg/Osgood parameters, are also described. Examples of estimating mechanical properties of cast stainless steel components during reactor service are presented. The differences between the correlations described in this report and those presented earlier are as follows:

- The correlations have been optimized by using a larger data base (e.g., $\approx 80$ compositions of cast SS) and mechanical-property results on materials that were aged up to $\approx 58,000 \mathrm{~h}$ at $290-350^{\circ} \mathrm{C}\left(554-662^{\circ} \mathrm{F}\right)$. The earlier correlations were based on $\approx 45$ compositions of cast SS and aging times up to $30,000 \mathrm{~h}$. For the 80 compositions of cast SSs used in this study, estimates based on the old correlations yleld conservattve values of fracture toughness.

- The saturation RT impact energy CVsat is estimated from two different correlations. For most heats, the two methods give comparable estimates. For a few heats, however, one or the other set of expressions gives more accurate estimates. It is likely that minor differences in the composition and microstructure of the ferrite caused by differences in production heat treatment and possibly the casting process influence $\mathrm{Cvsat}$ values. These factors cannot be quantified from the present data base. To ensure that the estimates are either accurate or conservative for all heats of cast SS within ASTM Specification A 351, the lower of the two estimated values is used for estimating the fracture properties.

- Different correlations are used to estimate the saturation RT impact energy CVsat for CF-8M steels with $<10$ and $\geq 10$ wt. $\%$ NI.

- Separate correlations are given for estimating fracture toughness J-R curves for staticand centrifugally cast SSs.

- The correlation for estimating exponent $n$ of the power-law $J-R$ curve has been modified.

- For CF-3 and CF-8 steels, the expression for estimating the activation energy for thermal embrittlement has been modified. The effect of Mo and Mn content has been omitted and the effect of $\mathrm{C}$ content has been added in the updated expression.

- Correlations are included for estimating the yield and flow stresses and Ramberg/Osgood parameters of aged cast stainless steels from the initial tensile properties and the kinetics of thermal embrittlement.

The criteria used in developing these correlations ensure that the estimated mechanical properties are adequately conservative for cast stainless steels defined by ASTM Specification A 351. The correlations do not consider the effects of metallurgical differences that may arise from differences in production heat treatment or casting processes and, therefore, may be overly conservative for some steels. Mechanical properties are expressed in SI units (see Nomenclature for units of measure and for conversion factors for British units).

\footnotetext{
* These correlations may yield nonconservative estimates of fracture toughness J-R curve for a few compositions of static-cast $\mathrm{CF}-8 \mathrm{M}$-steel that are very sensitive to thermal aging, 1.e., those compositions of static-cast stainless steel for which the estimated value of CVsat is $<25 \mathrm{~J} / \mathrm{cm}^{2}$ ( $<15 \mathrm{ft} \cdot \mathrm{lb}$ ). These compositions contain $\mathbf{2 2 5 \%}$ ferrite. The existing data are not adequate to accurately establish the correlations between roomtemperature Charpy-impact energy and fracture toughness parameters for estimated values of CVsat $<25 \mathrm{~J} / \mathrm{cm}^{2}$.
} 


\section{Mechanism of Thermal Embrittlement}

Thermal embrittlement of cast duplex stainless steels results in brittle fracture associated with either cleavage of ferrite or separation of the ferrite/austenite phase boundary. Thermal aging of cast stainless steels at temperatures $<500^{\circ} \mathrm{C}\left(932^{\circ} \mathrm{F}\right)$ leads to precipitation of additional phases in the ferrite, e.g., formation of a $\mathrm{Cr}$-rich $\alpha^{\prime}$ phase by spinodal decomposition; nucleation and growth of $\alpha$; precipitation of a $\mathrm{NI}$ and SI-rich $\mathrm{G}$ phase, $\mathrm{M}_{23} \mathrm{C}_{6}$ carbide, and $\gamma_{2}$ austenite; and additional precipitation and/or growth of existing carbides at the ferrite/austenite phase boundaries, 10-14.24-29 Thermal aging has little or no effect on the austenite phase. The formation of $\mathrm{Cr}-\mathrm{rich} \alpha^{\prime}$ phase by spinodal decomposition of ferrite is the primary mechanism for thermal embrittlement. The $\alpha^{\prime}$ phase strengthens the ferrite matrix, 1.e.. It increases strain hardening and local tensile stress, so that the critical stress level for brittle fracture is achieved at higher temperatures.

The degree or extent of thermal embrittlement is controlled by the amount of brittle fracture, which depends on both material and aging conditions. In some cast stainless steels, a fraction of the material may fall in brittle fashion but the surrounding austenite provides ductility and toughness. Such steels have adequate impact strength even after long-term aging. Predominantly brittle fallure occurs when either the ferrite phase is continuous, e.g., in cast material with a large ferrite content, or the ferrite/austenite phase boundary provides an easy path for crack propagation, e.g., in high-C or high-N steels that contain phase-boundary carbides or nitrides. Consequently. the amount, size, and distribution of ferrite in the duplex structure and phase-boundary precipitates are important parameters that control the extent of thermal embrittlement. The decrease in RT Charpy-impact energy during thermal aging at $400^{\circ} \mathrm{C}\left(752^{\circ} \mathrm{F}\right)$ of various heats of cast stainless steel $1^{4-6,15,19,21}$ is shown in Fig. 1. The results indicate that all the materials reach a "saturation" RT impact energy, 1.e., a minimum value that would be achieved by the material after long-term aging. The actual value of saturation RT impact energy for a specific cast stainless steel is independent of aging temperature but depends strongly on the chemical composition of the steel; it is lower for the Mo-bearing CF-8M

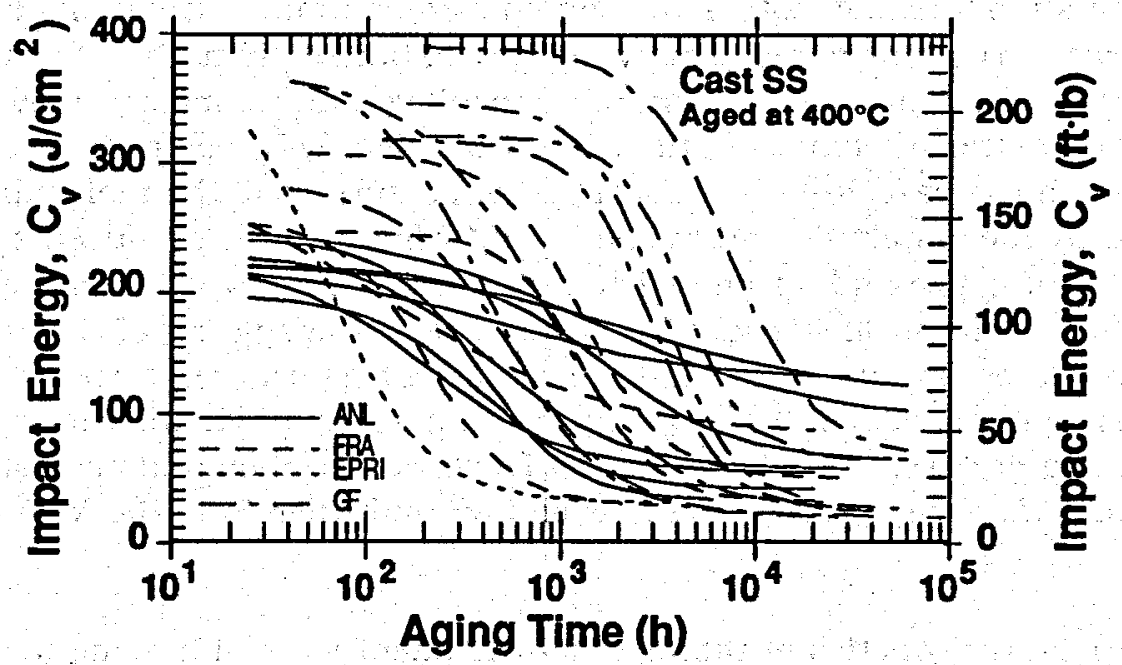

Figure 1. Decrease in Charpy-tmpact energy for varlous heats of cast statnless steels aged at $400^{\circ} \mathrm{C}$ 
steels than for the Mo-free CF-3 or CF-8 steels, and decreases with an increase in ferrite content or the concentration of $\mathrm{C}$ or $\mathrm{N}$ in the steel.

The time to reach saturation, 1.e., the kinetics of thermal embrittlement, depends on both material and aging parameters. Figure 1 indicates that the time for aging at $400^{\circ} \mathrm{C}$ for a given decrease in impact energy varies by more than two orders of magnitude for the various heats, e.g., $<1,000 \mathrm{~h}$ for the Electric Power Research Institute (EPRI) heat, 1,000-10,000 $\mathrm{h}$ for the ANL and Framatome (FRA) heats, and 10,000-30,000 $\mathrm{h}$ for the Georg Fischer Co. (GF) heats. Activation energies of thermal embrittlement range from 65 to $230 \mathrm{~kJ} / \mathrm{mole}(15$ to $55 \mathrm{kcal} / \mathrm{mole}$ ). 1-6,13-15,17-19.30 These values are well below the $202 \mathrm{~kJ} / \mathrm{mole}(48 \mathrm{kcal} / \mathrm{mole})$ value associated with $\mathrm{Cr}$ bulk diffusion in the $\mathrm{Fe}-28 \mathrm{Cr}$ alloy. 31 Small changes in the constituent elements of the material can cause the kinetics of thermal embrittlement to vary significantly. The logarithm of the aging time at $400^{\circ} \mathrm{C}$ for a $50 \%$ reduction in $\mathrm{RT}$ Charpy-impact energy has been shown to be an important parameter for characterizing the kinetics of thermal embrittlement. 9

Activation energy is high for steels that show fast embrittlement at $400^{\circ} \mathrm{C}$ and low for those that show slow embrittlement at $400^{\circ} \mathrm{C}$. Also, materials with the same chemical composition but different heat treatment show different kinetics of embrittlement. 15 Microstructural examination of aged cast stainless steels suggests that slow embrittlement at $400^{\circ} \mathrm{C}$ and low activation energy are associated with clusters of Ni-SI, Mo-Si, and Ni-Si-Mo in the ferrite matrix. 12-14 These clusters are considered precursors of G-phase nucleation and precipitation. Cast stainless steels with low activation energy and slow embrittlement at $400^{\circ} \mathrm{C}$ show G-phase precipitation after aging, and steels with high activation energy and fast embrittlement at $400^{\circ} \mathrm{C}$ do not contain a $\mathrm{G}$ phase. $12-14,24,25$ The presence of NI-Si-Mo clusters in the ferrite matrix of an unaged material may be considered a signature of steels that are potentially sensitive to thermal embrittlement, 1.e., steels with NI-Si-Mo clusters in the ferrite matrix show low activation energy for thermal embrittlement but take longer to embrittle at $400^{\circ} \mathrm{C}$.

The kinetics of thermal embrittlement of cast stainless steels are controlled primarily by the kinetics of ferrite strengthening, e.g., activation energy determined from ferrite hardness measurements shows very good agreement with that obtained from the Charpy-impact data. 17,18,30 Microstructural characterization and annealing studies on thermally aged cast stainless steel show that strengthening of ferrite is caused primarily by spinodal decomposition of ferrite to form $\mathrm{Cr}$-rich $\alpha^{\prime}$ phase.4,12,13 Consequently, the kinetics of thermal embrittlement should be controlled by the amplitude and frequency of $\mathrm{Cr}$ fluctuations produced by spinodal decomposition, 1.e., by the size and spacing of the $\alpha^{\prime}$ phase. The low activation energies of thermal embrittlement are most likely caused by variations in the spacing of Cr fluctuations; atom probe field-ion microscopy studies indicate that the spacing between $\mathrm{Cr}$ fluctuations decreases with decreasing temperature.24,28 During thermal aging, production heat treatment and possibly the casting process, both of which affect ferrite composition and microstructure of unaged material, can influence microstructural evolution and, therefore, the kinetics of embrittlement.

For most materials, the knetics of thermal embrittlement vary with aging temperature. For a specific heat of cast stainless steel, activation energy of thermal embrittlement is not constant over the temperature range of $290-450^{\circ} \mathrm{C}\left(554-842^{\circ} \mathrm{F}\right)$, but increases with decreasing temperature. ${ }^{1-3,17}$ The increase is particularly significant between 400 and $450^{\circ} \mathrm{C}(752$ and $842^{\circ} \mathrm{F}$ ). In addition, materials aged at $450^{\circ} \mathrm{C}$ show precipitation of phase-boundary carbides 


$$
\text { taln }
$$

(also nitrides in high-N steels) and a decrease in ferrite content of the steel.1,2 At reactor temperatures, such processes either do not occur or their kinetics are extremely slow. Consequently, data obtained after $450^{\circ} \mathrm{C}$ aging do not reflect the mechanisms that are active under reactor operating conditions, and extrapolation of the $450^{\circ} \mathrm{C}$ data to predict the extent of thermal embrittlement at reactor temperatures is not valid. The activation energy for thermal embrittlement may be represented by an average value in the temperature range of $290-400^{\circ} \mathrm{C}$. $\left(554-752^{\circ} \mathrm{F}\right)$.

\section{Assessment of Thermal Embrittlement}

A flow diagram for estimating mechanical properties of cast stainless steels during reactor service is shown in Fig. 2. The estimation scheme is divided into three sections on the basis of available material information. In Section $A$ of the flow diagram, "predicted lower-bound" fracture toughness is defined for $C F-3, C F-8$, and $C F-8 M$ steels of unknown composition. When the ferrite content of the steel is known, a different lower-bound fracture toughness and impact energy are defined for steels containing $<10 \%, 10-15 \%$, or $>15 \%$ ferrite.

Sections $\mathrm{B}$ and $\mathrm{C}$ of the flow diagram present procedures for estimating mechanical properties when a CMTR is available, 1.e., the chemical composition of the steel is known. Section B describes the estimation of "saturation" impact energy and fracture toughness J-R curve. The only information needed for these estimations is the chemical composition of the material. The correlations presented here account for the degradation of mechanical properties due to thermal aging. They do not explicitly consider the initlal fracture properties of the unaged material. It is possible that the estimations of saturation fracture toughness based on chemical composition are higher than the fracture toughness of the unaged material. Some cast stainless steels are inherently weak and may have poor fracture properties in the unaged condition. When information is avallable on efther the initial fracture toughness of the material or the initial RT Charpy-Impact energy for estimating fracture toughness, and when the J-R curve estimated from the chemical composition is higher than the initial fracture toughness of unaged material, the latter is used as the saturation J-R curve of the material. Such cast stainless steels are relatively insensitive to thermal aging and the fracture toughness of the material would not change during reactor service. Furthermore, when no information is avallable on the initial fracture toughness of a material, the minimum fracture toughness of unaged cast stainless steels is used as an upper bound for the estimated fracture toughness. 1.e., when the $J-R$ curve estimated from the chemical composition is higher than the minimum fracture toughness of unaged cast stainless steels, the latter is used as the saturation J-R curve of the material.

Estimation of mechanical properties at any given time and temperature of service, 1.e.. service time properties, is described in Section C. The initial impact energy of the unaged material is required for these estimations. If not known, the initial impact energy can be assumed to be $200 \mathrm{~J} / \mathrm{cm}^{2}$ (118 ft.1b). However, similar to Section B. Initial fracture toughness of the unaged materlal or the minimum fracture toughness of unaged cast stainless steels is used as a upper bound for the estimations. The initial tensile properties of the unaged material are needed for estimations of the tensile strength and Ramberg/Osgood strain hardening parameters. The $\mathrm{J}_{\mathrm{IC}}$ value and tearing modulus can be determined from the estimated $\mathrm{J}-\mathrm{R}$ curve and flow stress. 


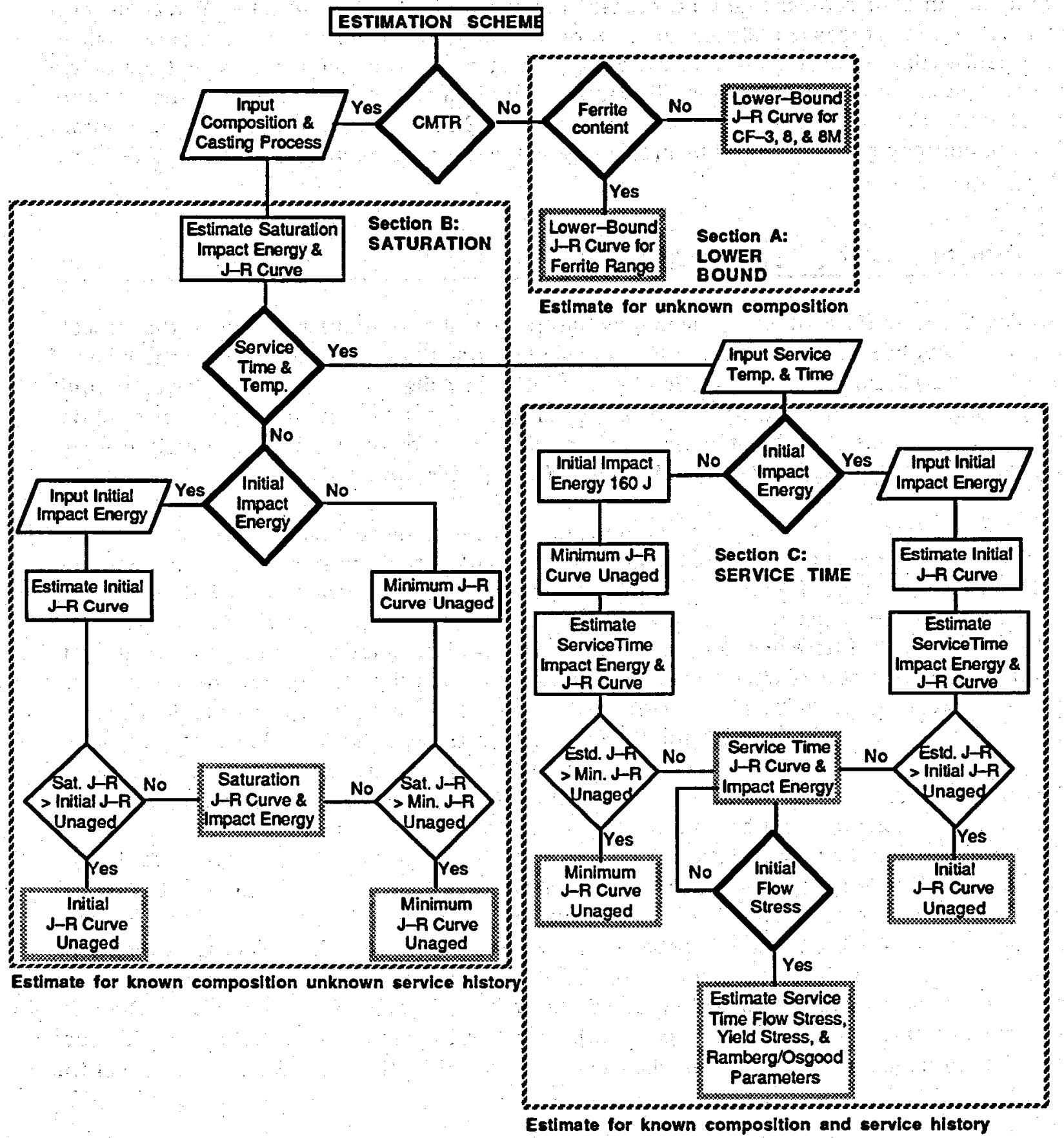

Figure 2. Flow diagram for estimating mechantcal propertles of aged cast stainless steels in LWR systems

\subsection{Estimate for Steels of Unknown Composition: Lower-Bound Values}

For cast stainless steels of unknown chemical composition within ASTM Specification A 351, the lower-bound fracture toughness $J-R$ curve is defined for a given method of casting, material grade, and temperature. The lower-bound curve is based on the "worst case" material condition, e.g., $>20 \%$ ferrite content. The cast SSs used in the U.S. nuclear industry generally 
contain $<15 \%$ ferrite. The lower-bound fracture properties for a specific casting method and grade of steel may therefore be very conservative for most steels. More realistic estimates of lower-bound properties are obtained if the ferrite content of the steel is known.- The ferrite content of a cast SS component can be measured in the field with a ferrite scope. The predicted lower-bound J-R curves at RT and $290^{\circ} \mathrm{C}$ for static- and centrifugally cast CF-3, CF8, and CF-8M steels with $>15 \%, 10-15 \%$, and $<10 \%$ ferrite are shown in Figs. 3 and 4.

\subsubsection{Ferrite Content $>15 \%$}

A lower-bound fracture toughness J-R curve at RT, for static-cast CF-3 steel with $>15 \%$ ferrite, is given by

$$
\mathrm{J}_{\mathrm{d}}=287[\Delta \mathrm{a}]^{0.39} \text { : }
$$

for static-cast CF- 8 steel with $>15 \%$ ferrite, by

$$
J_{d}=261[\Delta a]^{0.37}
$$

and for static-cast CF-8M steel with $15-25 \%$ ferrite, ${ }^{\circ}$ by

$$
\mathrm{J}_{\mathrm{d}}=119[\Delta \mathrm{a}]^{0.33} \text {. }
$$

At $290^{\circ} \mathrm{C}\left(554^{\circ} \mathrm{F}\right)$, a lower-bound fracture toughness J-R curve, for static-cast CF-3 steel with $>15 \%$ ferrite. Is given by

$$
\mathrm{J}_{\mathrm{d}}=264[\Delta \mathrm{a}]^{0.35}
$$

for static-cast CF- 8 steel with $>15 \%$ ferrite, by

$$
\mathrm{J}_{\mathrm{d}}=251[\Delta \mathrm{a}]^{0.34} \text {; }
$$

and for static-cast CF-8M steel with $15-25 \%$ ferrite, by

$$
J_{d}=167|\Delta \mathrm{a}| 0.31 \text {. }
$$

A lower-bound fracture toughness $\mathrm{J}-\mathrm{R}$ curve at RT, for centrifugally cast CF-3 steel with $>15 \%$ ferrite, is given by

$$
\mathrm{J}_{\mathrm{d}}=334[\Delta \mathrm{a}]^{0.39} \text {; }
$$

for centrifugally cast $C F-8$ steel with $>15 \%$ ferrite, by

$$
\mathrm{J}_{\mathrm{d}}=304[\Delta \mathrm{a}]^{0.37}
$$

and for centrifugally cast CF-8M steel with $>15 \%$ ferrite, by

$$
J_{d}=149[\Delta a]^{0.33} \text {. }
$$

At $290^{\circ} \mathrm{C}\left(554^{\circ} \mathrm{F}\right)$, a lower-bound fracture toughness J-R curve, for centrifugally cast CF-3 steel with $>15 \%$ ferrite, is given by

$$
J_{d}=347[\Delta a]^{0.35} \text {; }
$$

for centrifugally cast $C F-8$ steel with $>15 \%$ ferrite, by

$$
J_{d}=330[\Delta]^{0.34}
$$

\footnotetext{
* The lower-bound J-R curve is not applicable for those compositions of static-cast CF-8M steel for which the estimated CVsat is $<25 \mathrm{~J} / \mathrm{cm}^{2}$ (<15 ft.lb); these compositions contain $>25 \%$ ferrite.
} 

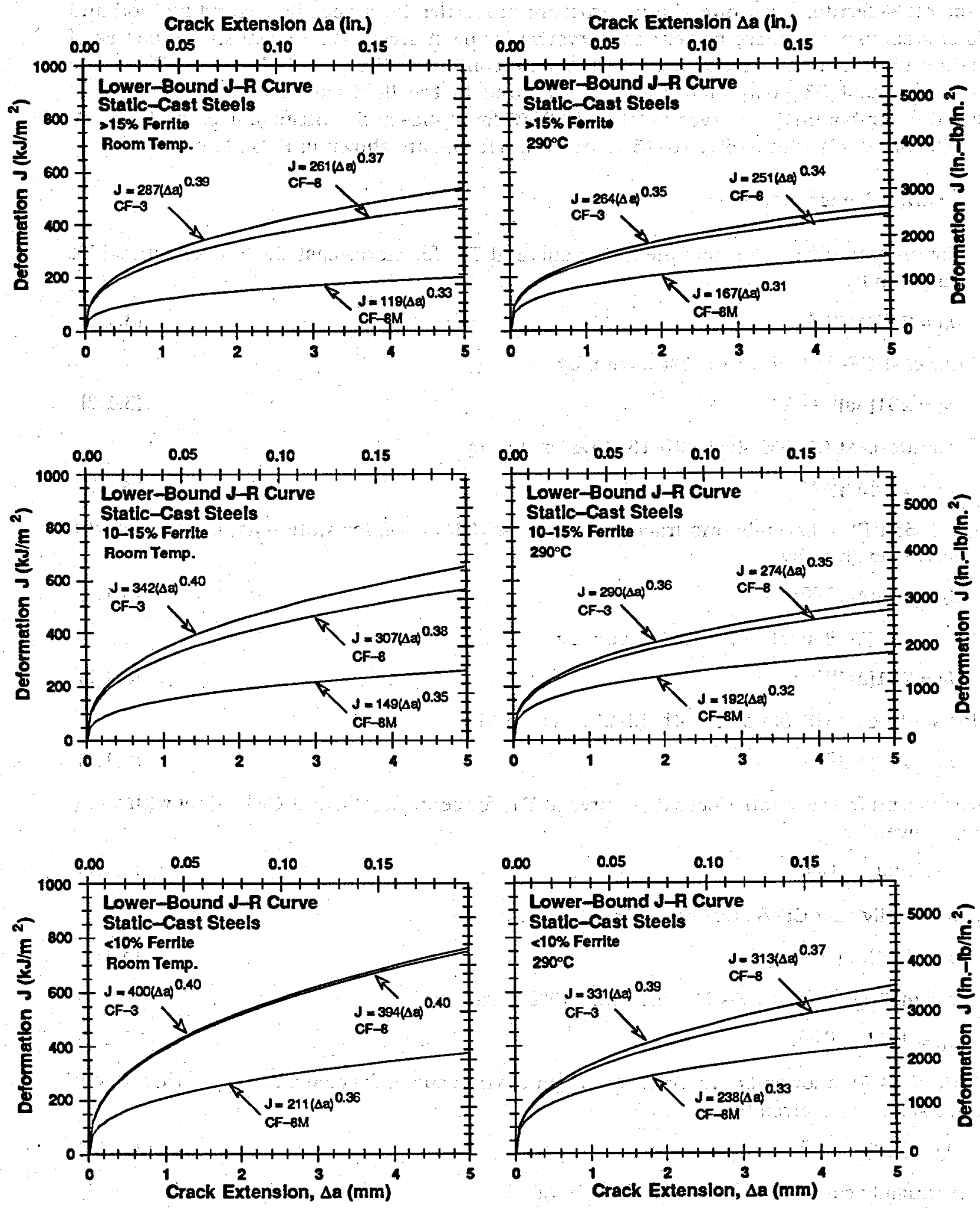

Figure 3. Predicted lower-bound J-R curves at RT and $290^{\circ} \mathrm{C}$ for static-cast SSs with ferrte contents $>15,10-15$, or $<10 \%$ 

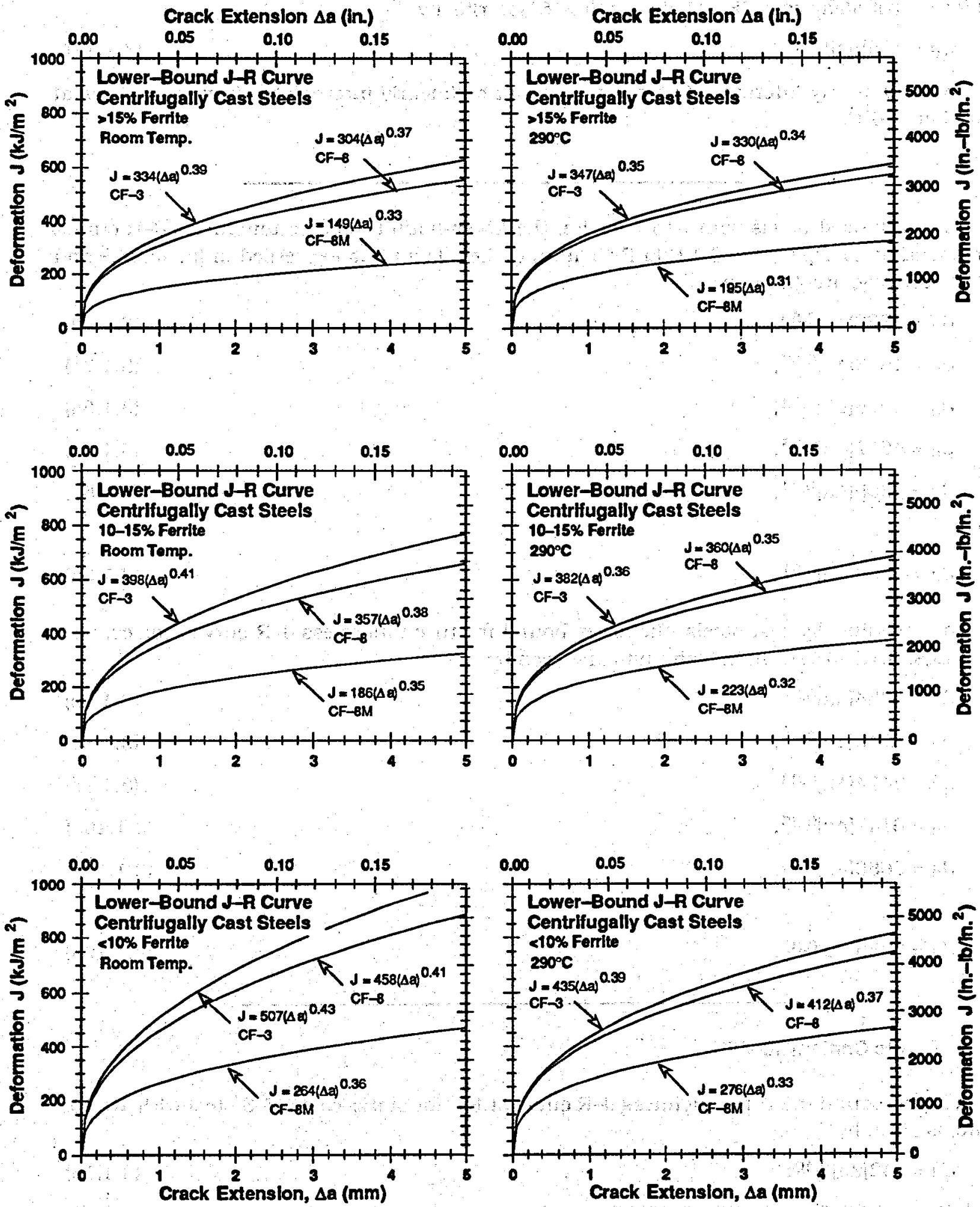

Figure 4. Predicted lower-bound J-R curves at RT and $290^{\circ} \mathrm{C}$ for centrlfugally cast SSs with ferrite contents $>15,10-15$, or $<10 \%$ 
and for centrifugally cast CF-8M steel with $>15 \%$ ferrite. by

$$
J_{d}=195[\Delta \mathrm{a}]^{0.31} \text {. }
$$

The $\mathrm{J}$ values at any intermediate temperature can be linearly interpolated from the values at $\mathrm{RT}$ and at $290^{\circ} \mathrm{C}$.

For static-cast steels with $>15 \%$ ferrite, the lower-bound fracture toughness $J-R$ curves corresponding to Eqs. 3.1.1-3.1.6 in British units, 1.e., $J_{d}$ and $\Delta a$ expressed in in.- $1 \mathrm{~b} / \mathrm{in} .2$ and in., respectively, are given by

$$
\begin{aligned}
& J_{d}=5786[\Delta a]^{0.39}, \\
& J_{d}=4933[\Delta a]^{0.37}, \\
& J_{d}=1976[\Delta a]^{0.33}, \\
& J_{d}=4677[\Delta a]^{0.35}, \\
& J_{d}=4305[\Delta a]^{0.34},
\end{aligned}
$$

and

$$
J_{d}=2599[\Delta a]^{0.31} \text {. }
$$

For centrifugally cast steels, the lower-bound fracture toughness $\mathrm{J}-\mathrm{R}$ curves corresponding to Eqs. 3.1.7-3.1.12 in British units are given by

$$
\begin{aligned}
& J_{d}=6734[\Delta a]^{0.39}, \\
& J_{d}=5745[\Delta a]^{0.37}, \\
& J_{d}=2474[\Delta a]^{0.33}, \\
& J_{d}=6147[\Delta a]^{0.35}, \\
& J_{d}=5660[\Delta a]^{0.34},
\end{aligned}
$$

and

$$
J_{d}=3035[\Delta a]^{0.31}
$$

\subsubsection{Ferrite Content 10-15\%}

A lower-bound fracture toughness J-R curve at RT, for static-cast CF-3 steel with 10-15\% ferrite, is given by

$$
J_{d}=342[\Delta a]^{0.40}
$$

for static-cast CF-8 steel with 10-15\% ferrite, by

$$
J_{\mathrm{d}}=307[\Delta \mathrm{a}]^{0.38} \text {; }
$$

and for static-cast CF-8M steel with $10-15 \%$ ferrite, by 


$$
J_{d}=149[\Delta a]^{0.35} \text {. }
$$

At $290^{\circ} \mathrm{C}\left(554^{\circ} \mathrm{F}\right)$, a lower-bound fracture toughness $\mathrm{J}-\mathrm{R}$ curve, for static-cast $\mathrm{CF}-3$ steel with $10-15 \%$ ferrite is given by

$$
\mathrm{J}_{\mathrm{d}}=290[\Delta \mathrm{a}]^{0.36} \text {, }
$$

for static-cast CF-8 steel with $10-15 \%$ ferrite by

$$
\left.J_{d}=274 \mid \Delta a\right]^{0.35} \text {, }
$$

and for static-cast CF-8M steel with $10-15 \%$ ferrite by

$$
J_{d}=192[\Delta a]^{0.32} \text {. }
$$

A lower-bound fracture toughness J-R curve at RT for centrifugally cast CF-3 steel with $10-15 \%$ ferrite, is given by

$$
\mathrm{J}_{\mathrm{d}}=398\left\lceil\left.\Delta \mathrm{a}\right|^{0.40}\right. \text {; }
$$

for centrifugally cast CF-8 steel with $10-15 \%$ ferrite, by

$$
\mathrm{J}_{\mathrm{d}}=357[\Delta \mathrm{a}]^{0.38} \text {; }
$$

and for centrifugally cast CF-8M steel with $10-15 \%$ ferrite, by

$$
\mathrm{J}_{\mathrm{d}}=186[\Delta \mathrm{a}]^{0.35} \text {. }
$$

At $290^{\circ} \mathrm{C}\left(554^{\circ} \mathrm{F}\right)$, a lower-bound fracture toughness J-R curve, for centrifugally cast CF-3 steel with $10-15 \%$ ferrite, is given by

$$
\mathrm{J}_{\mathrm{d}}=382[\Delta \mathrm{a}]^{0.36}
$$

for centrifugally cast CF-8 steel with $10-15 \%$ ferrite, by

$$
J_{\mathrm{d}}=360[\Delta \mathrm{a}]^{0.35}
$$

and for centrifugally cast CF-8M steel with $10-15 \%$ ferrite, by

$$
J_{d}=223[\Delta a]^{0.32} \text {. }
$$

The $\mathrm{J}$ values at any intermediate temperature can be linearly interpolated from the values at $\mathrm{RT}$ and at $290^{\circ} \mathrm{C}$.

For static-cast steels with $10-15 \%$ ferrite, the lower-bound fracture toughness $\mathrm{J}-\mathrm{R}$ curves corresponding to Eqs. 3.1.13-3.1.18 in British units, 1.e., $\mathrm{J}_{\mathrm{d}}$ and $\Delta \mathrm{a}$ expressed in in.-lb/in. 2 and in., respectively, are given by

$$
\begin{aligned}
& J_{d}=7122[\Delta a]^{0.40} \\
& J_{d}=5993[\Delta a]^{0.38} \\
& J_{d}=2640[\Delta a]^{0.35} \\
& J_{d}=5306[\Delta a]^{0.36} \\
& J_{d}=4854[\Delta a]^{0.35}
\end{aligned}
$$


and

$$
\mathrm{J}_{\mathrm{d}}=3087[\Delta \mathrm{a}]^{0.32}
$$

For centrifugally cast steels, the lower-bound fracture toughness J-R curves correspondIng to Eqs. 3.1.19-3.1.24 in British units are given by

$$
\begin{aligned}
& \mathrm{J}_{\mathrm{d}}=8561(\Delta \mathrm{a})^{0.40} \\
& \mathrm{~J}_{\mathrm{d}}=6969[\Delta \mathrm{a}]^{0.38}, \\
& \mathrm{~J}_{\mathrm{d}}=3295[\Delta \mathrm{a}]^{0.35}, \\
& \mathrm{~J}_{\mathrm{d}}=6990[\Delta \mathrm{a}]^{0.36}, \\
& \mathrm{~J}_{\mathrm{d}}=6377[\Delta \mathrm{a}]^{0.35},
\end{aligned}
$$

and

$$
\mathrm{J}_{\mathrm{d}}=3585[\Delta \mathrm{a}]^{0.32}
$$

\subsubsection{Ferrite Content $<10 \%$}

A lower-bound fracture toughness J-R curve at RT, for static-cast CF-3 steel with $<10 \%$ ferrite, is given by

$$
J_{d}=400[\Delta a]^{0.40} \text {; }
$$

for static-cast $\mathrm{CF}-8$ steel with $<10 \%$ ferrite, by

$$
\mathrm{J}_{\mathrm{d}}=394[\Delta \mathrm{a}]^{0.40} \text {; }
$$

and for static-cast CF-8M steel with $<10 \%$ ferrite, by

$$
J_{d}=211[\Delta a]^{0.36} \text {. }
$$

At $290^{\circ} \mathrm{C}\left(554^{\circ} \mathrm{F}\right)$, a lower-bound fracture toughness J-R curve, for static-cast CF-3 steel with $<10 \%$ ferrite, is given by

$$
J_{d}=331[\Delta a]^{0.39} ;
$$

for static-cast CF- 8 steel with $<10 \%$ ferrite, by

$$
\mathrm{J}_{\mathrm{d}}=313[\Delta \mathrm{a}]^{0.37}
$$

and for static-cast CF-8M steel with $<10 \%$ ferrite, by

$$
\mathrm{J}_{\mathrm{d}}=238[\Delta \mathrm{a}]^{0.33} \text {. }
$$

A lower-bound fracture toughness J-R curve at RT, for centrifugally cast CF-3 steel with $<10 \%$ ferrite, is given by

$$
\mathrm{J}_{\mathrm{d}}=507[\Delta \mathrm{a}]^{0.43} ;
$$

for centrifugally cast CF -8 steel with $<10 \%$ ferrite, by

$$
\mathrm{J}_{\mathrm{d}}=458[\Delta \mathrm{a}]^{0.41} \text {; }
$$


and for centrifugally cast CF- $8 \mathrm{M}$ steel with $<10 \%$ ferrite, by

$$
J_{d}=264[\Delta \mathrm{a}]^{0.36}
$$

At $290^{\circ} \mathrm{C}\left(554^{\circ} \mathrm{F}\right)$, a lower-bound fracture toughness $\mathrm{J}-\mathrm{R}$ curve, for centrifugally cast CF-3 steel with $<10 \%$ ferrite, is given by

$$
J_{d}=435[\Delta \mathrm{a}]^{0.39}
$$

for centrifugally cast $\mathrm{CF}-8$ steel with $<10 \%$ ferrite, by

$$
\mathrm{J}_{\mathrm{d}}=412[\Delta \mathrm{a}]^{0.37}
$$

and for centrifugally cast CF-8M steel with $<10 \%$ ferrite, by

$$
J_{d}=276[\Delta a]^{0.33} \text {. }
$$

The $\mathrm{J}$ values at any intermediate temperature can be linearly interpolated from the values at $\mathrm{RT}$ and at $290^{\circ} \mathrm{C}$.

For static-cast steels with $<10 \%$ ferrite, the lower-bound fracture toughness $\mathrm{J}-\mathrm{R}$ curves corresponding to Eqs. 3.1.25-3,1.30 in British units, 1.e., $\mathrm{J}_{\mathrm{d}}$ and $\Delta \mathrm{a}$ expressed in in.- $\mathrm{lb} / \mathrm{In}_{.}{ }^{2}$ and in., respectively, are given by

$$
\begin{aligned}
& J_{d}=8330[\Delta a]^{0.40} \\
& J_{d}=8205[\Delta a]^{0.40} \\
& J_{d}=3861[\Delta a]^{0.36} \\
& J_{d}=6674[\Delta a]^{0.39} \\
& J_{d}=5915[\Delta a]^{0.37}
\end{aligned}
$$

and

$$
\mathrm{J}_{\mathrm{d}}=3952[\Delta \mathrm{a}]^{0.33}
$$

For centrifugally cast steels, the lower-bound fracture toughness J-R curves corresponding to Eqs. 3.1.31-3.1.36 in British units are given by

$$
\begin{aligned}
& J_{d}=11634[\Delta a]^{0.43} \\
& J_{d}=9851[\Delta a]^{0.41} \\
& J_{d}=4830[\Delta a]^{0.36} \\
& J_{d}=8770[\Delta a]^{0.39} \\
& J_{d}=7786[\Delta a]^{0.37}
\end{aligned}
$$

and

$$
J_{d}=4583[\Delta a]^{0.33}
$$




\subsection{Estimate for Steels of Known Composition and Unknown Service History: Saturation Values}

\subsubsection{Charpy-Impact Energy}

When a CMTR is avallable, the saturation RT impact energy of a specific cast stainless steel is determined from the chemical composition and ferrite content of the material. The ferrite content is calculated from chemical composition in terms of Hull's equivalent factors 32

$$
\mathrm{Cr}_{\text {eq }}=\mathrm{Cr}+1.21(\mathrm{Mo})+0.48(\mathrm{~S})-4.99
$$

and

$$
\mathrm{N}_{\mathrm{eq}}=(\mathrm{Ni})+0.11(\mathrm{Mn})-0.0086(\mathrm{Mn})^{2}+18.4(\mathrm{~N})+24.5(\mathrm{C})+2.77
$$

The concentration of $\mathrm{N}$ is often not available in a CMTR; if not known, it is assumed to be 0.04 wt.\%. The ferrite content $\delta_{c}$ is given by

$$
\delta_{c}=100.3\left(\mathrm{Cr}_{\mathrm{eq}} / \mathrm{Ni}_{\mathrm{eq}}\right)^{2}-170.72\left(\mathrm{Cr}_{\mathrm{eq}} / \mathrm{Ni}_{\mathrm{eq}}\right)+74.22 \text {. }
$$

The measured and calculated values of ferrite content for the various heats used in studies at ANL, 4 GF, ${ }^{15}$ Electricité de France (EdF), 17 National Power (NP), ${ }^{18}$ FRA, ${ }^{19}$ and EPRI ${ }^{21}$ are shown in Fig. 5. For most heats, the difference between the estimated and measured values is $\pm 6 \%$ ferrite. The few heats for which the calculated ferrite content is significantly lower than the measured values generally contain $\geq 10 \%$ nickel.

Different correlations are used to estimate the saturation RT impact energy of the various grades of cast stainless steel. To ensure that the estimates are either accurate or conservative for all heats, the saturation RT Impact energy for a specific cast stainless steel is determined by two different expressions, and the lower value is used for estimating fracture properties. For CF-3 and CF-8 steels, the saturation value of RT impact energy CVsat is the lower value determined from

$$
\log _{10} C_{\text {Vsat }}=1.15+1.36 \exp (-0.035 \Phi) \text {, }
$$

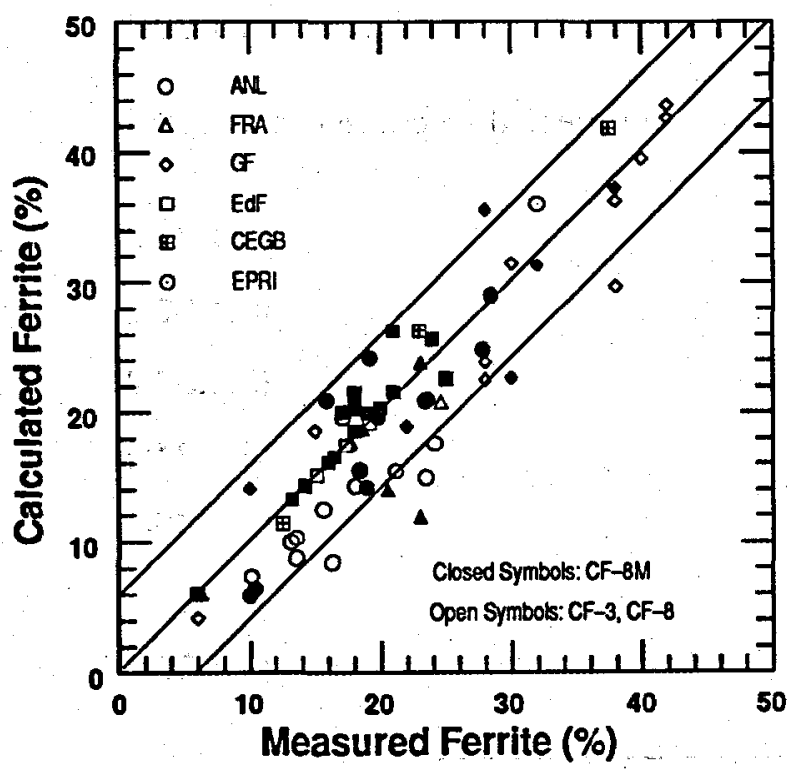

Figure 5.

Measured and calculated ferrite content of various heats of cast stainless steel. The band represents $\pm 6 \%$ deviation. 
where the material parameter $\Phi$ is expressed as

$$
\Phi=\delta_{c}(C r+S i)(C+0.4 N)
$$

and from

$$
\begin{aligned}
\log 10 C_{V s a t}= & 5.64-0.006 \delta_{C}-0.185 \mathrm{Cr}+0.273 \mathrm{Mo}-0.204 \mathrm{~S} 1 \\
& +0.044 \mathrm{Ni}-2.12(\mathrm{C}+0.4 \mathrm{~N}) .
\end{aligned}
$$

For $\mathrm{CF}-8 \mathrm{M}$ steel with $<10 \% \mathrm{N1}$, the saturation value of $\mathrm{RT}$ impact energy $\mathrm{CV}_{\mathrm{V}}$ at is the lower value determined from

$$
\log 10 C_{\text {sat }}=1.10+2.12 \exp (-0.041 \Phi)
$$

where the materlal parameter $\Phi$ is expressed as

$$
\Phi=\delta_{c}(N I+S i+M n)^{2}(C+0.4 N) / 5
$$

and from

$$
\begin{aligned}
\log _{10} \mathrm{CVsat}_{\mathrm{V}}= & 7.28-0.011 \delta_{\mathrm{c}}-0.185 \mathrm{Cr}-0.369 \mathrm{Mo}-0.451 \mathrm{Si} \\
& -0.007 \mathrm{Ni}-4.71(\mathrm{C}+0.4 \mathrm{~N})
\end{aligned}
$$

For CF-8M steel with $>10 \% \mathrm{Ni}$, the saturation value of $\mathrm{RT}$ impact energy $\mathrm{CV}_{\text {vat }}$ is the lower value determined from

$$
\log _{10} C_{V s a t}=1.10+2.64 \exp (-0.064 \Phi) \text {. }
$$

where the material parameter $\Phi$ is expressed as

$$
\Phi=\delta_{c}(N 1+S i+M n)^{2}(C+0.4 N) / 5
$$

and from

$$
\begin{aligned}
\log _{10} \mathrm{CV}_{\text {sat }}= & 7.28-0.011 \delta_{\mathrm{c}}-0.185 \mathrm{Cr}-0.369 \mathrm{Mo}-0.451 \mathrm{Si} \\
& -0.007 \mathrm{Ni}-4.71(\mathrm{C}+0.4 \mathrm{~N})
\end{aligned}
$$

If not known, the $\mathrm{N}$ content can be assumed to be $0.04 \mathrm{wt}$.\%. The saturation values of $\mathrm{RT}$ tm pact energy for CF-3, CF-8, and CF-8M steels observed experimentally at ANL, 4-6 GF, 15 Westinghouse (WH), $16 \mathrm{EdF}, 17 \mathrm{NP}, 18 \mathrm{FRA},{ }^{19}$ and EPRI ${ }^{21}$ are plotted as a function of the material parameter $\Phi$ in Fig. 6. The solid lines represent best-fit curves for the data, 1.e., Eq. 3.2.4 for $C F-3$ or $C F-8$ steels and Eqs. 3.2.7 and 3.2.10 for $C F-8 M$ steel. The chemical composition, ferrite content, and saturation RT Charpy-impact energy of the materials from ANL, GF. FRA. WH, and EPRI studies are given in Table 1. The difference between the predicted and observed values is $<+15 \%$ for most of the CF -3 and $C F-8$ steels and $< \pm 25 \%$ for the CF- 8 M steels.

The correlations described above for estimating CVsat are somewhat different from those presented earlier in Ref. 9. The differences between the new and old set of correlations are as follows:

- The correlations have been optimized by using a larger data base (e.g., $\approx 80$ different compositions of cast stainless steel) and mechanical-property results on materials that were aged up to $\approx 58,000 \mathrm{~h}$ at $290-350^{\circ} \mathrm{C}\left(554-662^{\circ} \mathrm{F}\right) \cdot 10,11$ Data on $\approx 45$ compositions of cast stainless steel and for aging times up to $30,000 \mathrm{~h}$ were used in developing the earlier correlations. 
Table 1. Chemical composttion, ferrite content, and ktnetics of thermal embrttlement for various heats of cast stainless steels

\begin{tabular}{|c|c|c|c|c|c|c|c|c|c|c|c|c|c|c|}
\hline \multirow[b]{2}{*}{ Heat } & \multicolumn{7}{|c|}{ Chemical Compositton (wt.\%) } & \multicolumn{2}{|c|}{ Ferrite (\%) } & \multirow{2}{*}{$\begin{array}{c}\text { Cveat } \\
\left(\mathrm{J} / \mathrm{cm}^{2}\right)\end{array}$} & \multicolumn{3}{|c|}{ Constants } & \multirow{2}{*}{$\begin{array}{c}\theta \\
(\mathrm{kJ} / \mathrm{mole})\end{array}$} \\
\hline & $\alpha$ & Mo & $\mathbf{S i}$ & $\mathbf{N I}$ & Mn & C & $\mathbf{N}$ & Calc. & Meas. & & B & $\theta$ & $\alpha$ & \\
\hline \multicolumn{15}{|c|}{ Argonne } \\
\hline 52 & 19.49 & 0.35 & 0.92 & 9.40 & 0.57 & 0.009 & 0.052 & 10.3 & 13.5 & 161.8 & - & - & - & - \\
\hline 51 & 20.13 & 0.32 & 0.86 & 9.06 & 0.63 & 0.010 & 0.058 & 14.3 & 18.0 & 115.9 & 0.139 & 3.53 & 1.15 & 204.7 \\
\hline 47 & 19.81 & 0.59 & 1.06 & 10.63 & 0.60 & 0.018 & 0.028 & 8.4 & 16.3 & 163.7 & 0.069 & 2.29 & 1.20 & 195.7 \\
\hline P2 & 20.20 & 0.16 & 0.94 & 9.38 & 0.74 & 0.019 & 0.040 & 12.5 & 15.6 & 141.3 & 0.258 & 2.83 & 1.09 & 218.6 \\
\hline 1 & 20.20 & 0.45 & 0.83 & 8.70 & 0.47 & 0.019 & 0.032 & 20.4 & 17.1 & 134.3 & 0.094 & 2.10 & 1.00 & 250.0 \\
\hline 6 & 20.18 & 0.34 & 1.13 & 8.59 & 0.63 & 0.023 & 0.028 & 21.0 & 23.6 & 76.7 & 0.214 & 3.21 & 1.07 & 175.9 \\
\hline P1 & 20.49 & 0.04 & 1.12 & 8.10 & 0.59 & 0.036 & 0.057 & 17.6 & 24.1 & 53.7 & 0.305 & 2.57 & 0.75 & 252.7 \\
\hline 61 & 20.65 & 0.32 & 1.01 & 8.86 & 0.65 & 0.054 & 0.080 & 10.0 & 13.1 & 93.3 & 0.214 & 3.48 & 1.20 & 197.8 \\
\hline 59 & 20.33 & 0.32 & 1.08 & 9.34 & 0.60 & 0.062 & 0.045 & 8.8 & 13.5 & 89.1 & 0.197 & 3.14 & 1.20 & 249.4 \\
\hline 68 & 20.64 & 0.31 & 1.07 & 8.08 & 0.64 & 0.063 & 0.062 & 14.9 & 23.4 & 47.1 & 0.301 & 2.88 & 0.68 & 161.1 \\
\hline 60 & 21.05 & 0.31 & 0.95 & 8.34 & 0.67 & 0.064 & 0.058 & 15.4 & 21.1 & 44.8 & 0.291 & 2.89 & 0.88 & 210.9 \\
\hline 56 & 19.65 & 0.34 & 1.05 & 9.28 & 0.57 & 0.066 & 0.030 & 7.3 & 10.1 & 117.6 & - & - & - & - \\
\hline 74 & 19.11 & 2.51 & 0.73 & 9.03 & 0.54 & 0.064 & 0.048 & 15.5 & 18.4 & 63.1 & 0.269 & 3.44 & 0.70 & 95.0 \\
\hline 75 & 20.86 & 2.58 & 0.67 & 9.12 & 0.53 & 0.065 & 0.052 & 24.8 & 27.8 & 32.1 & 0.436 & 2.82 & 0.51 & 139.0 \\
\hline 66 & 19.45 & 2.39 & 0.49 & 9.28 & 0.60 & 0.047 & 0.029 & 19.6 & 19.8 & 87.9 & 0.208 & 3.16 & 1.57 & 163.9 \\
\hline 64 & 20.76 & 2.46 & 0.63 & 9.40 & 0.60 & 0.038 & 0.038 & 29.0 & 28.4 & 41.1 & 0.338 & 2.81 & 0.60 & 147.3 \\
\hline 65 & 20.78 & 2.57 & 0.48 & 9.63 & 0.50 & 0.049 & 0.064 & 20.9 & 23.4 & 59.7 & 0.260 & 2.99 & 0.59 & 153.8 \\
\hline P4 & 19.64 & 2.05 & 1.02 & 10.00 & 1.07 & 0.040 & 0.151 & 5.9 & 10.0 & 62.7 & 0.289 & 2.70 & 0.62 & 158.7 \\
\hline 63 & 19.37 & 2.57 & 0.58 & 11.85 & 0.61 & 0.055 & 0.031 & 6.4 & 10.4 & 126.5 & 0.119 & 2.83 & 1.11 & 155.5 \\
\hline \multicolumn{15}{|c|}{ Geore Fischer Co. } \\
\hline 284 & 23.00 & 0.17 & 0.52 & 8.23 & 0.28 & 0.025 & 0.037 & 43.6 & 42.0 & 20.5 & 0.551 & 3.66 & 0.39 & 85.9 \\
\hline 280 & 21.60 & 0.25 & 1.37 & 8.00 & 0.50 & 0.028 & 0.038 & 36.3 & 38.0 & 19.6 & 0.609 & 3.20 & 0.73 & 88.9 \\
\hline 282 & 22.50 & 0.15 & 0.35 & 8.53 & 0.43 & 0.035 & 0.040 & 29.7 & 38.0 & 28.5 & 0.500 & 3.65 & 0.39 & 91.6 \\
\hline 281 & 23.10 & 0.17 & 0.45 & 8.60 & 0.41 & 0.036 & 0.053 & 31.4 & 30.0 & 17.2 & 0.618 & 3.76 & 0.47 & 89.8 \\
\hline 283 & 22.60 & 0.23 & 0.53 & 7.88 & 0.48 & 0.036 & 0.032 & 42.6 & 42.0 & 18.6 & 0.599 & 3.60 & 0.44 & 83.7 \\
\hline 278 & 20.20 & 0.13 & 1.00 & 8.27 & 0.28 & 0.038 & 0.030 & 18.5 & 15.0 & 68.3 & 0.347 & 3.90 & 0.29 & 63.1 \\
\hline 279 & 22.00 & 0.22 & 1.36 & 7.85 & 0.37 & 0.040 & 0.032 & 39.5 & 40.0 & 23.8 & 0.546 & 3.06 & 0.58 & 93.5 \\
\hline 277 & 20.50 & 0.06 & 1.81 & 8.13 & 0.54 & 0.052 & 0.019 & 22.5 & 28.0 & 30.7 & 0.466 & 3.54 & 0.49 & 87.7 \\
\hline 291 & 19.60 & 0.66 & 1.59 & 10.60 & 0.28 & 0.065 & 0.054 & 4.2 & 6.0 & 121.9 & 0.195 & 3.65 & 0.35 & 71.2 \\
\hline 292 & 21.60 & 0.13 & 1.57 & 7.52 & 0.34 & 0.090 & 0.039 & 23.9 & 28.0 & 17.2 & 0.373 & 3.07 & 0.44 & 98.8 \\
\hline 290 & 20.00 & 2.40 & 1.51 & 8.30 & 0.41 & 0.054 & 0.050 & 31.3 & 32.0 & 15.8 & 0.624 & 3.48 & 0.12 & 81.0 \\
\hline 288 & 19.60 & 2.53 & 1.70 & 8.40 & 0.47 & 0.052 & 0.022 & 35.6 & 28.0 & 14.9 & 0.671 & 2.96 & 0.66 & 105.3 \\
\hline 287 & 20.50 & 2.58 & 0.51 & 8.46 & 0.50 & 0.047 & 0.033 & 37.2 & 38.0 & 20.5 & 0.555 & 3.46 & 0.36 & 90.3 \\
\hline 286 & 20.20 & 2.44 & 1.33 & 9.13 & 0.40 & 0.072 & 0.062 & 18.9 & 22.0 & 15.5 & 0.594 & 3.03 & 0.72 & 106.4 \\
\hline 289 & 19.70 & 2.30 & 1.44 & 8.25 & 0.48 & 0.091 & 0.032 & 22.6 & 30.0 & 16.2 & 0.580 & 3.29 & 0.41 & 90.1 \\
\hline 285 & 18.80 & 2.35 & 0.86 & 9.49 & 0.48 & 0.047 & 0.039 & 14.0 & 10.0 & 61.1 & 0.313 & 3.60 & 0.20 & 89.3 \\
\hline \multicolumn{15}{|c|}{ Eramatome } \\
\hline $\mathbf{A}$ & 18.90 & 0.10 & 0.99 & 8.90 & 1.14 & 0.021 & 0.074 & 6.0 & 6.3 & 166.0 & 0.090 & 3.44 & 0.20 & 111.7 \\
\hline $\mathbf{E}$ & 21.04 & 0.08 & 0.54 & 8.47 & 0.80 & 0.035 & 0.051 & 17.6 & 16.5 & 45.7 & 0.334 & 2.63 & 0.65 & 132.9 \\
\hline $\mathbf{F}$ & 19.72 & 0.34 & 1.16 & 8.33 & 0.26 & 0.038 & 0.026 & 17.7 & 12.0 & 83.2 & 0.282 & 2.45 & 1.23 & 176.2 \\
\hline C & 20.73 & 0.13 & 1.09 & 8.19 & 0.91 & 0.042 & 0.035 & 20.9 & 20.1 & 51.1 & 0.393 & 3.30 & 0.45 & 83.1 \\
\hline $\mathbf{G}$ & 20.65 & 0.02 & 1.03 & 8.08 & 0.74 & 0.040 & 0.073 & 15.3 & 17.0 & 62.5 & - & - & - & - \\
\hline $\mathrm{H}$ & 20.70 & 0.05 & 1.18 & 8.07 & 0.71 & 0.050 & 0.045 & 18.3 & 21.5 & 50.6 & - & - & - & - \\
\hline D & 19.15 & 2.50 & 0.94 & 10.32 & 1.12 & 0.026 & 0.063 & 12.2 & 13.9 & 33.0 & 0.439 & 3.30 & 0.40 & 89.7 \\
\hline $\mathbf{I}$ & 19.36 & 2.40 & 0.98 & 10.69 & 0.70 & 0.020 & 0.039 & 14.1 & 15.5 & 150.7 & - & - & - & - \\
\hline $\mathbf{K}$ & 20.80 & 2.62 & 0.75 & 10.45 & 1.09 & 0.060 & 0.056 & 15.4 & 14.0 & 48.5 & - & - & - & - \\
\hline L & 20.76 & 2.48 & 0.81 & 10.56 & 0.79 & 0.040 & 0.042 & 18.6 & 19.0 & 30.4 & - & 3.00 & - & - \\
\hline B & 20.12 & 2.52 & 0.93 & 10.56 & 0.83 & 0.053 & 0.042 & 14.0 & 17.3 & 28.2 & 0.478 & 2.55 & 0.47 & 128.6 \\
\hline \multicolumn{15}{|c|}{ Westinghouse } \\
\hline C1488 & 20.95 & 2.63 & 0.53 & 9.48 & 1.02 & 0.061 & 0.056 & 22.1 & 14.0 & 53.1 & - & 2.80 & - & - \\
\hline \multicolumn{15}{|c|}{ Electric Power Research Institute } \\
\hline EPRI & 22.04 & 0.23 & 0.84 & 7.93 & 0.74 & 0.030 & 0.045 & 36.0 & 32.0 & 30.0 & 0.564 & 2.10 & 0.60 & 225.0 \\
\hline
\end{tabular}



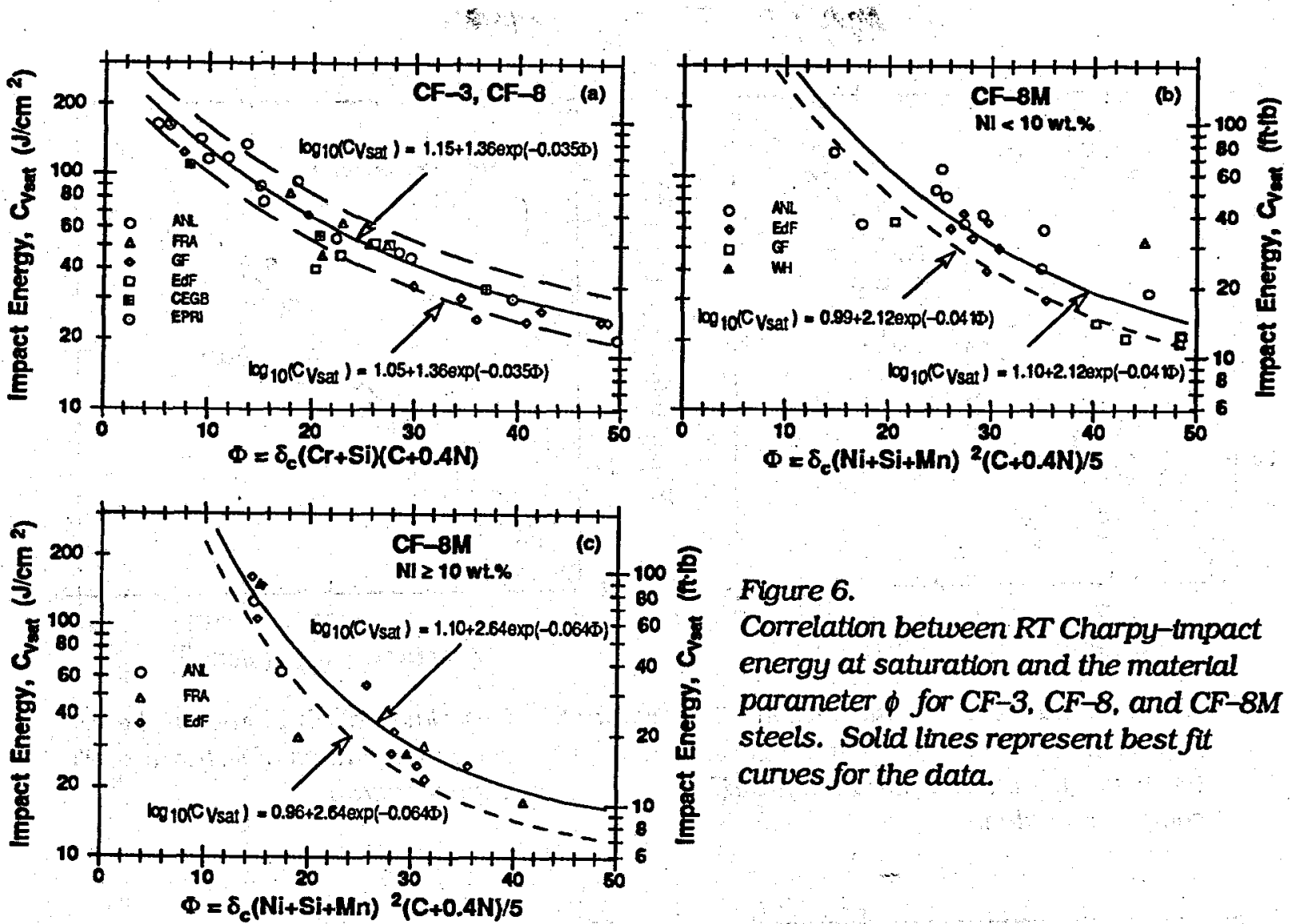

Figure 6.

Correlation between RT Charpy-impact energy at saturation and the materlal parameter $\phi$ for $C F-3, C F-8$, and $C F-8 M$ steels. Solid lines represent best fit curves for the data.

- The saturation RT impact energy is estimated from two differing correlations, i.e., in addition to $C_{V s a t}$ being expressed in terms of material parameter $\Phi$, it is also expressed in terms of the chemical composition alone. The experimental values of saturation RT impact energy and those estimated in terms of the materlal parameter (Eqs. 3.2.4, 3.2.7, or 3.2.10) and composition alone (Eqs. 3.2.6, 3.2.9, or 3.2.12) are shown in Fig. 7. For most heats, the two methods give comparable estimates of $C_{V s a t}$. For a few heats, however, one or the other set of expressions gives more accurate estimates. It is likely that minor differences in the composition and microstructure of the ferrite caused by differences in production heat treatment and possibly the casting process influence CVsat. These factors cannot be quantified from the present data base. To ensure that the estimates are etther accurate or conservative for all heats of cast stainiess steel within ASTM Specification A 351, the lower of the two estimated values is used for estimating the fracture properties. A comparison of the experimental and the lower of the two estimated values of CVsat is shown in Fig. 8. The estimated saturation RT impact energies are within 5-10\% of the experimental values for most of the heats and are conservative for some. Only two of $\approx 80$ heats included in developing these correlations show nonconservative estimates.

- For CF-8M steel, the expression for the material parameter $\Phi$ has been modified ${ }^{*}$ and different correlations between $\mathrm{C}_{\mathrm{Vsat}}$ and $\Phi$ are used for steels with $<10 \mathrm{wt} . \% \mathrm{Nl}$ and with $>10 \mathrm{wt} . \%$ N. The new correlations provide more accurate estimates of $\mathrm{C}_{\text {Vsat. The old }}$ correlations ${ }^{9}$ yleld conservative estimates of $\mathrm{C}_{V \text { sat }}$ for most compositions of cast statnless steel. The values of $C_{V s a t}$ estimated from the old and new correlations are shown in Fig. 9.

\footnotetext{
* For CF-8M steel, material parameter $\Phi$ was expressed as $\delta_{c} \mathrm{Cr}(\mathrm{NI}+\mathrm{SI})^{2}(\mathrm{C}+0.4 \mathrm{M}) / 100$ in Ref. 9.
} 


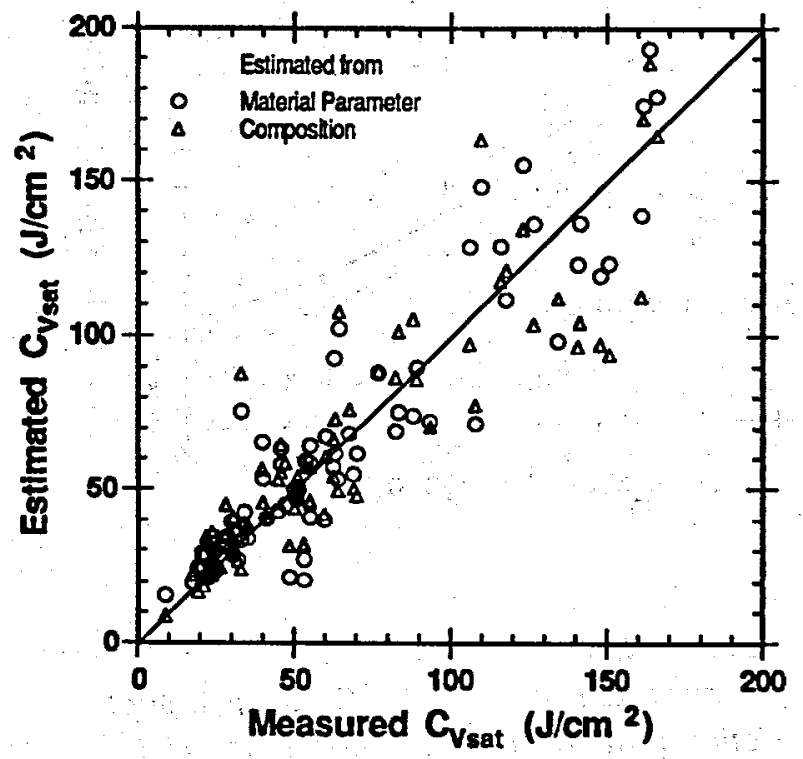

Figure 7. Expertmental values of saturation RT impact energy and those estimated in terms of the material parameter and composition alone

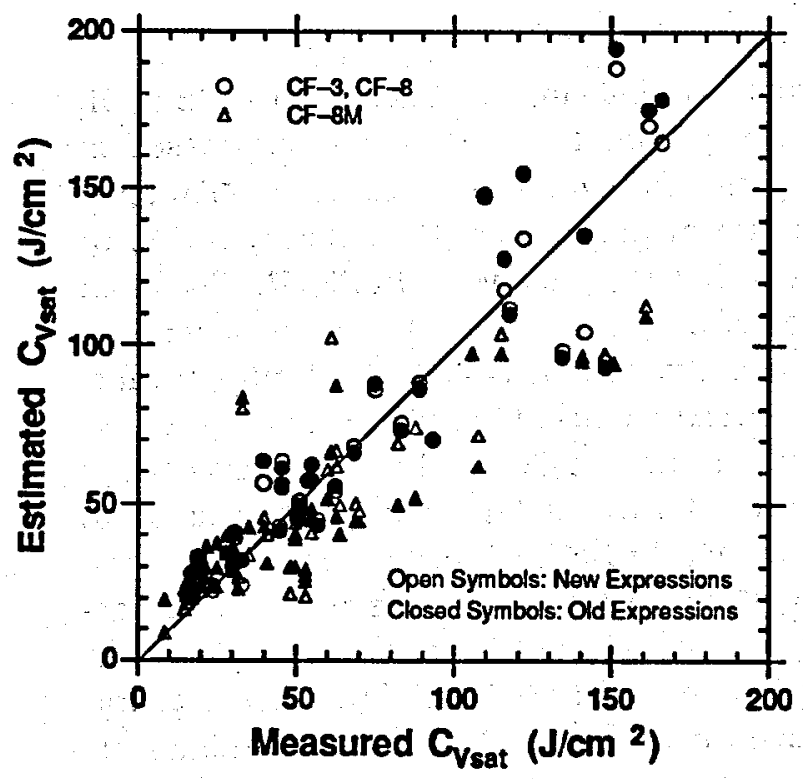

Figure 9. Expertmental values of saturation $R T$ impact energy and those estimated from old and new correlations

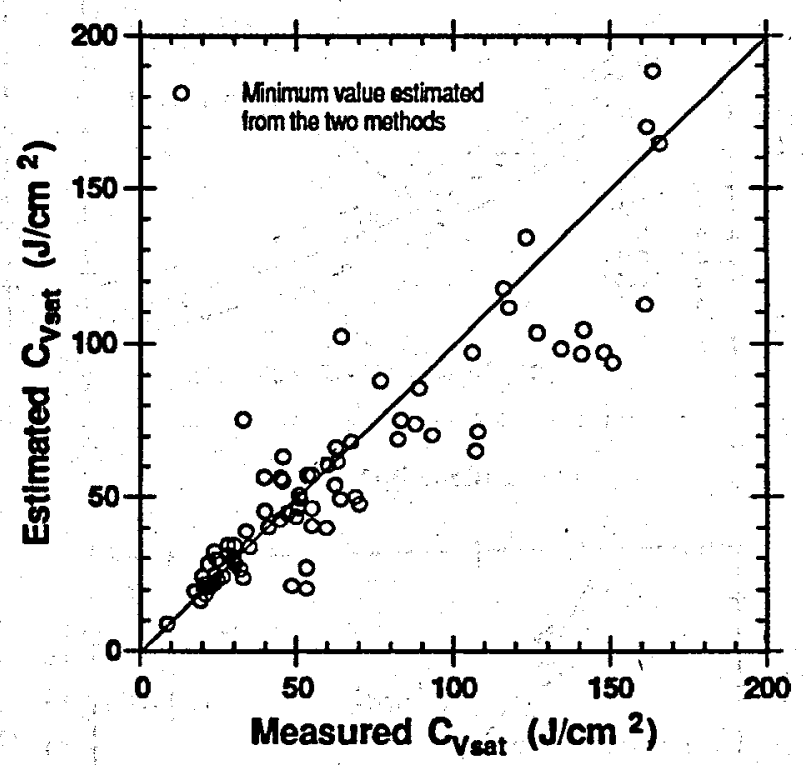

Figure 8. Expertmental and lower of the two estimated values of saturation $R T$. impact energy

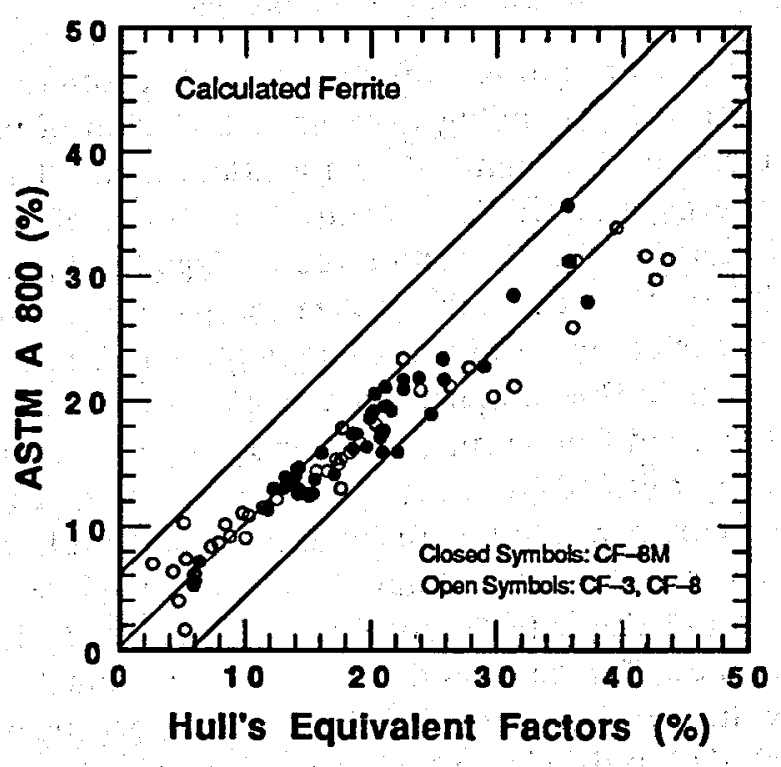

Fyure 10. Estimates of ferrite content obtained from Hull's equivalent factors and ASTM A 800

The ferrite content $\delta_{c}$ used in developing Eqs. 3.2.4-3.2.12 was calculated from Hull's equivalent factors. Using $\delta_{c}$ values determined by methods other than Hull's may result in nonconservative estimates of mechanical properties. For the various heats used in this investigation, the ferrite contents calculated from ASTM Specification A $800 / A$ 800M-84 33 and from 
the Hull's equivalent factors are shown in Fig. 10. Estimations of ferrite content based on the ASTM procedure are $\approx 20 \%$ lower than those obtained from Hull's method for ferrite levels $>12 \%$ and are comparable for lower ferrite levels. Consequently. $\delta_{c}$ determined by the ASTM method for cast stainless steels with $>12 \%$ ferrite may yield nonconservative estimates of fracture properties.

The correlations expressed in Eqs. 3.2.4-3.2.12 have been validated with Charpy-impact data from service-aged cast stainiess steel components from the decommissioned Shippingport reactor; KRB reactor in Gundremmingen. Germany; and the Ringhals 2 reactor in Sweden.8 The correlations do not consider the effect of $\mathrm{Nb}$, and may not be applicable for $\mathrm{Nb}$-bearing steels. Also, they do not differentiate between product form, 1.e., static-cast or centrifugally cast materials.

\subsubsection{Fracture Toughness J-R Curve}

The saturation fracture toughness $J-R$ curve for a specific cast stainless steel can be est1mated from its RT impact energy at saturation. The J-R curve is expressed by the power-law relation $J_{d}=C \Delta a^{n}$, where $J_{d}$ is deformation $J$ per ASTM Specifications E 813-85 and E 115287. $\Delta \mathrm{a}$ is crack extension, and $\mathrm{C}$ and $\mathrm{n}$ are constants. The coefficient $\mathrm{C}$ at room or reactor temperatures and the RT Charpy-impact energy for aged and unaged cast stainless steels are plotted in Fig. 11. Fracture toughness data from studies at ANL, 4-7 FRA, 19,20 EPRI, 21 The Welding Institute (TW), 22 and Materlals Engineering Associates, Inc. (MEA) ${ }^{34}$ are included in the figure. At both room and reactor temperatures, the coefficient $\mathrm{C}$ decreased with a decrease in impact energy. Separate correlations were obtained for CF-3 or CF-8 steels and for CF-8M steels; the latter showed a larger decrease in fracture toughness for a given impact energy. The correlations used to estimate $J-R$ curves for static-cast materials were obtained by subtracting the value of standard deviation for the fit to the data from the best-fit curve; shown as dashed ines in Fig. 11, they help ensure that the estimated J-R curve is conservative for all material and aging conditions. Best-fit correlations were used for centrifugally cast materials.
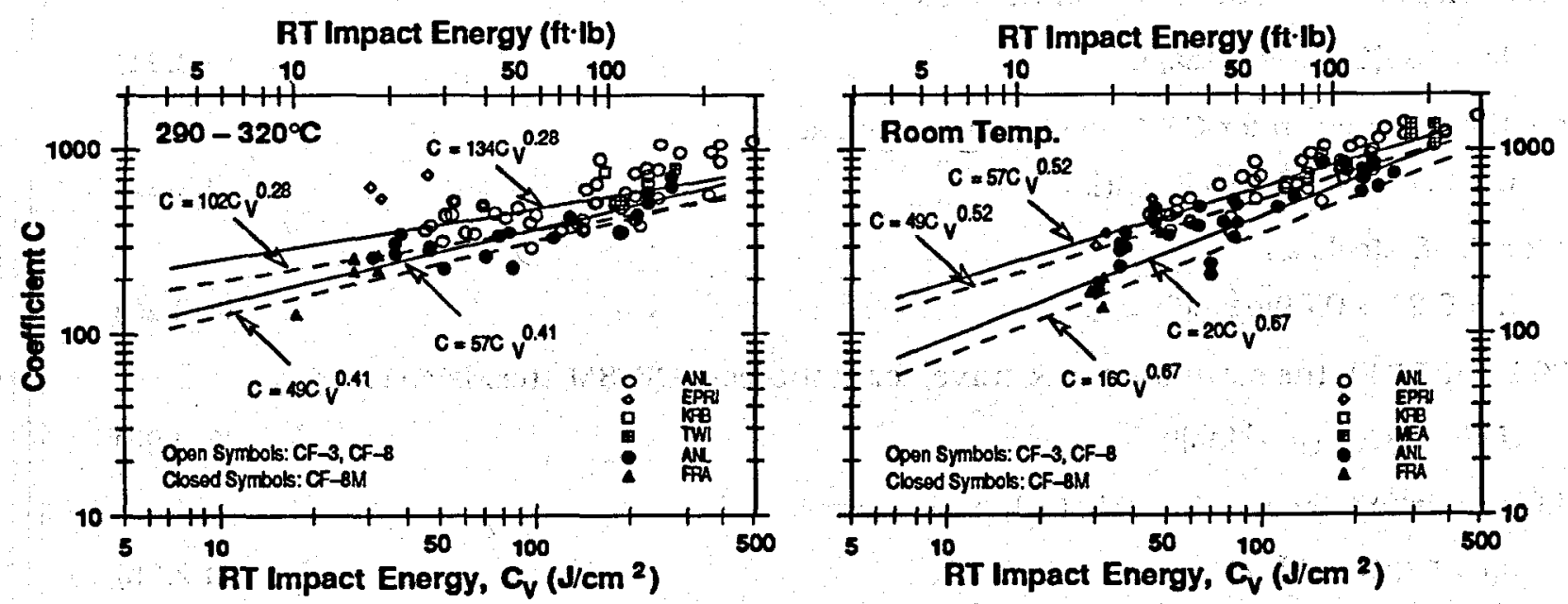

Figure 11. Correlation between RT Charpy-impact energy and coeffictent $C$ for cast statnless steel at $290-320^{\circ} \mathrm{C}$ and at $R T$. The solid and dashed lines represent the correlations used to estimate the J-R curves for centrifugally and static-cast materials, respectively. 
The exponent $n$ of $\Delta \mathrm{a}$ is correlated with the Charpy-impact energy $\mathrm{CV}$ in Fig. 12. The correlations shown in the figure bound the minimum values of the exponent $n$ observed experimentally, and help ensure that the estimated $\mathrm{J}-\mathrm{R}$ curves are conservative.

The saturation fracture toughness J-R curve at RT, for static-cast CF-3 and CF- 8 steels, is given by

$$
J_{d}=49\left[C_{\text {sat }}\right]^{0.52}[\Delta a]^{n}
$$

and for centrifugally cast $\mathrm{CF}-3$ and $\mathrm{CF}-8$ steels, by

$$
J_{d}=57\left[C_{V s a t}\right]^{0.52}[\Delta a]^{n}
$$

where the exponent $\mathbf{n}$ for $\mathrm{CF}-3$ steel is expressed as

$$
n=0.15+0.16 \log _{10}[\text { CVsat }] \text {. }
$$

and for CF-8 steels, as

$$
n=0.20+0.12 \log _{10}\left[C_{\text {Vsat }}\right]
$$

The saturation fracture toughness $J-R$ curve at $R T$, for static-cast CF-8M steel is given by

$$
J_{d}=16\left[C_{\text {Vsat }}\right]^{0.67}[\Delta a]^{n}
$$

and for centrifugally cast CF-8M steel, by

$$
J_{d}=20\left[C_{V s a t}\right]^{0.67}[\Delta a]^{n} \text {. }
$$

where the exponent $\mathrm{n}$ is expressed as

$$
\mathbf{n}=0.23+0.08 \log _{10}\left[C_{\text {Vsat }}\right] \text {. }
$$

At $290^{\circ} \mathrm{C}\left(554^{\circ} \mathrm{F}\right)$. the saturation $\mathrm{J}-\mathrm{R}$ curve, for static-cast CF-3 and CF- 8 steels is given by

$$
J_{d}=102\left[C_{V s a t}\right]^{0.28}[\Delta \mathrm{a}]^{n}
$$

and for centrifugally cast CF-3 and CF- 8 steels by

$$
\mathrm{J}_{\mathrm{d}}=134\left[\mathrm{C}_{\text {vsat }}\right]^{0.28}[\Delta \mathrm{a}]^{\mathrm{n}} \text {. }
$$

where the exponent $\mathbf{n}$ for $\mathrm{CF}-3$ steel is expressed as

$$
\mathrm{n}=0.17+0.12 \log 10\left[C_{\text {Vsat }}\right]
$$

and for $\mathrm{CF}-8$ steels as

$$
n=0.21+0.09 \log _{10}[\text { Cvsat }] \text {. }
$$

At $290^{\circ} \mathrm{C}\left(554^{\circ} \mathrm{F}\right)$, the saturation $\mathrm{J}-\mathrm{R}$ curve, for static-cast $\mathrm{CF}-8 \mathrm{M}$ steel is given by

$$
J_{d}=49\left[C_{V s a t}\right]^{0.41}[\Delta a]^{n}
$$

and for centrifugally cast CF-8M steel, by

$$
J_{d}=57\left[C_{V s a t}\right]^{0.41}[\Delta a]^{n} \text {. }
$$

where the exponent $n$ is expressed as

$$
\mathbf{n}=0.23+0.06 \log _{10}[\text { CVsat }]
$$



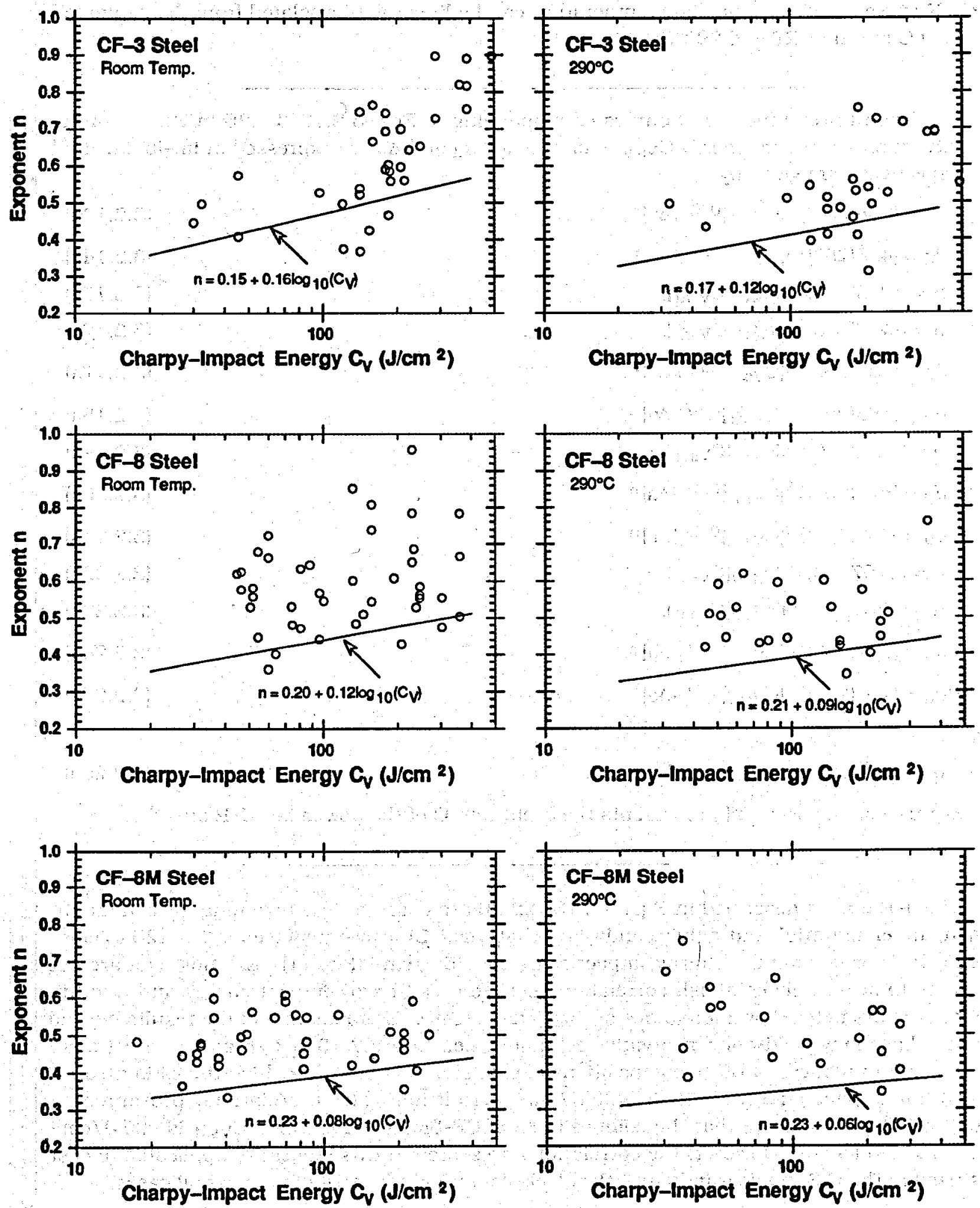

Figure 12. Correlation between RT impact energy and exponent $n$ of the power-law $J-R$ curve at RT and $290^{\circ} \mathrm{C}$ for cast stainless steels 
The J-R curve at any intermediate temperature can be linearly interpolated from the estimated values of $\mathrm{C}$ and $\mathrm{n}$ at $\mathrm{RT}$ and $290^{\circ} \mathrm{C}$.

The fracture toughness J-R curves corresponding to Eqs. 3.2.13-3.2.26 in British units, i.e., saturation $R T$ impact energy $C_{V \text { sat }}$ is in $\mathrm{ft}: \mathrm{lb}$ and $\mathrm{J}_{\mathrm{d}}$ and $\Delta \mathrm{a}$ are expressed in in.-lb/in.2 and in., respectively, are given by

$$
\begin{aligned}
& J_{d}=\left\{368(25.4)^{n}\left[C_{\text {sat }}\right]^{0.52}\right\}[\Delta a]^{n} \text {. } \\
& J_{d}=\left\{428(25.4)^{n}\left[C_{V_{s a t}}\right]^{0.52}\right\}[\Delta a]^{n} \text {. } \\
& \mathbf{n}=0.187+0.16 \log _{10}\left[C_{\text {vsat }}\right] \text {. } \\
& \mathrm{n}=0.227+0.12 \log _{10}\left[C_{\text {Vsat }}\right] \text {, } \\
& J_{d}=\left[130(25.4)^{n}\left[C_{V s a t}\right]^{0.67}\right][\Delta a]^{n} \text {. } \\
& J_{d}=\left\{163(25.4)^{n}\left[C_{\text {ssat }}\right]^{0.67}\right\}[\Delta a]^{n} \text {, } \\
& \mathrm{n}=0.248+0.08 \log _{10}\left[C_{\text {Vsat }}\right] \text {. } \\
& J_{d}=\left\{675(25.4) n\left[C_{\text {sat }}\right]^{0.28}\right][\Delta a]^{n} \text {. } \\
& J_{d}=\left\{887(25.4)^{n}\left[C_{V_{s a t}}\right]^{0.28}\right][\Delta a]^{n} \text {. } \\
& \mathrm{n}=0.197+0.12 \log _{10}\left[C_{\text {sat }}\right] \text {, } \\
& \mathrm{n}=0.231+0.09 \log _{10}[\text { CVsat }] \\
& J_{d}=\left[347(25.4)^{n}\left[C_{V s a t}\right]^{0.41}\right\}[\Delta a]^{n}, \\
& J_{d}=\left\{404(25.4)^{n}\left[C_{V_{s a t}}\right]^{0.41}\right\}[\Delta a]^{n},
\end{aligned}
$$

and

$$
\mathrm{n}=0.244+0.06 \log _{10}\left[C_{\text {Vsat }}\right]
$$

The expression enclosed in [\} represents the coefficient $C$ of the power-law J-R curve.

The J-R curves described in Eqs. 3.2.13-3.2.26 are based on fracture toughness data obtained under material and aging conditions that yield Charpy-impact energies $\geq 25 \mathrm{~J} / \mathrm{cm}^{2}$; there is little or no data for Charpy-impact energies $<25 \mathrm{~J} / \mathrm{cm}^{2}$ (Fig. 11). Existing data are not adequate to accurately establish correlations between RT Charpy-impact energy and fracture toughness parameter $\mathrm{C}$ or $\mathrm{n}$ for values of $\mathrm{CVsat}_{\mathrm{V} \text { s }}<25 \mathrm{~J} / \mathrm{cm}^{2}$. Extrapolation of the results beyond the data base may yield nonconservative estimates, 1.e., Eqs. 3.2.13-3.2.26 may over estimate the fracture toughness of those compositions of cast stainless steel for which the estimated RT saturation impact energy $\mathrm{C}_{\text {Vsat }}$ is $<25 \mathrm{~J} / \mathrm{cm}^{2}(<15 \mathrm{ft} \cdot \mathrm{lb})$. The correlations presented in Eqs. 3.2.1-3.2.12 indicate that the compositions of CF-8M steel for which CVsat is $<25 \mathrm{~J} / \mathrm{cm}^{2}$. contain $>25 \%$ ferrite. However, the correlations presented in this report are applicable to cast SSs used in the U.S. nuclear industry, the steels contain $<25 \%$ ferrite in almost all cases.

The fracture toughness $J-R$ curve at saturation for a specific cast stainless steel can be obtained from its chemical composition by using the correlations for CVsat given in Eqs. 3.2.13.2.12 and then using the estimated $\mathrm{C}_{\text {Vsat }}$ in Eqs. 3.2.13-3.2.26 to obtain the $\mathrm{J}-\mathrm{R}$ curve. 
Comparisons of the experimental and estimated $J-R$ curves at saturation, 1.e., the minimum fracture toughness that would be achieved for the material by thermal aging, are shown in Figs. 13-16. For most heats, the saturation fracture toughness is achieved after aging for $5000 \mathrm{~h}$ or more at $400^{\circ} \mathrm{C}\left(752^{\circ} \mathrm{F}\right)$. In most cases, estimated J-R curves show good agreement with experimental results and are essentially conservative. At RT, the maximum conservatism is for centrifugally cast Heats P2 and 205 and at $290^{\circ} \mathrm{C}$ for centrifugally cast Heat P2 and a static-cast EPRI heat. Estimated curves of these heats are $40-50 \%$ lower than those obtained experimentally.

The correlations described in Eqs. 3.2.4-3.2.26 account for the degradation of mechanical properties of typical heats of cast stainless steel. They do not consider the initial fracture properties of the unaged material. Some heats of cast stainless steels may have low initial fracture toughness and estimates from Eqs. 3.2.4-3.2.26 may be higher than the initial value. Some knowledge regarding the initial fracture toughness of the material is, therefore, needed to justify the use of the estimated fracture toughness.

The CMTR for a specific cast stainless steel component provides information on chemical composition, tensile strength, and possibly Charpy-impact energy of the material; fracture toughness is not avallable in CMTRs. The avallable fracture toughness J-R curve data at 290$320^{\circ} \mathrm{C}\left(554-608^{\circ} \mathrm{F}\right)$ for unaged cast stainless steels are shown in Fig. 17a. Fracture toughness J-R curves for a few "weak" heats of static-cast stainless steels are lower than those for wrought stainless steels, Fig. $17 \mathrm{~b}$. The fracture toughness of unaged cast stainless steels is slightly higher at $\mathrm{RT}$ than at $290-320^{\circ} \mathrm{C}$. At temperatures between $\mathrm{RT}$ and $320^{\circ} \mathrm{C}$, the minimum fracture toughness, of unaged static-cast stainless steels, can be expressed as

$$
J_{d}=400[\Delta a]^{0.40}
$$

and of centrifugally cast stainless steels, as :

$$
J_{d}=650[\Delta a]^{0.43} \text {. }
$$

The lower-bound fracture toughness $\mathrm{J}-\mathrm{R}$ curves for unaged static- and centrifugally cast stainless steels in British units are given by

and

$$
J_{\mathrm{d}}=8330[\Delta \mathrm{a}]^{0.40}
$$

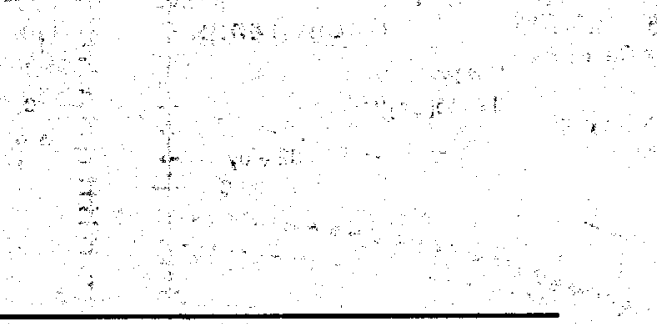

When no information is avallable, these minimum fracture toughness $\mathrm{J}-\mathrm{R}$ curves may be used as the initial fracture toughness of a cast material. The fracture toughness $J-R$ curve for unaged material may also be obtained by using the initial RT Charpy-impact energy, CVint, instead of $C_{\text {vsat }}$ in Eqs. 3.2.13-3:2.26. However, Eqs. 3.2.27 and 3.2.28 are used as a lower bound for these estimations. The correlations expressed in Eqs. 3.2.13-3.2.26 are based primarily on data for thermally aged steels and, therefore, are overly conservative for unaged steels, particularly at $290^{\circ} \mathrm{C}$. When the estimation based on $\mathrm{C}_{\text {Vint }}$ and Eqs. $3.2 .13-3.2 .26$ is 

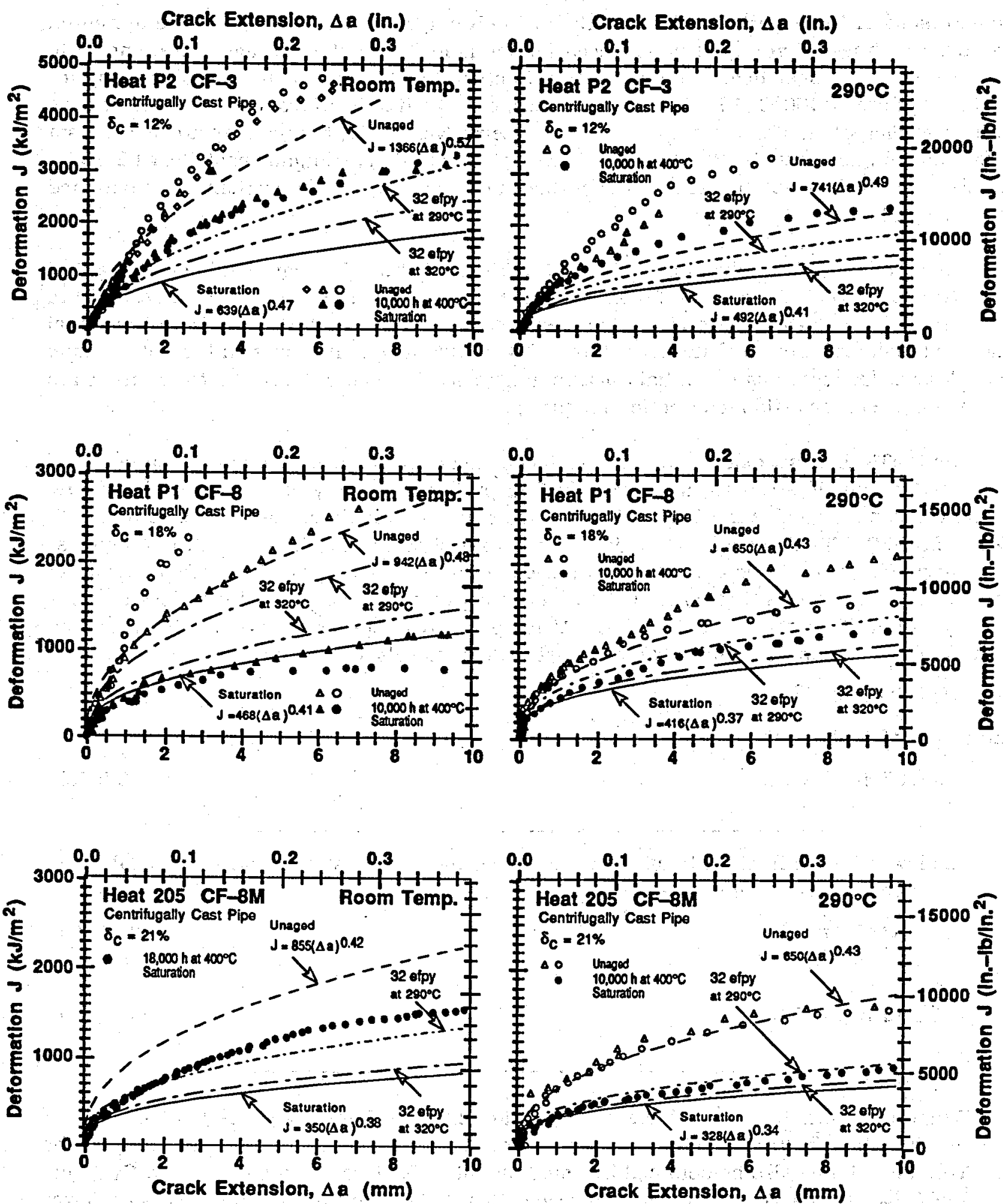

Flgure 13. Saturation fracture toughness $J-R$ curves at $R T$ and $290^{\circ} \mathrm{C}$, estimated from the chemical composition of centrifugally cast $C F-3, C F-8$, and $C F-8 M$ ptpes, and determined experimentally 

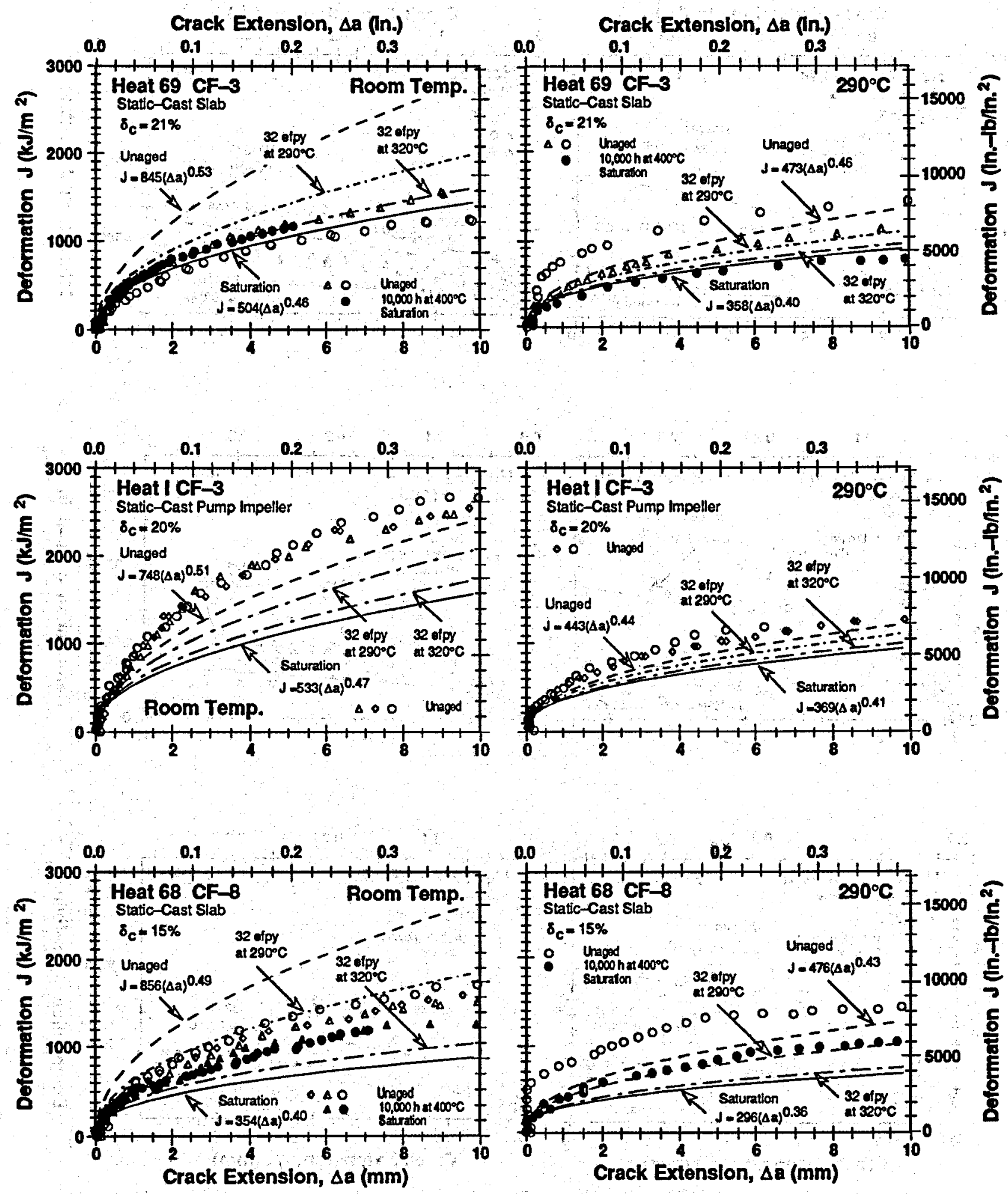

Figure 14. Saturation fracture toughness $J-R$ curves at $R T$ and $290^{\circ} \mathrm{C}$, estrmated from the chemical compositton of static-cast $C F-3$ and $C F-8$ steels, and determined expertmentally 

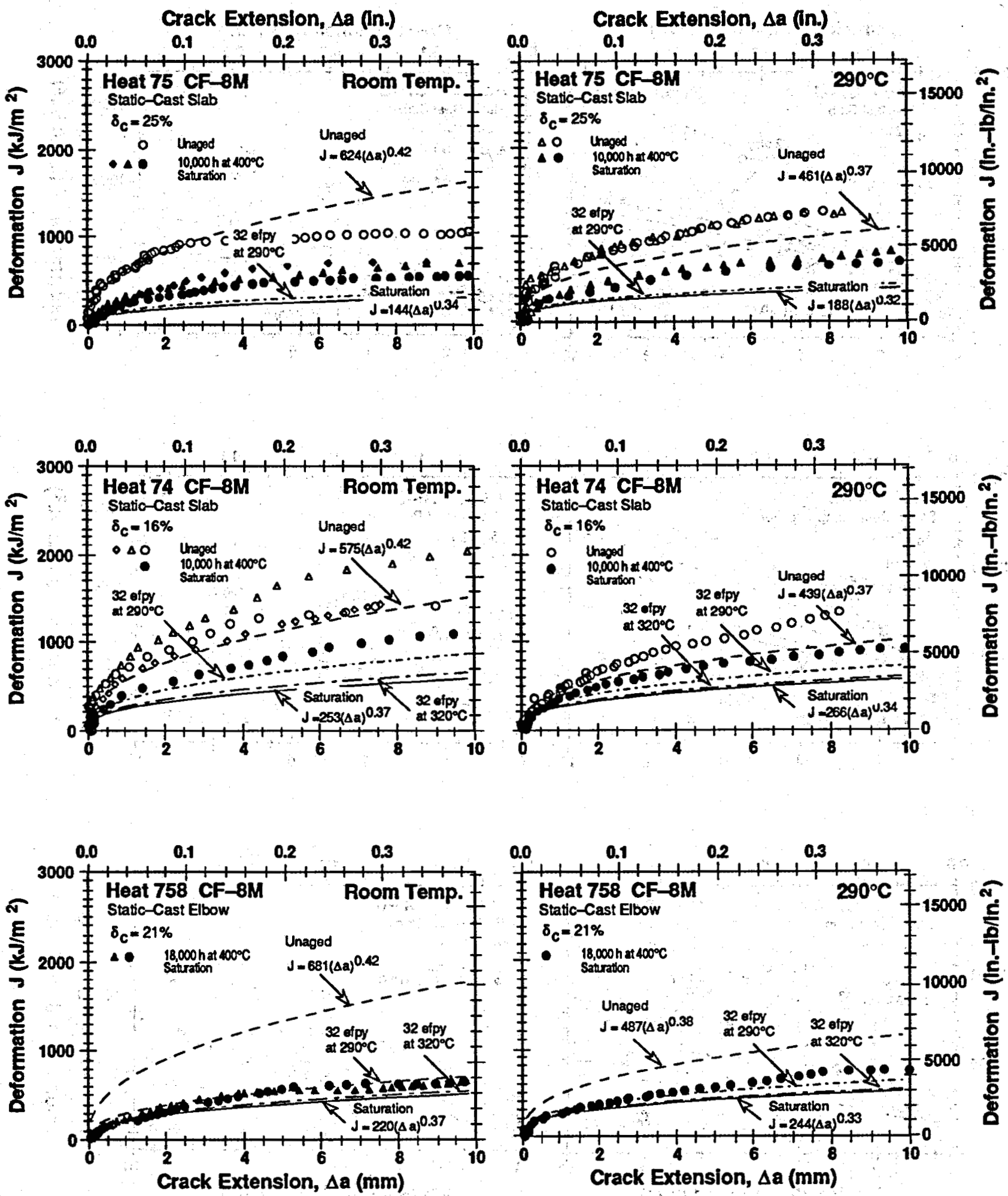

Figure 15. Saturation fracture toughness $J-R$ curves at $R T$ and $290^{\circ} \mathrm{C}$, estimated from the chemical composition of static-cast CF-8M steels, and determined expertmentally 

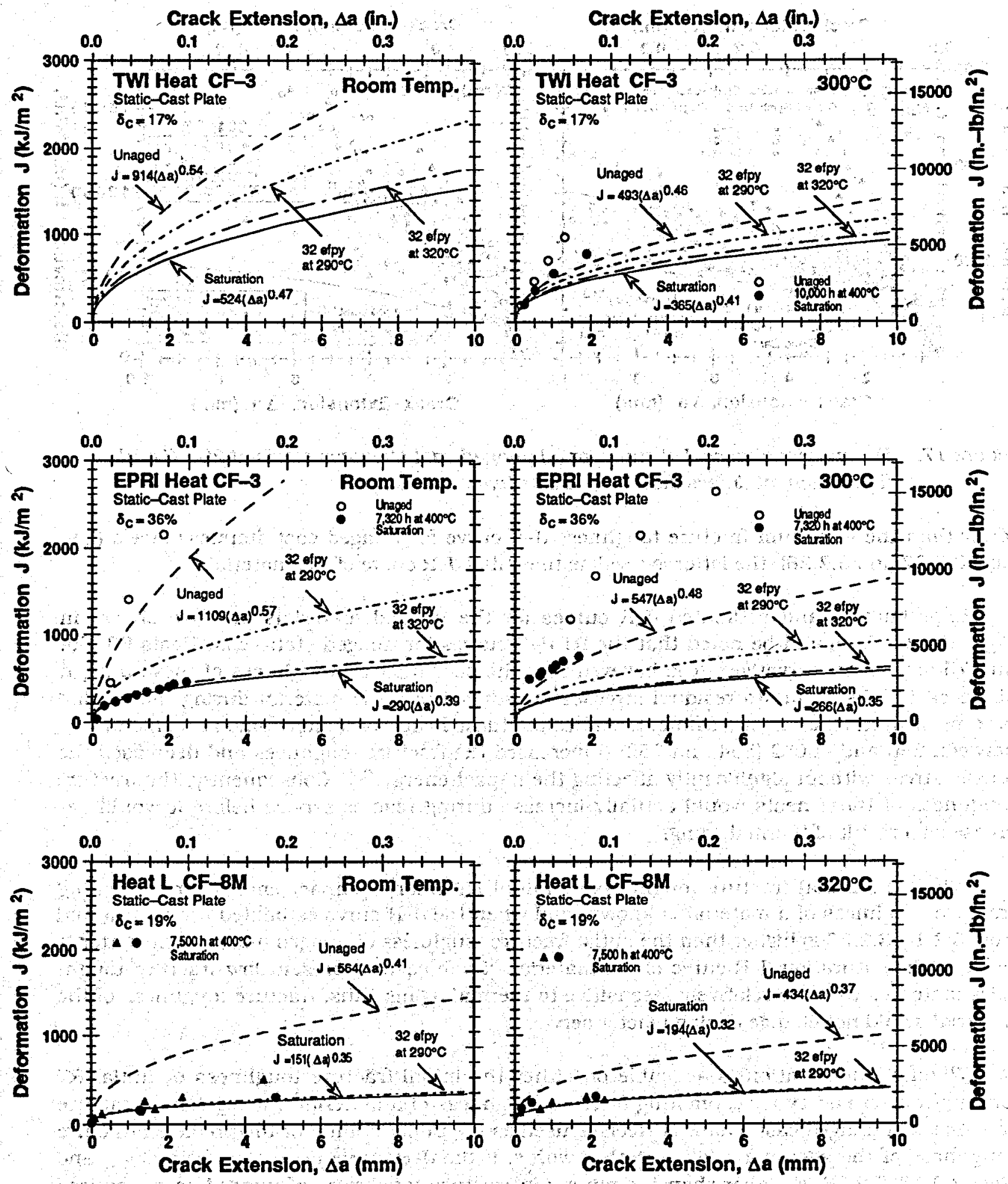

Figure 16. Saturation fracture toughness $J-R$ curves at $R T$ and $290^{\circ} \mathrm{C}$, estumated from the chemical composition of static-cast $C F-3$ and $C F-8 M$ steels, and determined expertmentally (Refs. 19,21,22) 

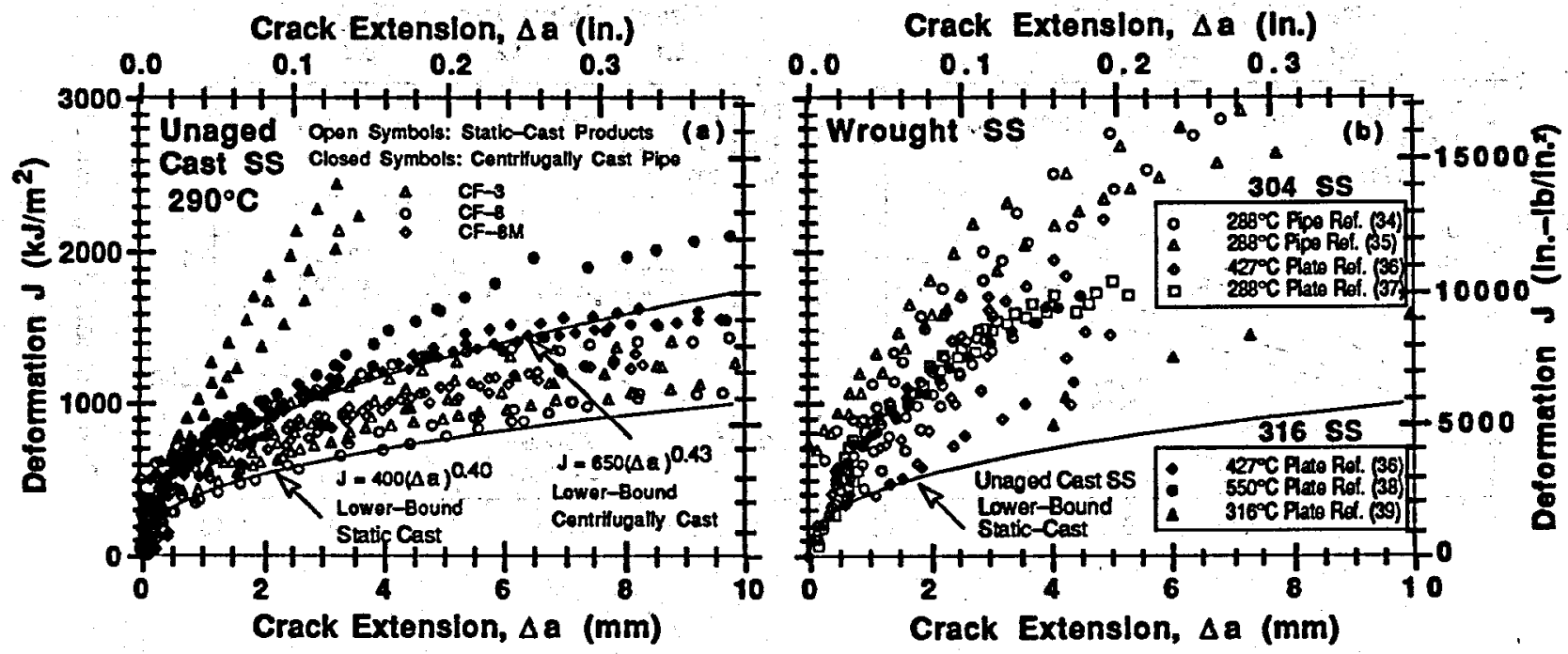

Figure 17. Fracture toughness $J-R$ curve for (a) unaged cast statnless steels at $290^{\circ} \mathrm{C}$ and (b) wrought stainless steels at varlous temperatures

lower than the minimum fracture toughness J-R curve for unaged cast stainless steels (1.e., Eqs. 3.2.27 and 3.2.28), the latter is used as the initial J-R curve of the material.

Experimental and estimated $J-R$ curves for the unaged materials are also shown in Figs. 13-16. It should be noted that the RT J-R curves for unaged static-cast Heats $68,69$. and 75 are nonconservative. It is believed that the poor fracture toughness of these unaged static-cast slabs is due to residual stresses introduced into the material during the casting process or production heat treatment. Annealing these heats for a short time at temperatures between 290 and $400^{\circ} \mathrm{C}\left(554\right.$ and $\left.752^{\circ} \mathrm{F}\right)$ increased the fracture toughness and decreased the tensile stress without significantly affecting the impact energy. ${ }^{6,7}$ Consequently, the fracture toughness of these heats would actually increase during reactor service before it would decrease as a result of thermal aging.

When the initial fracture toughness or initial RT Charpy-impact energy for estimating fracture toughness of a material is known, and when the J-R curve estimated from CVsat and Eqs. 3.2.13-3.2.26 is higher than the initial fracture toughness of unaged material, the latter is used as the saturation J-R curve of the material. Such cases represent low-fracture-toughness materials that are relatively insensitive to thermal aging; thus, fracture toughness of the material would not change during reactor service.

When no information is available on either the initial fracture toughness or initial RT Charpy-impact energy for estimating fracture toughness of a material, the minimum fracture toughness of unaged cast stainless steels is used as the upper bound for the predicted fracture toughness of the aged material. In other words, if the $J-R$ curve estimated from $C_{V s a t}$ and Eqs. 3.2.13-3.2.26 is higher than the minimum fracture toughness of unaged cast stainless steels (i.e., Eqs. 3.2.27 and 3.2.28), the latter is used as the saturation J-R curve of a material.

The estimated $J-R$ curves after 32 effective full power years (efpys) of service (1.e., the end of $\approx 40$-yr design life) at 290 and $320^{\circ} \mathrm{C}\left(554\right.$ and $\left.608^{\circ} \mathrm{F}\right)$ are also shown in Figs. 13-16. These curves provide information about the rate of thermal embrittlement. The results indicate that, 
for service at $320^{\circ} \mathrm{C}$, fracture toughness of these materials will reach saturation or will be close to saturation within the 40-yr design life. A few compositions of CF-8M steel alone will reach saturation fracture toughness within the 40 -yr design life at $290^{\circ} \mathrm{C}$.

\subsection{Estimate for Steels of Known Composition and Service History: Service Time Values}

\subsubsection{Charpy-Impact Energy}

Room-temperature impact energy as a function of time and temperature of aging is estimated from the RT saturation impact energy $\mathrm{C}_{\text {vsat }}$ and the kinetics of embrittlement. The decrease in RT Charpy-Impact energy CV with time is expressed as

$$
\log 10 C V=\log 10 C_{\text {sat }}+\beta\{1-\tanh [(P-\theta) / \alpha]\} \text {. }
$$

where the aging parameter $P$ is defined by

$$
\mathrm{P}=\log _{10}(\mathrm{t})-\frac{1000 \mathrm{Q}}{19.143}\left(\frac{1}{\mathrm{~T}_{\mathrm{s}}+273}-\frac{1}{673}\right)
$$

The constants $\alpha$ and $\beta$ can be determined from CVint and CVsat as follows:

$$
\alpha=-0.585+0.795 \log 10 C_{V s a t}
$$

and

$$
\beta=\left(\log _{10} C_{V i n t}-\log _{10} C_{V s a t}\right) / 2 .
$$

If CVint is not known, a typical value of $200 \mathrm{~J} / \mathrm{cm}^{2}$ (118 ft.lb) may be used. The value of $\theta$ is not avallable for cast stainless steel components in the field, and can only be obtained from aging archival material for $5,000-10,000 \mathrm{~h}$ at $400^{\circ} \mathrm{C}\left(752^{\circ} \mathrm{F}\right)$. However, parametric studies show that the aging response at reactor temperatures is relatively insensitive to the values of $\theta .9$ A value of 2.9 for $\theta$ (1.e., mean value of the experimental data) is used to estimate thermal embrittlement at $280-330^{\circ} \mathrm{C}\left(536-626^{\circ} \mathrm{F}\right)$. A $\theta$ value of 3.3 is used for estimates at temperatures $<280^{\circ} \mathrm{C}\left(<536^{\circ} \mathrm{F}\right)$ and 2.5 for estlmates at $330-360^{\circ} \mathrm{C}\left(626-680^{\circ} \mathrm{F}\right)$. Activation energy for thermal embrittlement is expressed in terms of both chemical composition and the constant $\theta$. The activation energy $8 \mathrm{in} \mathrm{kJ} /$ mole is given by

$$
\begin{aligned}
\mathrm{Q}= & 10\left[74.52-7.20 \theta-3.46 \mathrm{SI}-1.78 \mathrm{Cr}-4.35 \mathrm{I}_{1} \mathrm{Mn}\right. \\
& \left.+\left(148-125 \mathrm{I}_{1}\right) \mathrm{N}-61 \mathrm{I}_{2} \mathrm{C}\right]
\end{aligned}
$$

where the indicators $I_{1}=0$ and $I_{2}=1$ for $C F-3$ or $C F-8$ steels and assume the values of 1 and 0 , respecttvely, for CF-8M steels.

The activation energy $Q$ in $\mathrm{kcal} / \mathrm{mole}$ is defined by

$$
\begin{aligned}
\mathrm{Q}= & 178.10-17.21 \theta-8.27 \mathrm{SI}-4.25 \mathrm{Cr}-10.40 \mathrm{I}_{1} \mathrm{Mn} \\
& +\left(353.7-298.8 \mathrm{I}_{1}\right) \mathrm{N}-145.8 \mathrm{I}_{2} \mathrm{C}
\end{aligned}
$$

where the indicators $I_{1}=0$ and $I_{2}=1$ for $C F-3$ or CF-8 steels and assume the values of 1 and 0 , respectively, for $\mathrm{CF}-8 \mathrm{M}$ steels. 


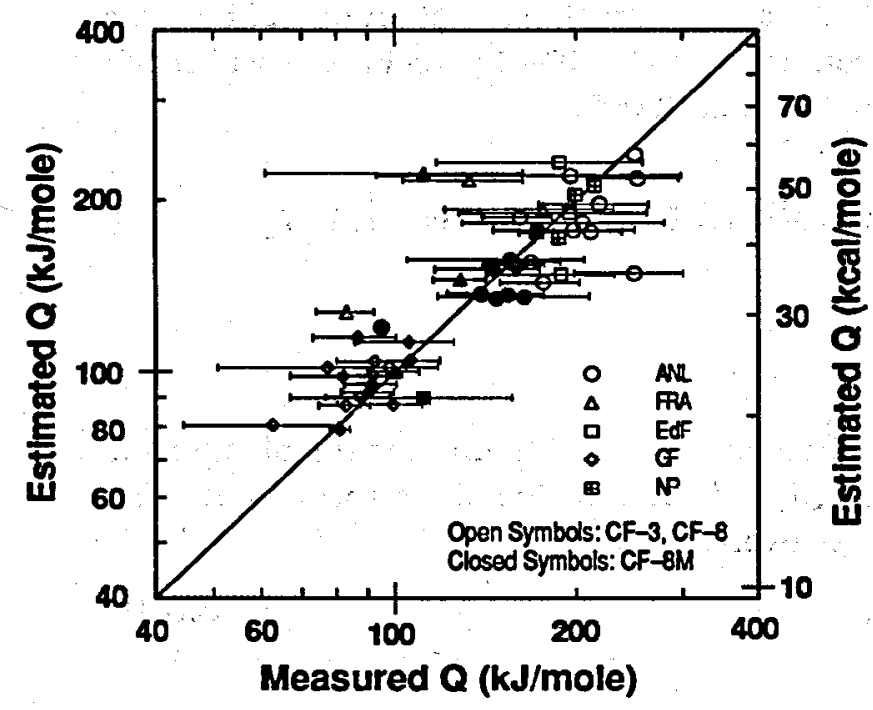

Figure 18.

Observed and estimated activation energy for thermal embrittlement of cast stainless steels

The estimated and observed values of $Q$ for the ANL, 1-6 GF, 15 EdF, 17 NP, 18 and FRA 19 heats are plotted in Fig. 18. The predicted values are within the $95 \%$ confidence limits for all the heats. Equation 3.3.5 is applicable to compositions within ASTM Specification A 351, with an upper limit of $1.2 \mathrm{wt} . \%$ for Mn content. Actual Mn content is used when materials contain up to $1.2 \mathrm{wt} . \% \mathrm{Mn}$; for steels containing $>1.2 \mathrm{wt} . \% \mathrm{Mn}, 1.2 \mathrm{wt} . \%$ is assumed. Furthermore. the values of $Q$ predicted from Eq. 3.3 .5 should be between $65 \mathrm{~kJ} / \mathrm{mole}(15.5 \mathrm{kcal} / \mathrm{mole}) \mathrm{minimum}$ and $250 \mathrm{~kJ} / \mathrm{mole}(59.8 \mathrm{kcal} / \mathrm{mole})$ maximum; $Q$ is assumed to be $65 \mathrm{~kJ} / \mathrm{mole}$ if the predicted values are lower, and $250 \mathrm{~kJ} /$ mole if the predicted values are higher.

Equation 3.3.5 is an updated version ${ }^{*}$ of an expression presented earlier: 9 qualitatively $1 t$ agrees with the microstructural and mechanical-property data. For example, an increase in the value of $\theta$ decreases the activation energy, as expected. The contributions of Si for all grades of steel and Mn for CF-8M steels are consistent with their effect on G-phase precipitation. These elements should promote precipitation of $G$ phase: hence, the coefficients for these elements should have a negative sign, because activation energy for thermal embrittlement is low for steels that show $G$-phase precipitation. An increase in $\mathrm{C}$ or $\mathrm{N}$ in the steel will promote carbide or nitride precipitation at high temperatures and thus increase the activation energy. The positive sign of the coefficient for $N$ agrees with this behavior. The coefficient of $C$ in CF-8M steel, however, has a negative sign. It is likely that $\mathrm{C}$ also promotes precipitation of $\mathrm{G}$ phase, a multicomponent phase consisting of $\mathrm{Ni}$, Si, Mo, $\mathrm{Cr}, \mathrm{Fe}$, and some $\mathrm{Mn}$ and $\mathrm{C.} 25,29$

The RT Charpy-impact energy of a specific cast stainless steel as a function of service time and temperature can be obtained from estimated CVsat (Eqs. 3.2.1-3.2.12) and the kinettes of embrittlement (Eqs. 3.3.1-3.3.5). The initial Charpy-impact energy of the unaged steel is needed for estimating the decrease in impact energy as a function of time and temperature of service. The RT Charpy-impact energy observed experimentally and that estimated from the chemical composition and initial impact energy of the ANL, 4-7 GF, ${ }^{15} \mathrm{EdF}, 17$ FRA, 19 and EPRI 21 heats aged at temperatures between 290 and $350^{\circ} \mathrm{C}\left(554\right.$ and $\left.662^{\circ} \mathrm{F}\right)$ are shown in Figs. 19 and 20. The estimates for 31 of the 47 heats used in developing the correlations for the kinetics of

\footnotetext{
- The updated expression for CF-8M steel is essentially an optimized version of the earlier expression. For CF-3 and $C F-8$ steels, the effect of Mo and Mn content has been omitted and the effect of $C$ has been added.
} 

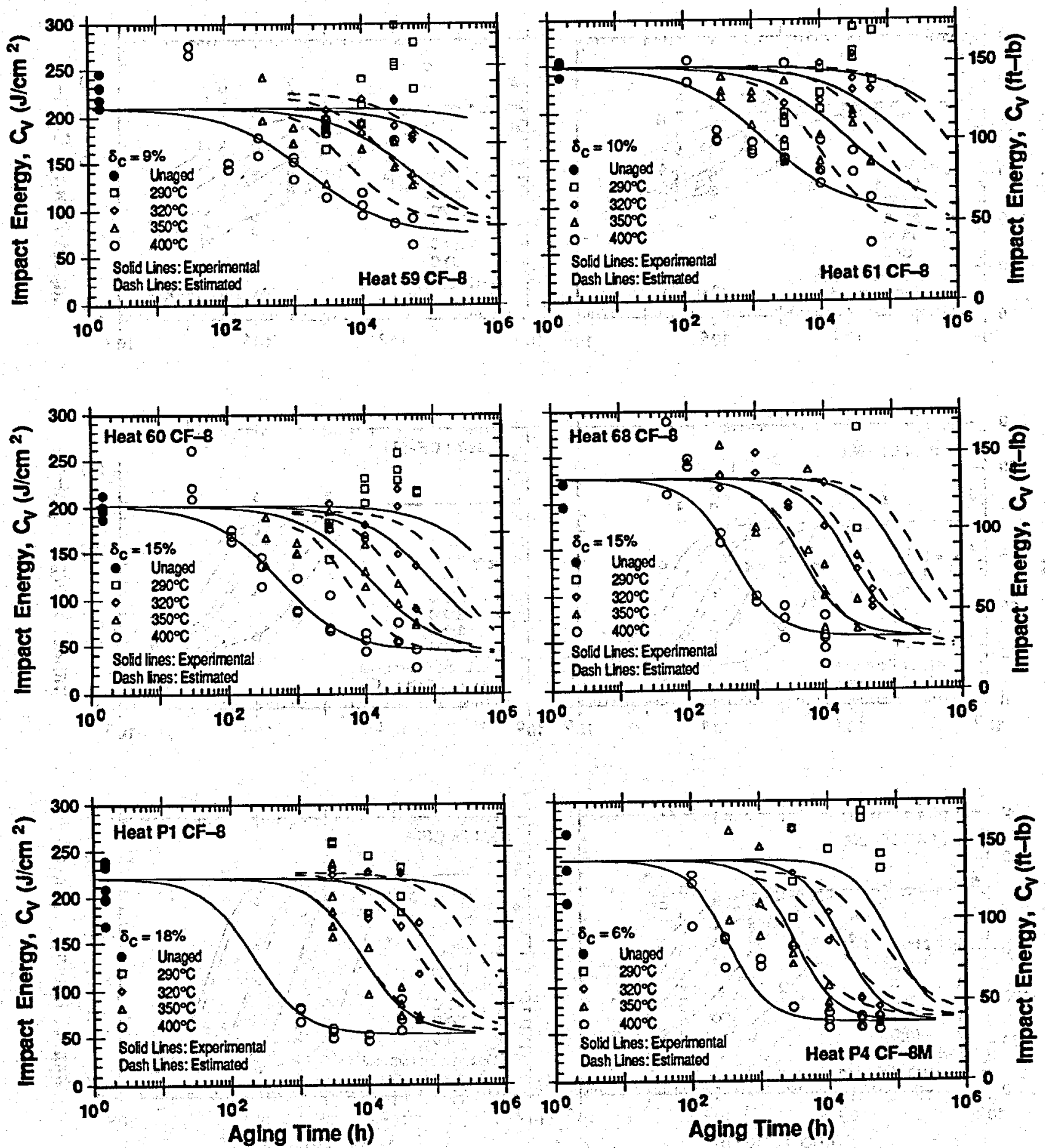

Figure 19. RT Charpy-tmpact energy for 16 ANL heats and 1 EPRI heat, observed expertmentally and estimated from the composition and tititial impact energy of the materials. Soltd ines represent the best fit of the data at $290-400^{\circ} \mathrm{C}$ and dash lines are the estmates at $290-350^{\circ} \mathrm{C}$. 

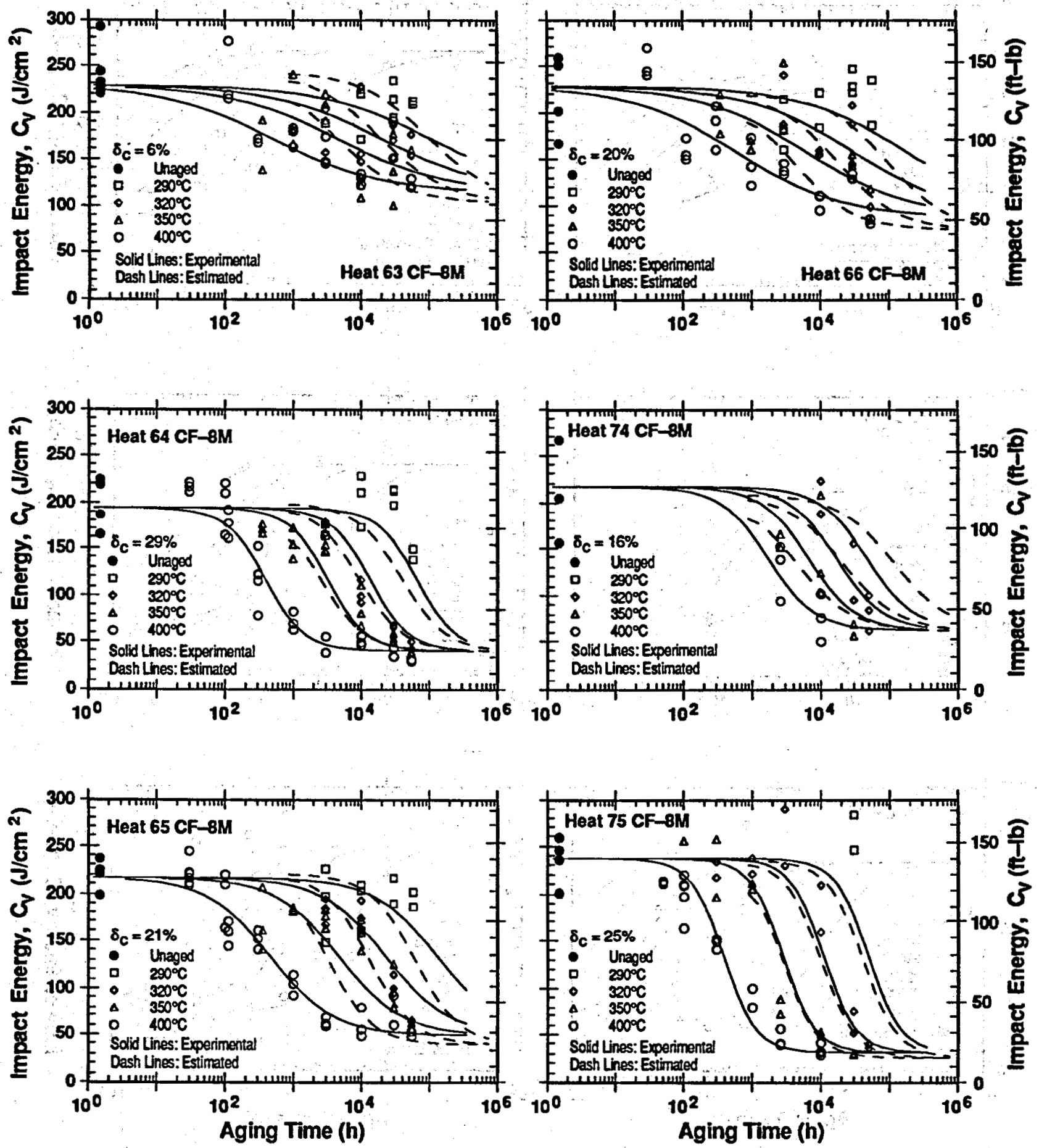

Figure 19. (Contd) 

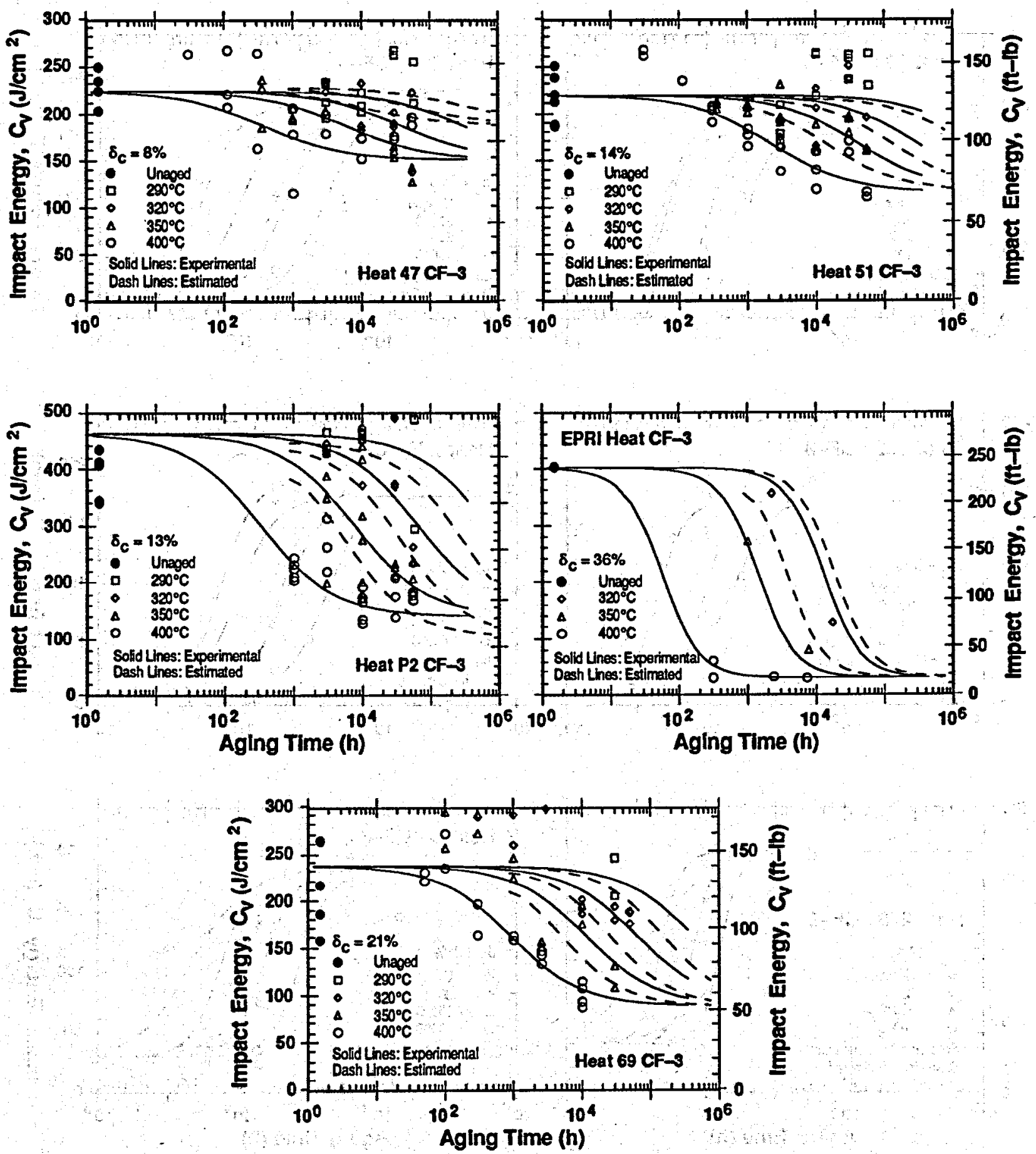

Figure 19. (Contd.) 

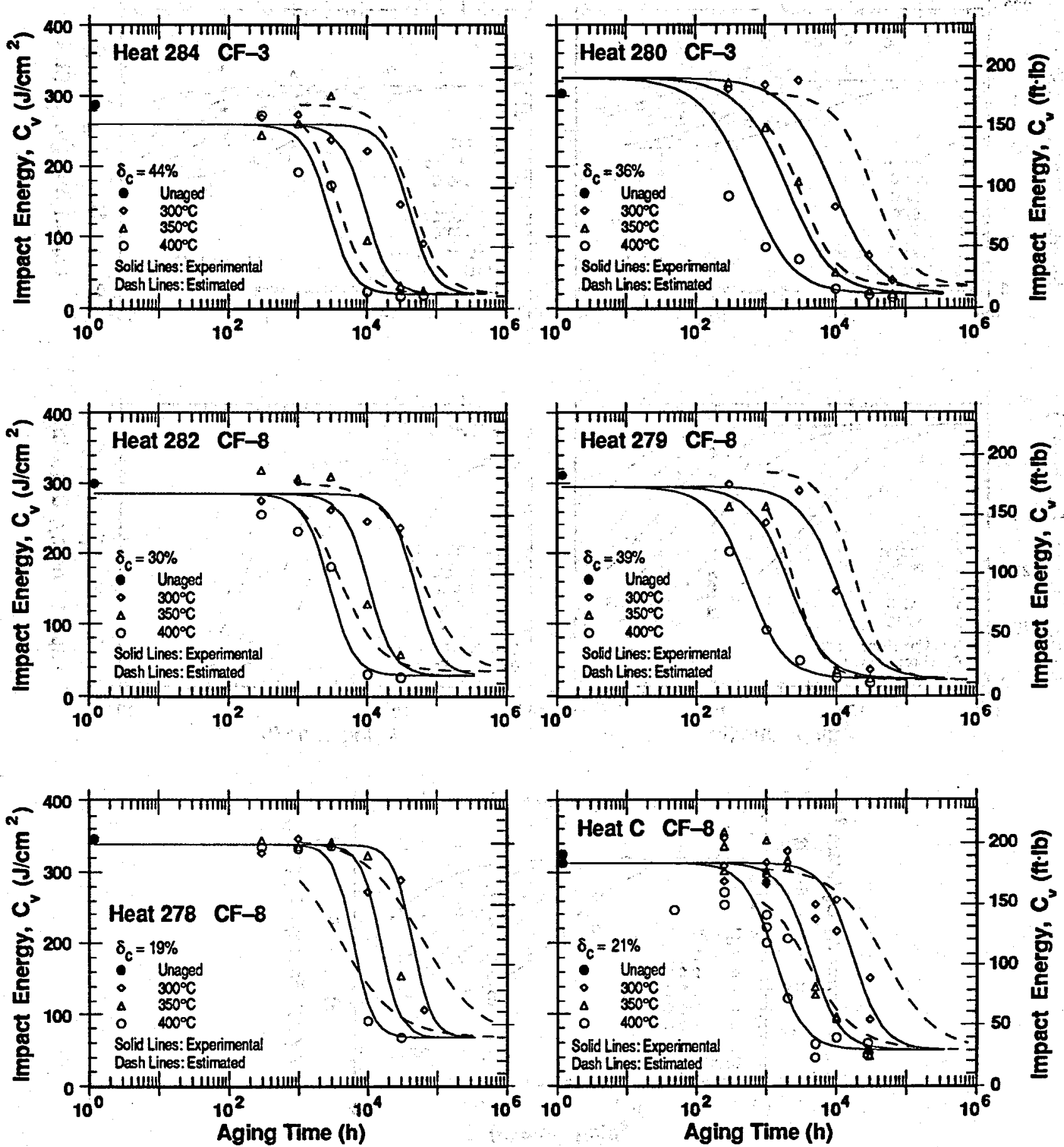

Figure 20. RT Charpy-impact energy for the GF, FRA and EdF heats, observed expertmentally and estimated from the composition and initial impact energy of the materials. Solid lines represent the best fit of the data at 300,350 , and $400^{\circ} \mathrm{C}$ and dash lines are the estimates at 300 and $350^{\circ} \mathrm{C}$. 

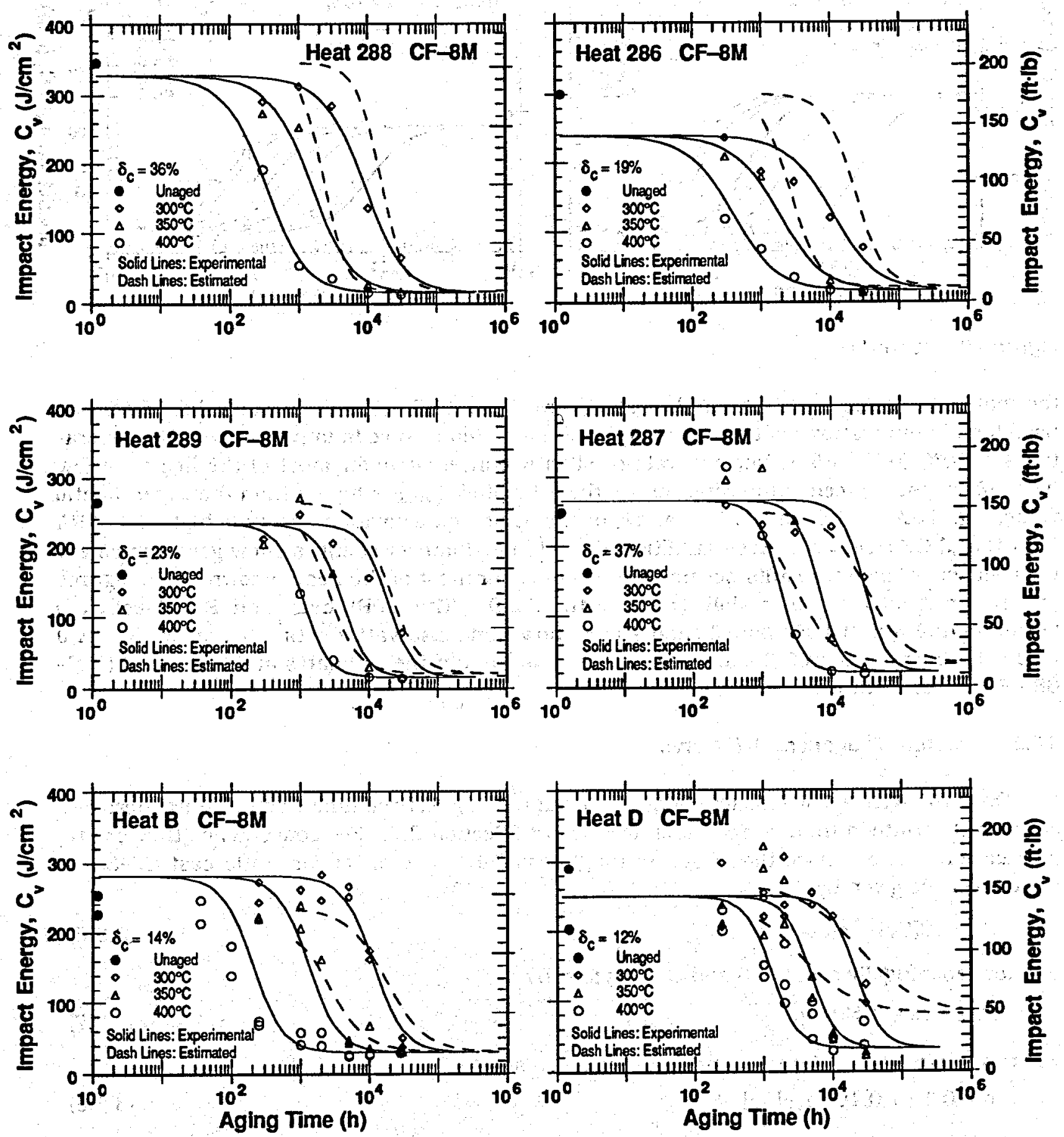

Figure 20. (Contd.) 

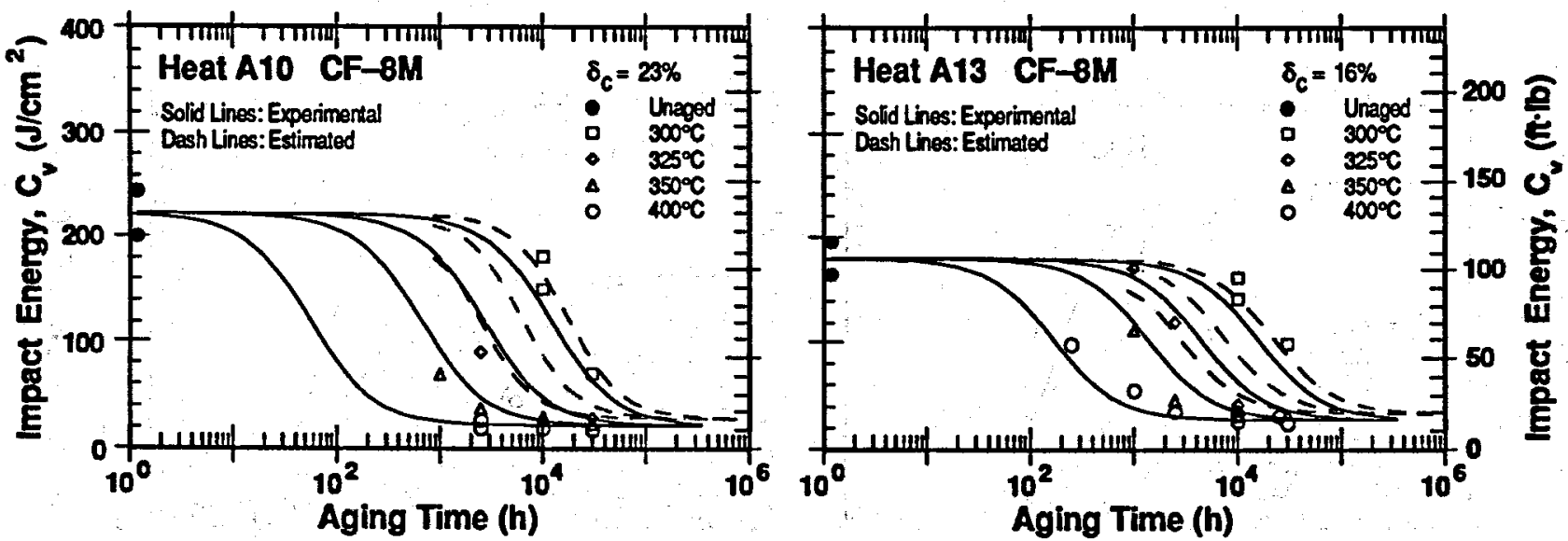

Figure 20. (Contd.)

thermal embrittlement of cast stainless steels are shown in these figures. A $\theta$ value of 2.9 was used for all temperatures of thermal aging. The estimated change in impact energy at temperatures $\leq 330^{\circ} \mathrm{C}\left(626^{\circ} \mathrm{F}\right)$ is either accurate or slightly conservattve for most of the heats. A few heats show poor agreement because either the estimated CVsat is higher than the experimental value, e.g., FRA Heat $D$ and ANL Heat 47, or the estimated activation energy is high, e.g.. FRA Heat $\mathrm{C}$ and $\mathrm{GF}$ Heat 278 . Even at $350^{\circ} \mathrm{C}$, the estimated impact energies show good agreement with the experimental results because the $\theta$ values for most of the heats shown in the figures are either greater or only slightly lower than 2.9. The EPRI heat and EdF Heat A10 (experimental $\theta$ is 2.1 for both heats) alone show nonconservative estimates at $350^{\circ} \mathrm{C} . \mathrm{A} \theta$ value of 2.5 rather than 2.9 should be used to ensure that the estimates at $330-360^{\circ} \mathrm{C}(626-$ $680^{\circ} \mathrm{F}$ ) are conservative.

\subsubsection{Fracture Toughness J-R Curve}

Once the RT Charpy-impact energy $C_{V}$ is known, the service time fracture toughness J-R curve is determined from correlations described in Section 3.2. For convenience they are repeated here. The service time fracture toughness J-R curve at RT for static-cast CF-3 and CF-8 steels, is given by.

$$
\mathrm{J}_{\mathrm{d}}=49[\mathrm{Cv}]^{0.52}[\Delta \mathrm{a}]^{\mathrm{n}} \text {, }
$$

and for centrifugally cast CF- 3 and CF- 8 steels, by

$$
J_{d}=57[C V]^{0.52}[\Delta a]^{n} \text {, }
$$

where the exponent $n$, for CF-3 steel, is expressed as

$$
\mathrm{n}=0.15+0.16 \log _{10}[\mathrm{Cv}] \text {. }
$$

and for CF-8 steels, as

$$
\mathrm{n}=0.20+0.12 \log _{10}[\mathrm{CV}] \text {. }
$$

The service time fracture toughness J-R curve at RT for static-cast CF-8M steel, is given by

$$
J_{d}=16[C v]^{0.67}[\Delta a]^{n},
$$

and for centrifugally cast CF-8M steel, by 


$$
J_{d}=20[C V]^{0.67}[\Delta \mathrm{a}]^{n},
$$

where the exponent $\mathbf{n}$ is expressed as

$$
n=0.23+0.08 \log _{10}[\mathrm{Cv}] \text {. }
$$

At $290^{\circ} \mathrm{C}\left(554^{\circ} \mathrm{F}\right)$, the service time $\mathrm{J}-\mathrm{R}$ curve, for static-cast $\mathrm{CF}-3$ and $\mathrm{CF}-8$ steels, is given by

$$
J_{d}=102[\mathrm{Cv}]^{0.28}[\Delta \mathrm{a}]^{n_{\text {: }}}
$$

and for centrifugally cast $\mathrm{CF}-3$ and $\mathrm{CF}-8$ steels, by

$$
J_{d}=134[C v]^{0.28}[\Delta \mathrm{a}]^{n} \text {. }
$$

where the exponent $n$, for CF-3 steel, is expressed as

$$
\mathrm{n}=0.17+0.12 \log 10[\mathrm{Cv}]
$$

and for CF-8 steels, as

$$
\mathrm{n}=0.21+0.09 \log _{10}[\mathrm{CV} l \text {. }
$$

At $290^{\circ} \mathrm{C}\left(554^{\circ} \mathrm{F}\right)$, the service time $\mathrm{J}-\mathrm{R}$ curve, for static-cast CF-8M steel, is given by

$$
\mathrm{J}_{\mathrm{d}}=49[\mathrm{CV}]^{0.41}[\Delta \mathrm{a}]^{\mathrm{n}} \text {, }
$$

and for centrifugally cast CF-8M steel, by

$$
\mathrm{J}_{\mathrm{d}}=57[\mathrm{CV}]^{0.41}[\Delta \mathrm{a}]^{\mathrm{n}} \text {, }
$$

where the exponent $n$ is expressed as

$$
\mathrm{n}=0.23+0.06 \log _{10}[\mathrm{Cv}] \text {. }
$$

The $J-R$ curve at any intermediate temperature can be linearly interpolated from the estimated values of $\mathrm{C}$ and $\mathrm{n}$ at $\mathrm{RT}$ and $290^{\circ} \mathrm{C}$.

The fracture toughness J-R curves corresponding to Eqs. 3.3.13-3.3.26 in British untts. 1.e., RT impact energy $C_{V}$ is in $\mathrm{ft} \cdot \mathrm{lb}$ and $\mathrm{J}_{\mathrm{d}}$ and $\Delta \mathrm{a}$ are expressed in $\mathrm{in} . \mathrm{lb} / \mathrm{in} .^{2}$ and in., respectively, are given by

$$
\begin{aligned}
& J_{d}=\left\{368(25.4)^{n}[C,]^{0.52}\right\}[\Delta a]^{n} \text {. } \\
& J_{d}=\left\{428(25.4)^{n}[C v]^{0.52}\right\}[\Delta a]^{n} \text {, } \\
& \mathrm{n}=0.187+0.16 \log _{10}[\mathrm{CV}] \text { ] } \\
& n=0.227+0.12 \log _{10}[C v] \text {. } \\
& J_{d}=\left\{130(25.4)^{n}[C V]^{0.67}\right\}[\Delta a]^{n} \text {. } \\
& J_{d}=\left\{163(25.4)^{n}[C V]^{0.67}\right\}[\Delta a]^{n} \text {. } \\
& \mathrm{n}=0.248+0.08 \log _{10}[\mathrm{Cv}] \text {. } \\
& J_{d}=\left[675(25.4)^{n}[C v]^{0.28}\right\}[\Delta a]^{n} \text {. } \\
& J_{d}=\left\{887(25.4)^{n}[C]^{0.28}\right\}[\Delta a]^{n} \text {, } \\
& \mathrm{n}=0.197+0.12 \log _{10}[\mathrm{Cv}] \text {. } \\
& n=0.231+0.09 \log _{10}[C V] \text {. }
\end{aligned}
$$




$$
\begin{aligned}
& J_{d}=\left\{347(25.4)^{n}[C]^{0.41}\right\}[\Delta a]^{n}, \\
& J_{d}=\left\{404(25.4)^{n}[C v]^{0.41}\right\}[\Delta a]^{n},
\end{aligned}
$$

and

$$
\mathrm{n}=0.244+0.06 \log _{10}[\mathrm{Cv}]
$$

The expression enclosed in \{ \} represents the coefficient $\mathbf{C}$ of the power-law J-R curve.

As discussed in Section 3.2, the correlations described in Eqs. 3.3.6-3.3.19 account for the degradation of fracture toughness of typical heats of cast stainless steel and do not consider the initial fracture properties of the unaged material. Depending on the avallable information, initial fracture toughness of the unaged material or minimum fracture toughness of unaged cast stainless steels (Eqs. 3.2.27 or 3.2.28) is used as an upper bound for the estimations (see Section $C$ of flow diagram in Fig. 2). Examples of the experimental and estimated $J-R$ curves for several partially aged (e.g., $30,000 \mathrm{~h}$ at $320^{\circ} \mathrm{C}$ ) cast stainless steels are shown in Figs. 21 and 22. The estimated J-R curves show good agreement with experimental results.

\subsection{Estimation of Tensile Properties}

\subsubsection{Tensile Strength}

Tensile flow stress of aged cast stainless steels can be estimated from correlations between the ratio of the tensile flow stress of aged and unaged cast stainless steels and a normalized aging parameter. The ratio of the tenstle flow stress of aged and unaged cast stainless steels at $\mathrm{RT}$ and $290^{\circ} \mathrm{C}\left(554^{\circ} \mathrm{F}\right)$ is plotted as a function of a normalized aging parameter in Fig. 23. Flow stress is characterized as the mean of the $0.2 \%$ yield stress and ultimate stress, and the aging parameter is normalized with respect to a $\theta$ value of 2.9. The aging parameter $P$ was determined from Eq. 3.3.2 and experimental values of activation energy. At both temperatures, the flow-stress ratio increased with thermal aging; the increase in flow stress of CF-3 steels was the smallest and that of CF-8M steels the largest. The correlations (shown as solid lines in Fig. 23) were obtained by subtracting the value of standard deviation for the fit to the data from the best-fit curve. The $X$ axis in Fig. 23 is reduced to $P$ when a $\theta$ value of 2.9 is used in Eqs. 3.3.5 and 3.3.2 to determine $P$.

Tensile flow stress of aged cast stainless steels can be estimated from the initial tensile flow stress and the correlations given in Fig. 23. At RT, the tensile-flow-stress ratio $R_{\mathrm{f}}=\left(\sigma_{\mathrm{f} \text { aged }} / \sigma_{f_{\text {unaged }}}\right)$, for CF-3 steel, is gtven by

$$
R_{\mathrm{f}}=0.90+0.05 \mathrm{P} \quad\left(1.00 \leq R_{\mathrm{f}} \leq 1.10\right) \text {; }
$$

for $\mathrm{CF}-8$ steel, by

$$
R_{f}=0.84+0.08 P \quad\left(1.00 \leq R_{f} \leq 1.16\right) ;
$$

and for CF-8M steel, by

$$
R_{\mathrm{f}}=0.77+0.10 P \quad\left(1.00 \leq R_{\mathrm{f}} \leq 1.19\right) \text {. }
$$

At $290^{\circ} \mathrm{C}\left(554^{\circ} \mathrm{F}\right)$, the tensile-flow-stress ratio $R_{f}=\left(\sigma_{f_{\text {aged }}} / \sigma_{f_{\text {unaged }}}\right)$, for CF-3 steel, is given by

$$
R_{\mathrm{f}}=0.87+0.06 \mathrm{P} \quad\left(1.00 \leq \mathrm{R}_{\mathrm{f}} \leq 1.08\right)
$$



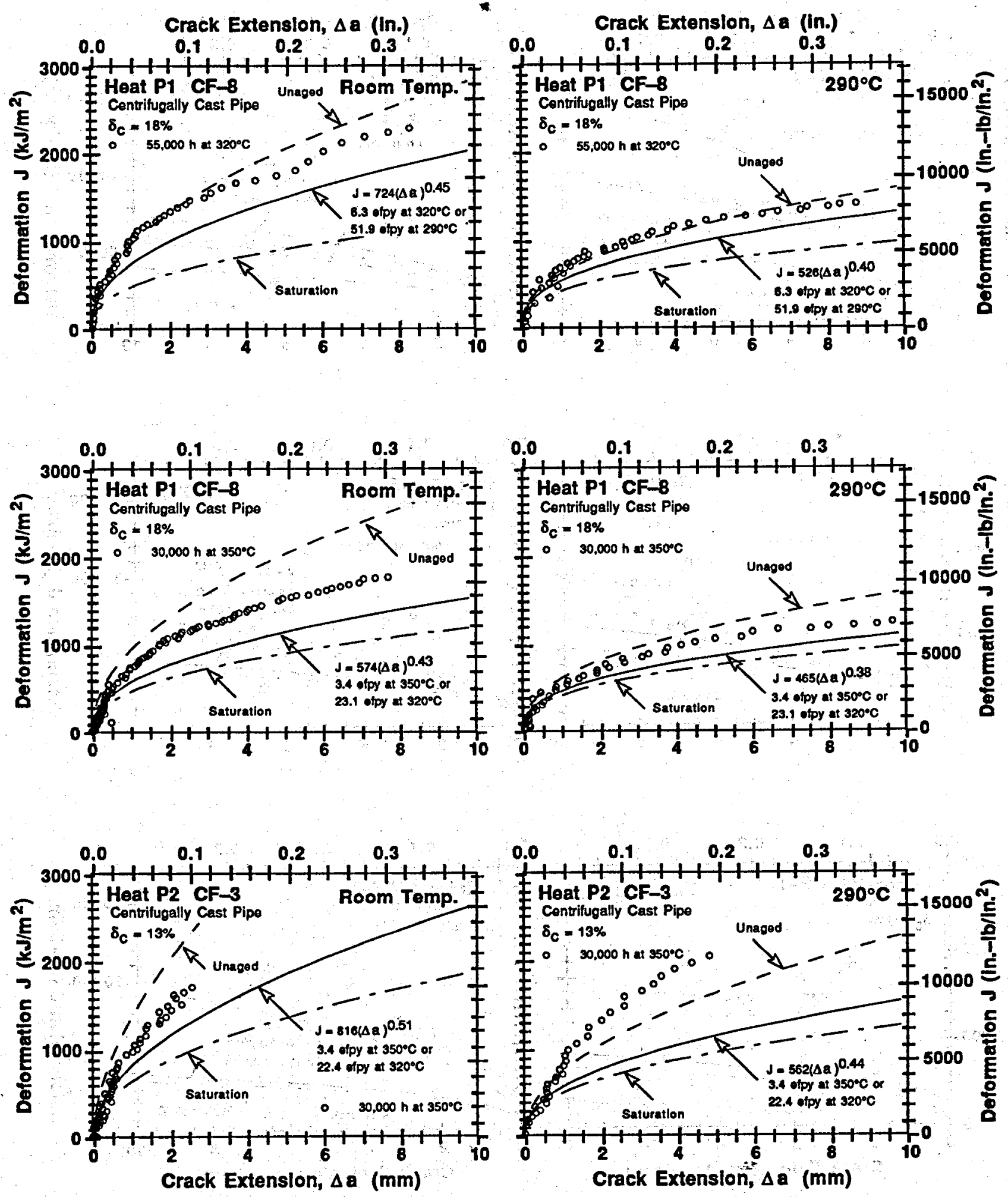

Figure 21. Fracture toughness $J-R$ curve at $R T$ and $290^{\circ} \mathrm{C}$, estumated from the chemical composittion and initial Charpy-tmpact energy and determined expertmentally for partially aged, centrifugally cast $\mathrm{CF}-3$ and $\mathrm{CF}-8$ ptpes 

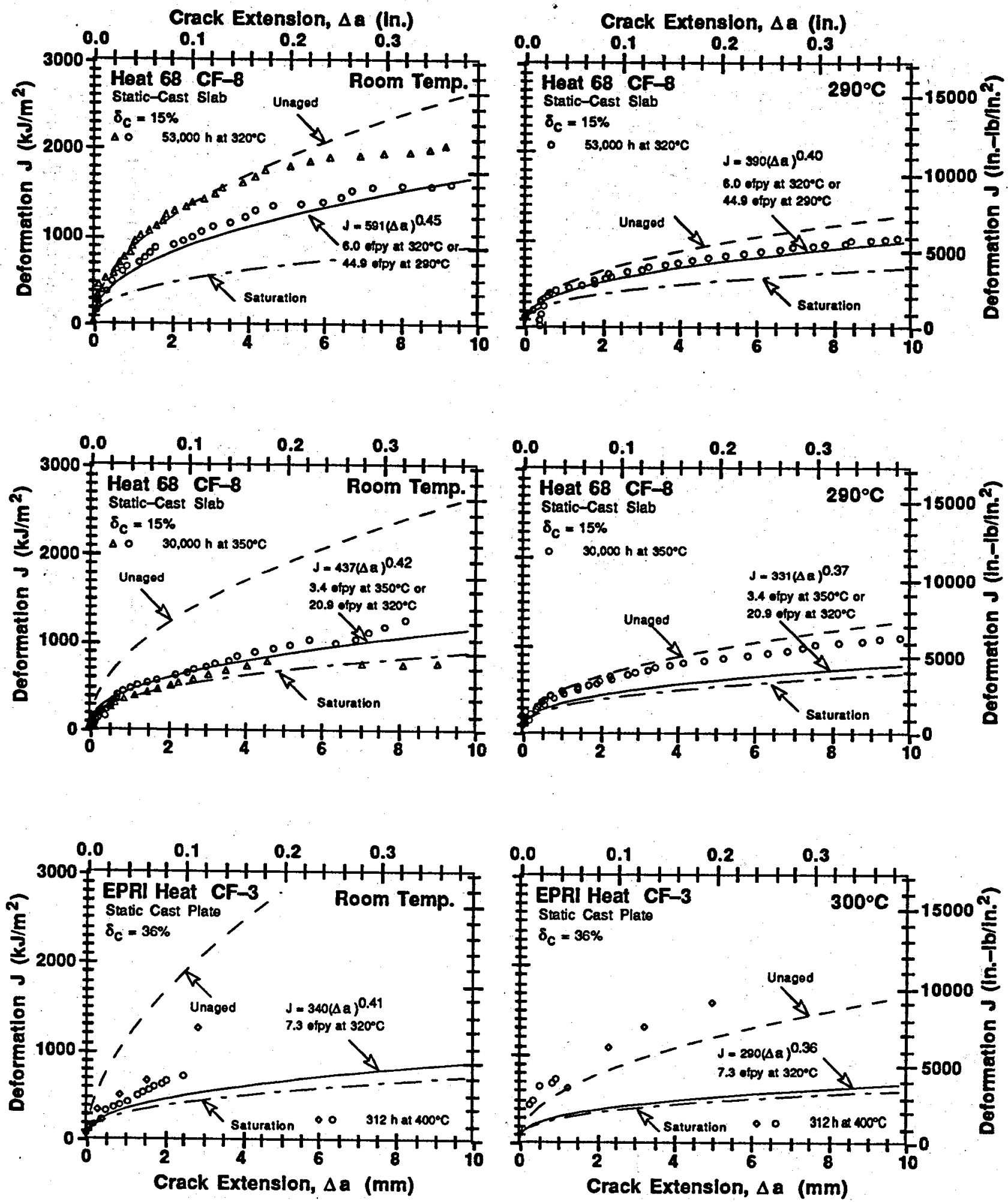

Figure 22. Fracture toughness $J-R$ curves at $R T$ and $290^{\circ} \mathrm{C}$, estimated from the chemical composition and initial Charpy-impact energy and determined experimentally for partially aged, static-cast $C F-3, C F-8$, and $C F-8 M$ steels 

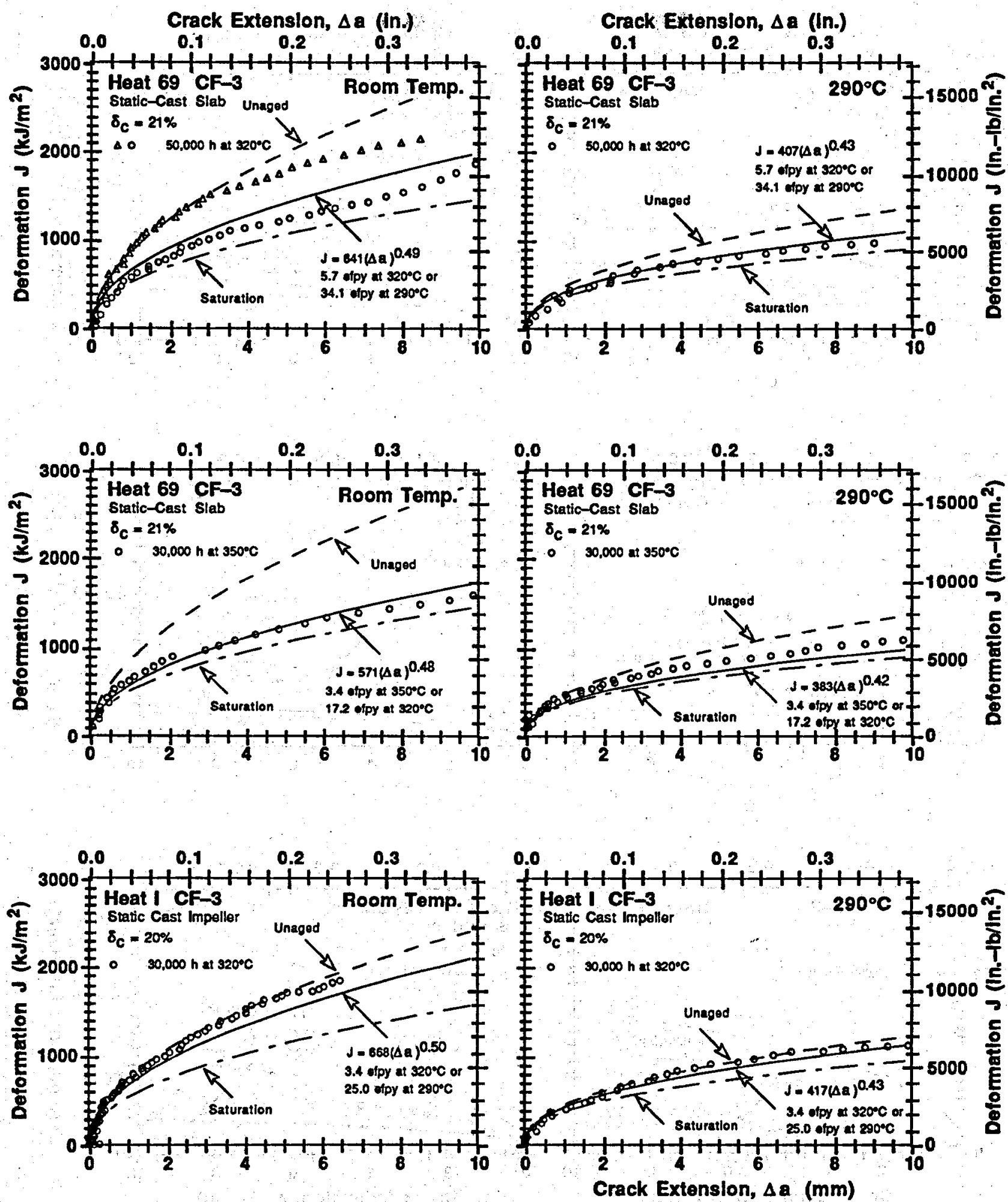

Fyure 22. (Contd) 

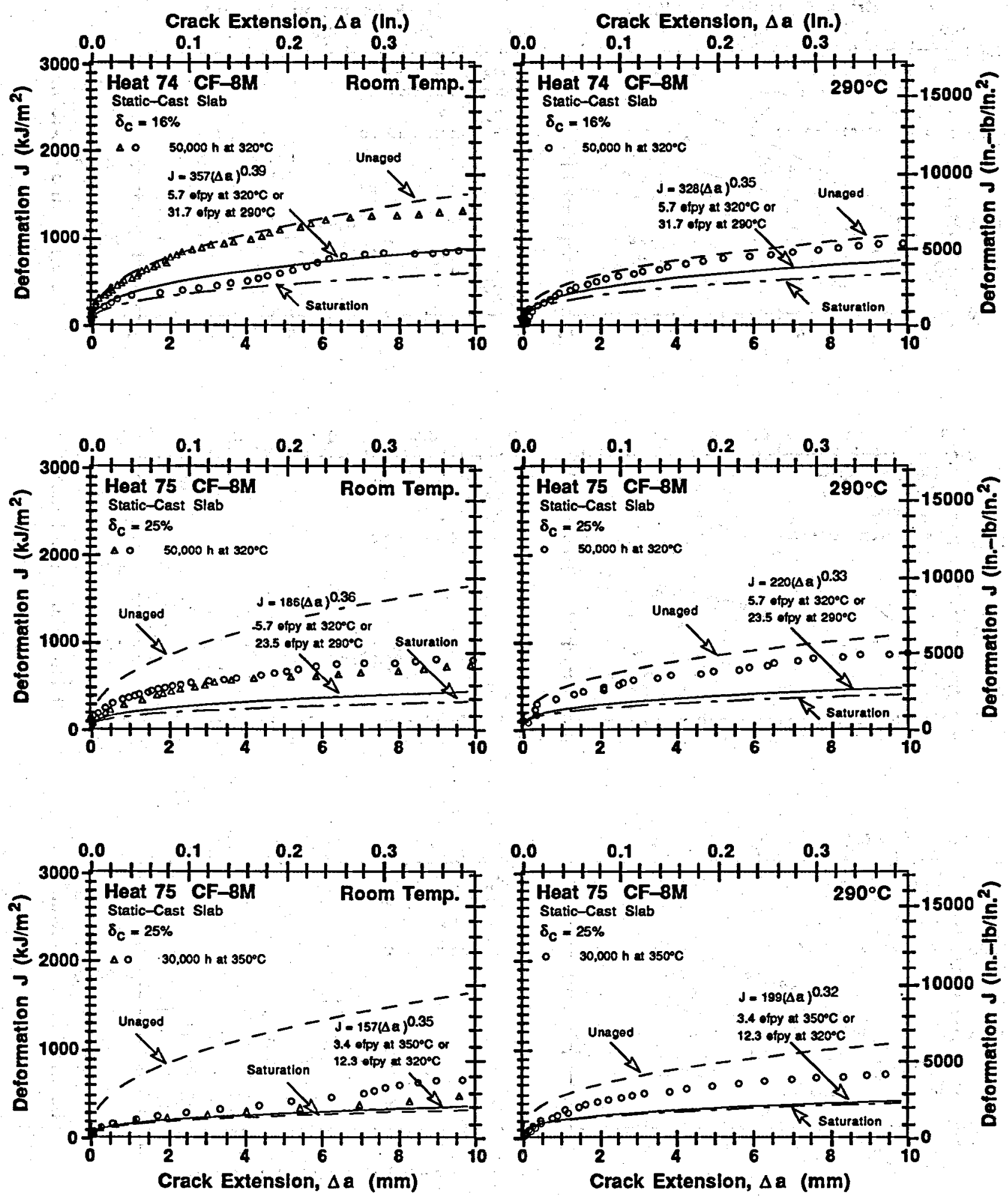

Figure 22. (Contd.) 

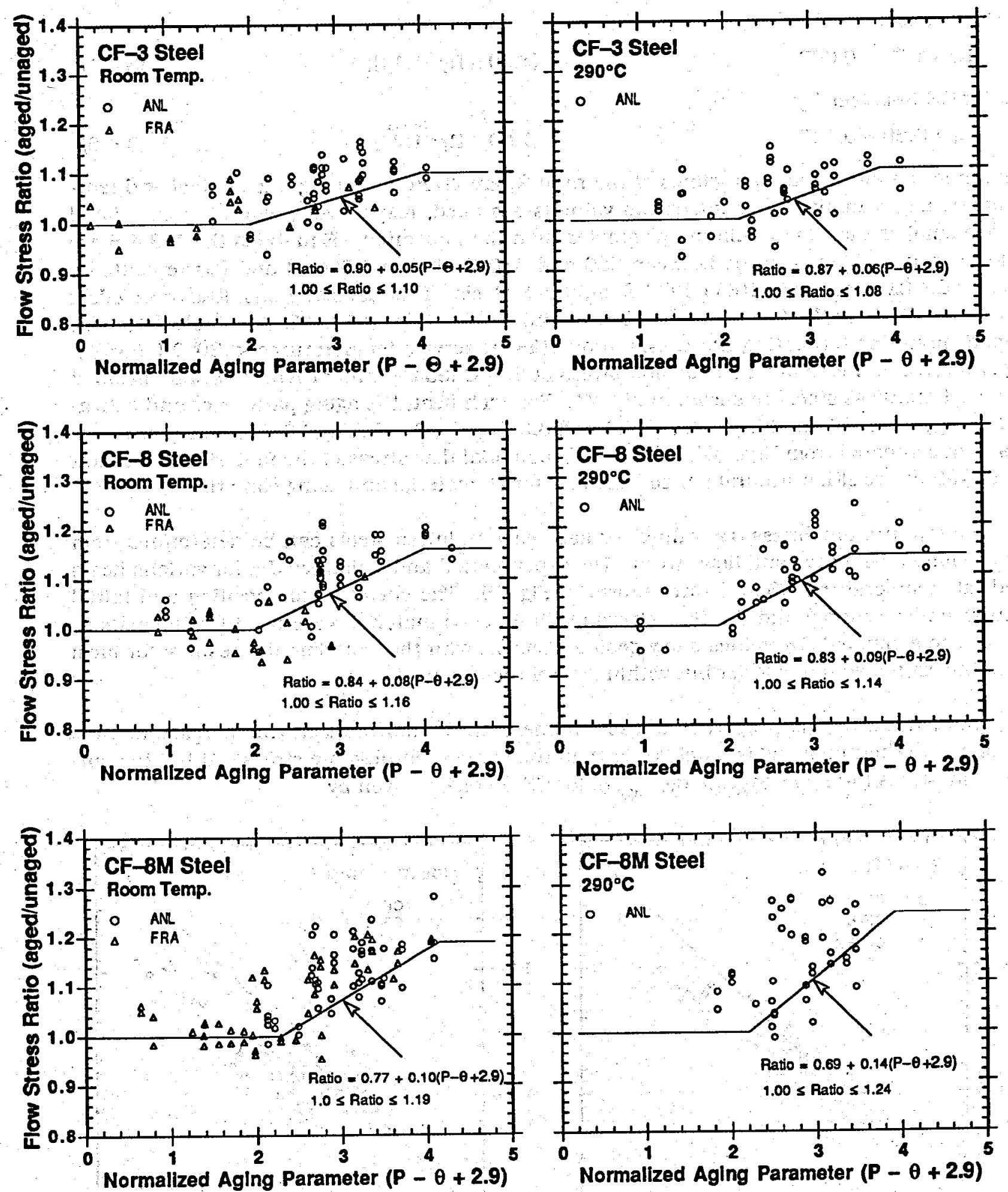

Figure 23. Flow stress ratio of aged cast stainless steels at $R T$ and $290^{\circ} \mathrm{C}$ as a function of the normalized aging parameter. The solid lines represent correlations obtained by subtracting $\sigma$ from the best fit curve. 
for CF-8 steel, by

$$
R_{\mathrm{f}}=0.83+0.09 P
$$

$\left(1.00 \leq R_{f} \leq 1.14\right):$

and for CF-8M steel, by

$$
R_{f}=0.69+0.14 P \quad\left(1.00 \leq R_{f} \leq 1.24\right) \text {. }
$$

The minimum and maximum values of the ratio $R_{f}$ are given for each grade of steel and temperature, 1.e., a minimum or maximum value is assumed, respectively, when the calculated ratio is smaller than the minimum or greater than the maximum. Equations 3.4.1-3.4.6 are valid for service temperatures between 280 and $330^{\circ} \mathrm{C}\left(536\right.$ and $\left.626^{\circ} \mathrm{F}\right)$ and ferrite contents $>7 \%$ for CF-8M steel and $>10 \%$ for CF-3 and CF-8 steels. Thermal aging has little or no effect on the tensile strength of cast stainless steels with low ferrite content. The avallable data base is inadequate for estimating the tensile properties at service temperatures $<280^{\circ} \mathrm{C}\left(<536^{\circ} \mathrm{F}\right)$. Experimental and estimated tensile flow stress at $290^{\circ} \mathrm{C}\left(554^{\circ} \mathrm{F}\right)$ and at $\mathrm{RT}$ for various heats of aged cast stainless steel are shown in Fig. 24. For each heat, the aging parameter and activation energy were obtained from Eqs. 3.3.2 and 3.3.5 and a $\theta$ value of 2.9. Tensile flow stress was then estimated from Eqs. 3.4.1-3.4.6 and the initial flow stress of the materials. The est1mated values are either accurate or conservative for all material and aging conditions.

The fracture toughness $J_{I C}$ values for aged cast stainless steels can be determined from the estimated $J-R$ curve and flow stress. The experimental and estimated $J_{I C}$ for various heats aged at temperatures $\leq 350^{\circ} \mathrm{C}$ are shown in Fig. 25. The chemical composition and initial Charpy-Impact energy and the flow stress of the unaged material were used for the estimations. The estimated $J_{I C}$ values show good agreement with the experimental results; for most cases the estimated $\mathrm{J}_{\mathrm{IC}}$ is lower but within $30 \%$ of the observed value.

The data on tensile properties of cast stainless steels indicate that the increase in yleld stress due to thermal aging is much lower than the increase in ultimate stress. At RT, the tensile-yield-stress ratio $R_{y}=\left(\sigma_{\text {yaged }} / \sigma_{\text {yunaged }}\right)$, for $\mathrm{CF}-3$ steel, is given by
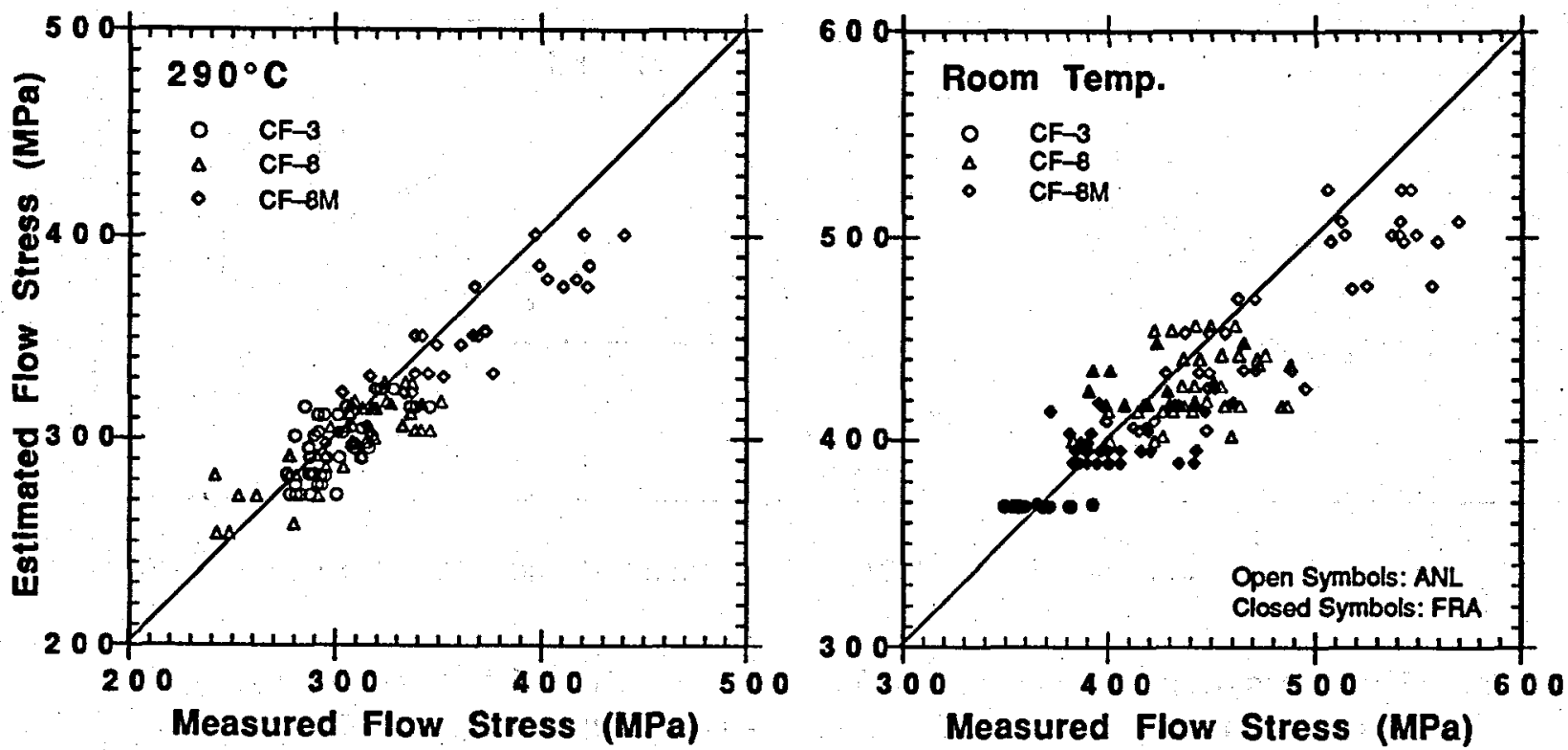

Figure 24. Expertmental and estumated flow stress of aged cast statnless steel at $290^{\circ} \mathrm{C}$ and $R T$ 

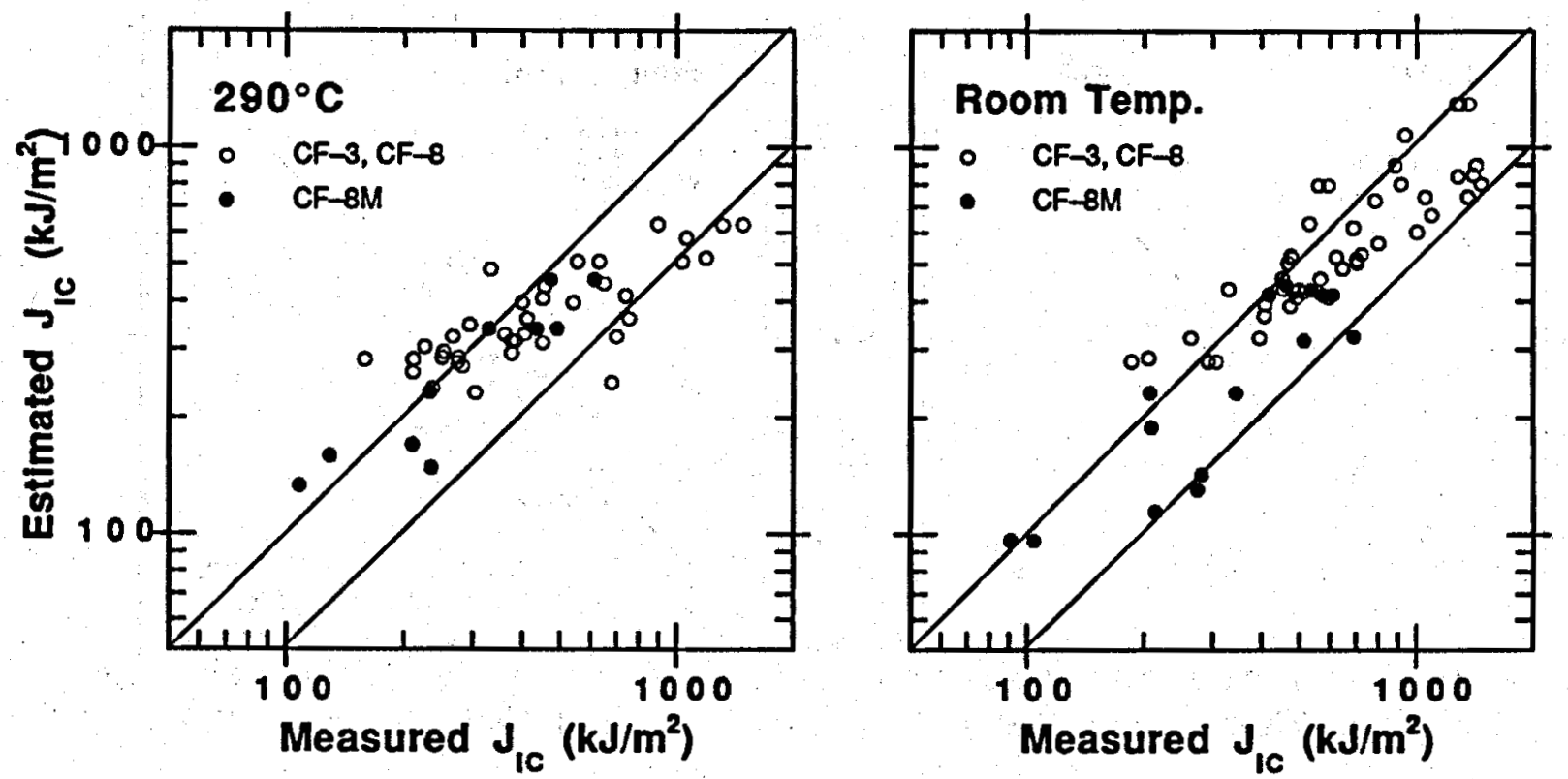

Figure 25. Experimental and esttmated values of $J_{I C}$ for aged cast stainless steels

$$
R_{y}=0.873+0.048 P
$$

for CF-8 steel, by

$$
R_{y}=0.798+0.076 P \quad\left(1.00 \leq R_{y} \leq 1.10\right):
$$

and for CF-8M steel, by

$$
R_{y}=0.708+0.092 P \quad\left(1.00 \leq R_{y} \leq 1.10\right) \text {. }
$$

At $290^{\circ} \mathrm{C}\left(554^{\circ} \mathrm{F}\right)$, the tensile-yield-stress ratio $R_{y}=\left(\sigma_{\text {yaged }} / \sigma_{\text {yunaged }}\right)$, for $C F-3$ steel, is given by

$$
R_{y}=0.844+0.058 P \quad\left(1.00 \leq R_{y} \leq 1.05\right):
$$

for CF-8 steel, by

$$
R_{y}=0.788+0.086 P \quad\left(1.00 \leq R_{y} \leq 1.09\right) ;
$$

and for CF-8M steel, by

$$
\mathrm{R}_{\mathrm{y}}=0.635+0.129 \mathrm{P} \quad\left(1.00 \leq \mathrm{R}_{\mathrm{y}} \leq 1.14\right) .
$$

The minimum and maximum values of the tensile-yield-stress ratio $R_{\mathbf{y}}$ are given for each grade of steel and temperature. Equations 3.4.7-3.4.12 are valid for service temperatures between 280 and $330^{\circ} \mathrm{C}\left(536\right.$ and $\left.626^{\circ} \mathrm{F}\right)$ and ferrite contents $>7 \%$ for $\mathrm{CF}-8 \mathrm{M}$ steel and $>10 \%$ for CF-3 and $\mathrm{CF}-8$ steels.

Experimental and estimated tenstle yield stress at $290^{\circ} \mathrm{C}\left(554^{\circ} \mathrm{F}\right)$ and at $\mathrm{RT}$ for various heats of aged cast stainless steel are shown in Fig. 26. As for flow stress estimations, the aging parameter and activation energy were obtained from Eqs. 3.3.2 and 3.3.5 and a $\theta$ value of 2.9. Tensile yleld stress was then estimated from Eqs. 3.4.7-3.4.12 and the initial yield stress of the materials. The estimated values are conservattve for most material and aging conditions. 

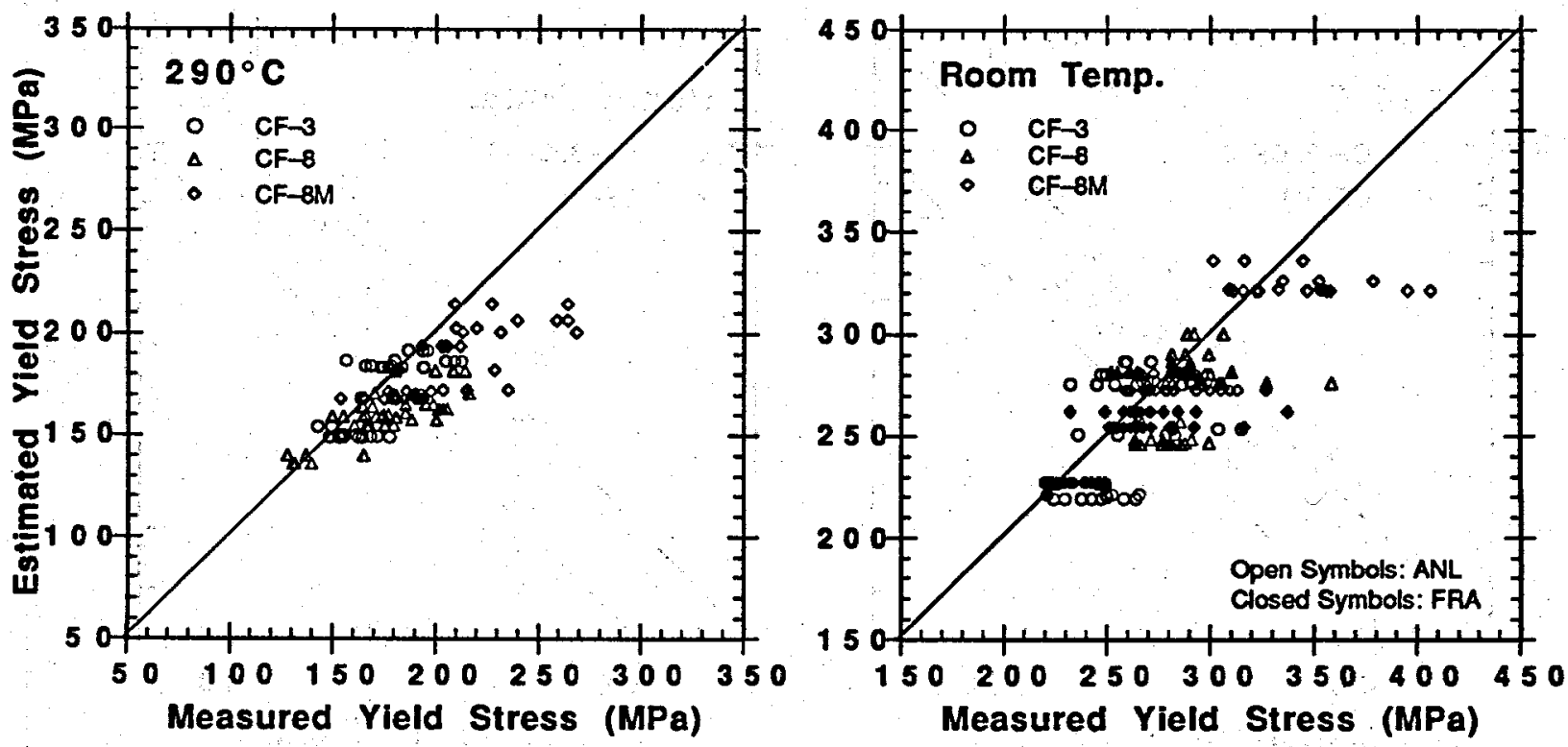

Figure 26. Experimental and estimated yield stress of aged cast stainless steel at $290^{\circ} \mathrm{C}$ and $R T$

\subsubsection{Ramberg-Osgood Parameters}

The engineering stress vs. strain behavior of aged cast stainless steel can also be obtained from the estimated flow stress. ${ }^{23}$ The engineering stress-vs.-strain curve is expressed by the Ramberg-Osgood equation

$$
\frac{\varepsilon}{\varepsilon_{0}}=\frac{\sigma}{\sigma_{0}}+\alpha_{1}\left(\frac{\sigma}{\sigma_{0}}\right)^{\mathrm{n}_{1}}
$$

where $\sigma$ and $\varepsilon$ are engineering stress and strain, respectively; $\sigma_{0}$ is an arbitrary reference stress, often assumed to be equal to flow or yield stress; the reference strain $\varepsilon_{0}=\sigma_{0} / \mathrm{E} ; \alpha_{1}$ and $\mathrm{n}_{1}$ are Ramberg-Osgood parameters; and $\mathrm{E}$ is elastic modulus. The Ramberg-Osgood equation can be rearranged to the form

$$
\frac{E \varepsilon-\sigma}{\sigma_{\mathrm{f}}}=\alpha_{1}\left(\frac{\sigma}{\sigma_{\mathrm{f}}}\right)^{\mathrm{n}_{1}} .
$$

which is more convenient for fitting stress vs. strain data; $\alpha_{1}$ can be determined at $\sigma / \sigma_{\mathrm{f}}=1$ and $n_{1}$ can be obtained from the slope of the $\log -\log$ plot of Eq. 3.4.13b. For all grades of cast stainless steel, the parameter $n_{1}$ does not change with thermal aging. The parameter $\alpha_{1}$ decreases with aging and shows good correlation with the flow stress $\sigma_{f}$ of the material, Fig. 27. For engineering stress-vs.-strain curves up to $5 \%$ strain, the Ramberg-Osgood parameters at room RT, for CF-3 steels, are given by

$$
\alpha_{1}=143.9-0.267 \sigma_{\mathrm{f}} \quad\left(n_{1}=6.1\right)
$$

for CF-8 steel, by

$$
\alpha_{1}=157.9-0.300 \sigma_{f} \quad\left(n_{1}=6.4\right) ;
$$



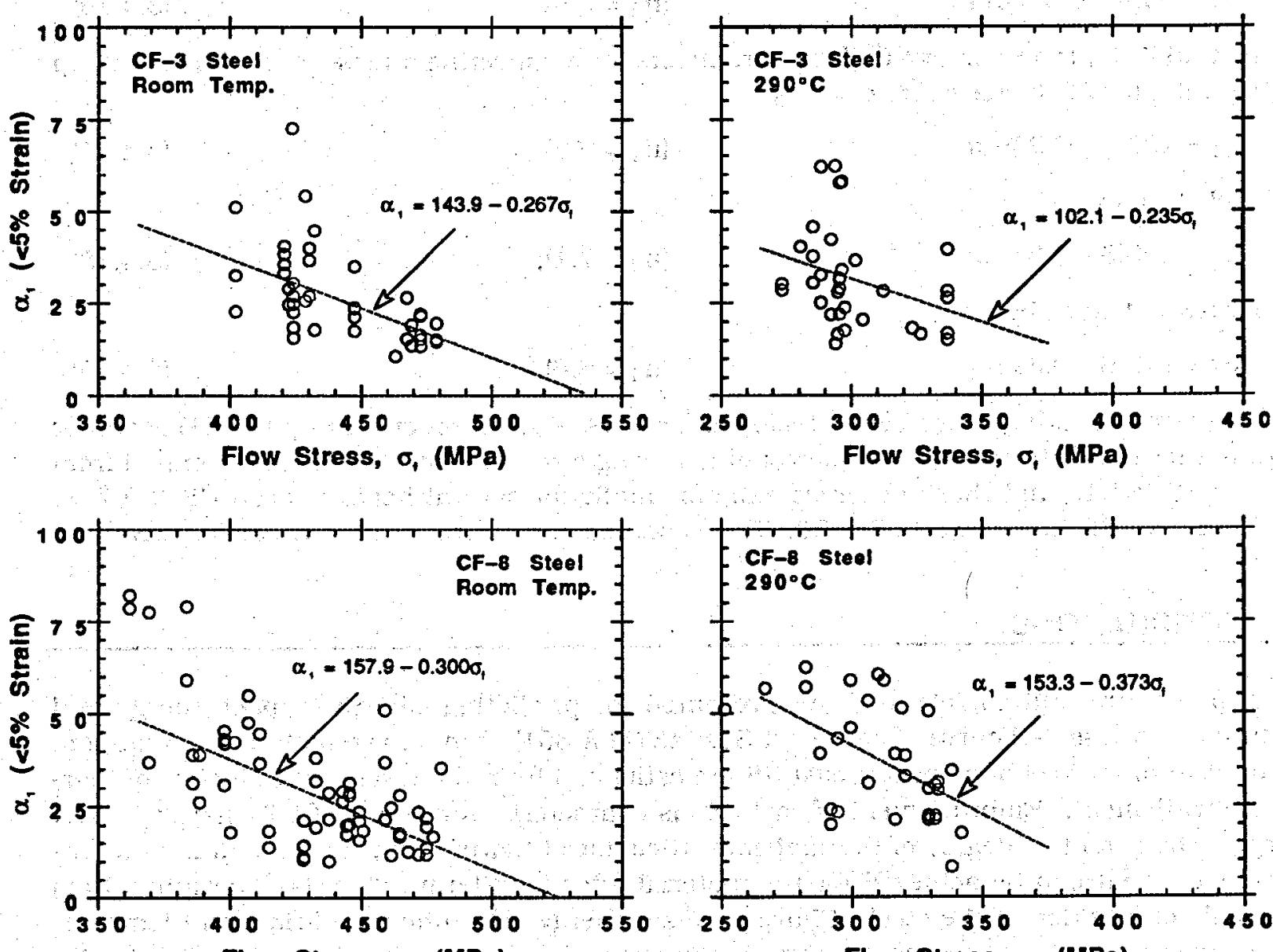

Flow Stress, $\sigma_{1}(\mathrm{MPa})$

Flow Stress, $\sigma,(\mathrm{MPa})$
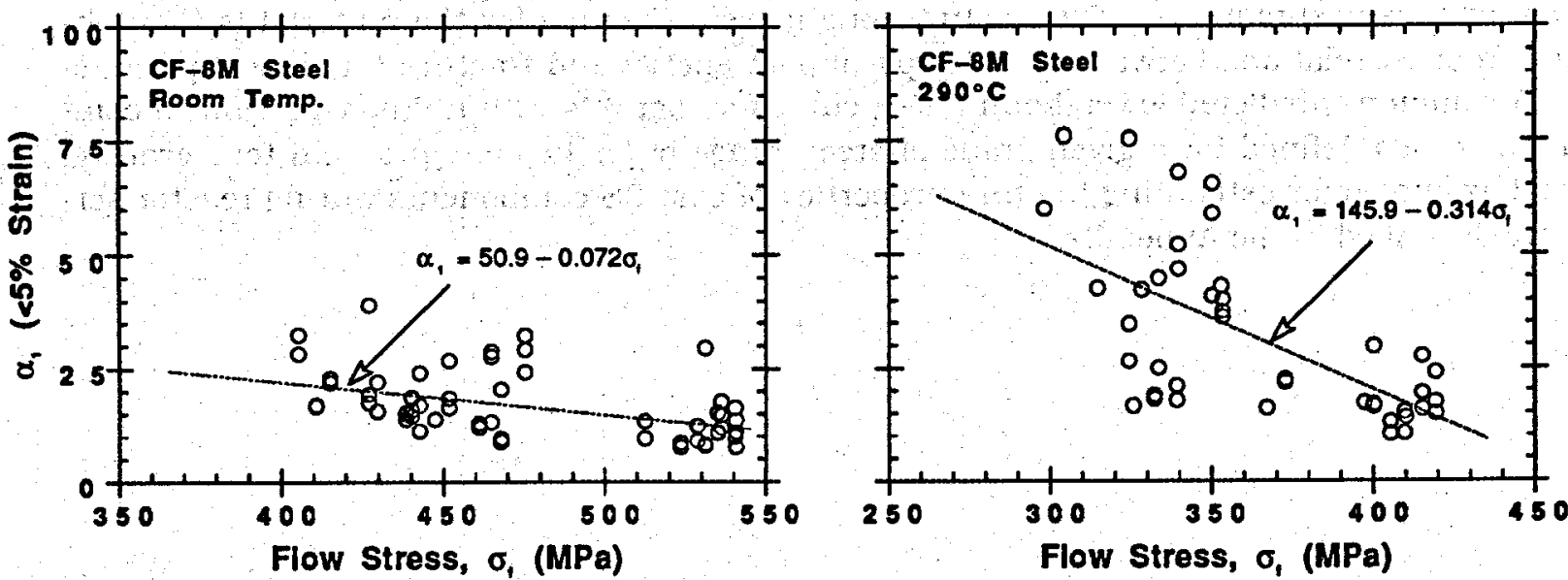

Figure 27. Correlation between the Ramberg/Osgood parameter $\alpha_{1}$ and flow stress at $R T$ and $290^{\circ} \mathrm{C}$ for cast stainless steels 
and for CF-8M steel, by

$$
\alpha_{1}=50.9-0.0724 \sigma_{f} \quad\left(n_{1}=5.6\right) .
$$

At $290^{\circ} \mathrm{C}\left(554^{\circ} \mathrm{F}\right)$, the Ramberg-Osgood parameters for engineering stress-vs.-strain curves up to $5 \%$ strain, for $\mathrm{CF}-3$ steels, are given by

$$
\alpha_{1}=102.1-0.235 \sigma_{f} \quad\left(n_{1}=6.2\right)
$$

for $\mathrm{CF}-8$ steel, by

$$
\alpha_{1}=153.3-0.373 \sigma_{f} \quad\left(n_{1}=7.1\right)
$$

and for CF-8M steel, by

$$
\alpha_{1}=145.9-0.314 \sigma_{\mathrm{f}} \quad\left(n_{1}=6.6\right) .
$$

Similar correlations have also been developed for stress-vs.-strain curves up to $15 \%$ strain or up to the ultimate stress. ${ }^{23}$ Examples of engineering stress-vs.-strain curves estimated from Eqs. 3.4.13-3.4.19 and those observed experimentally for several heats of aged CF-3, CF-8. and CF-8M steels, are shown in Fig. 28. The estimated curves are essentially conservative.

\section{Conclusions}

A procedure and correlations are presented for predicting Charpy-impact energy and fracture toughness J-R curve of aged cast SSs (ASTM A 351) from known material information. Mechanical properties of a specific cast SS are estimated from the extent and kinetics of thermal embrittlement. Embrittlement of cast SSs is characterized in terms of RT Charpy-impact energy. The extent or degree of thermal embrittlement at "saturation," 1.e., the minimum impact energy that can be achleved for the material after long-term aging, is determined from chemical composition of the steel. Charpy-impact energy as a function of time and temperature of reactor service is estimated from the kinetics of thermal embrittlement, which is also determined from the chemical composition. The initial impact energy of the unaged steel is required for these estimations. The fracture toughness $\mathrm{J}-\mathrm{R}$ curve for the material is then obtained from correlations between RT Charpy-impact energy and fracture toughness parameters. A common "predicted lower-bound" J-R curve for cast SSs with unknown chemical composition is also defined for a given grade of steel, range of ferrite contents, and temperature. Typical examples for estimating fracture properties of cast SS components during reactor service are described in the Appendix. 

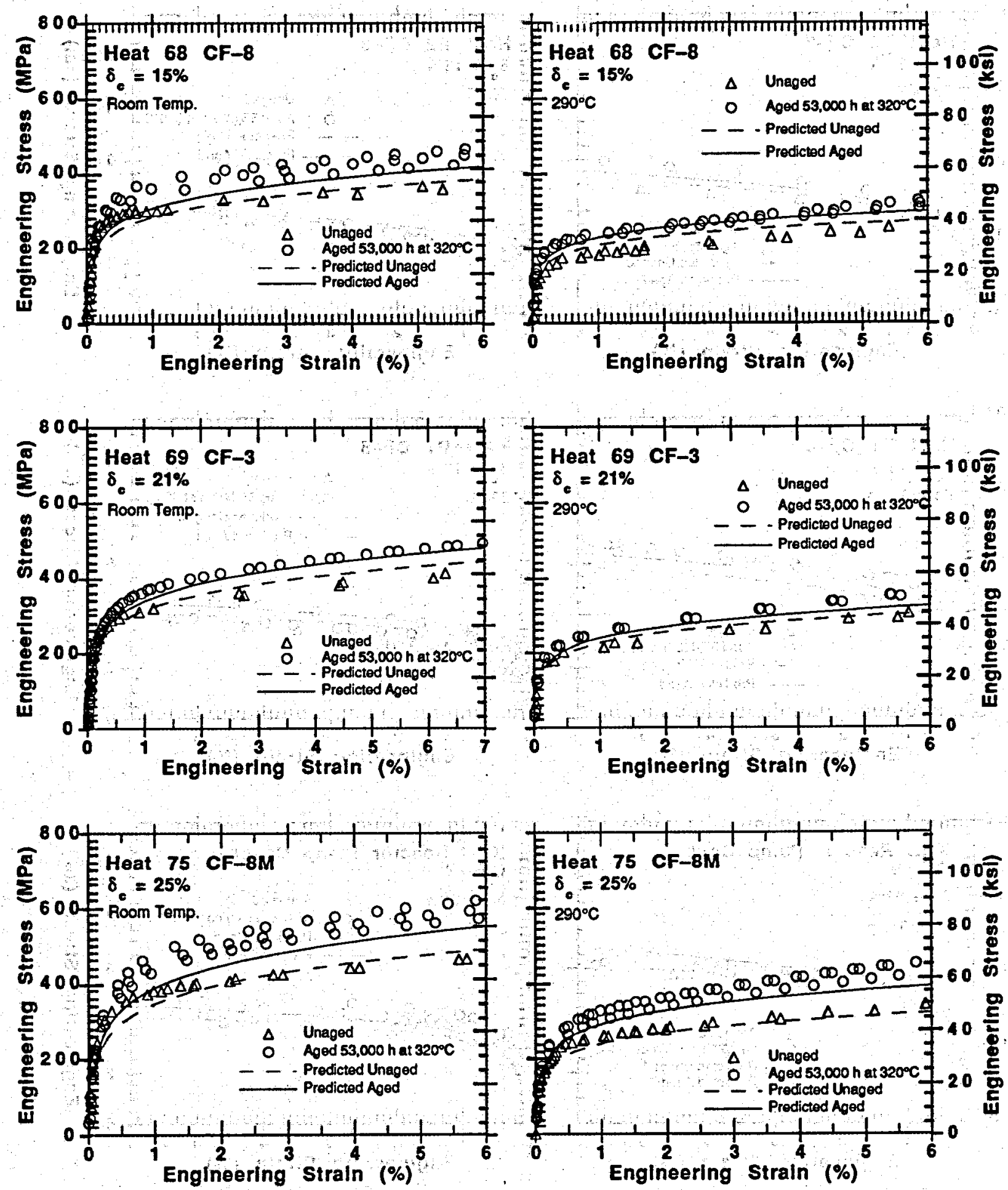

Figure 28. Engtneering stress-us.-strain curve at $R T$ and $290^{\circ} \mathrm{C}$, estimated from the chemical composition and initial tensile strength and determined experimentally for thermally aged $C F-3, C F-8$, and $C F-8 M$ steels 

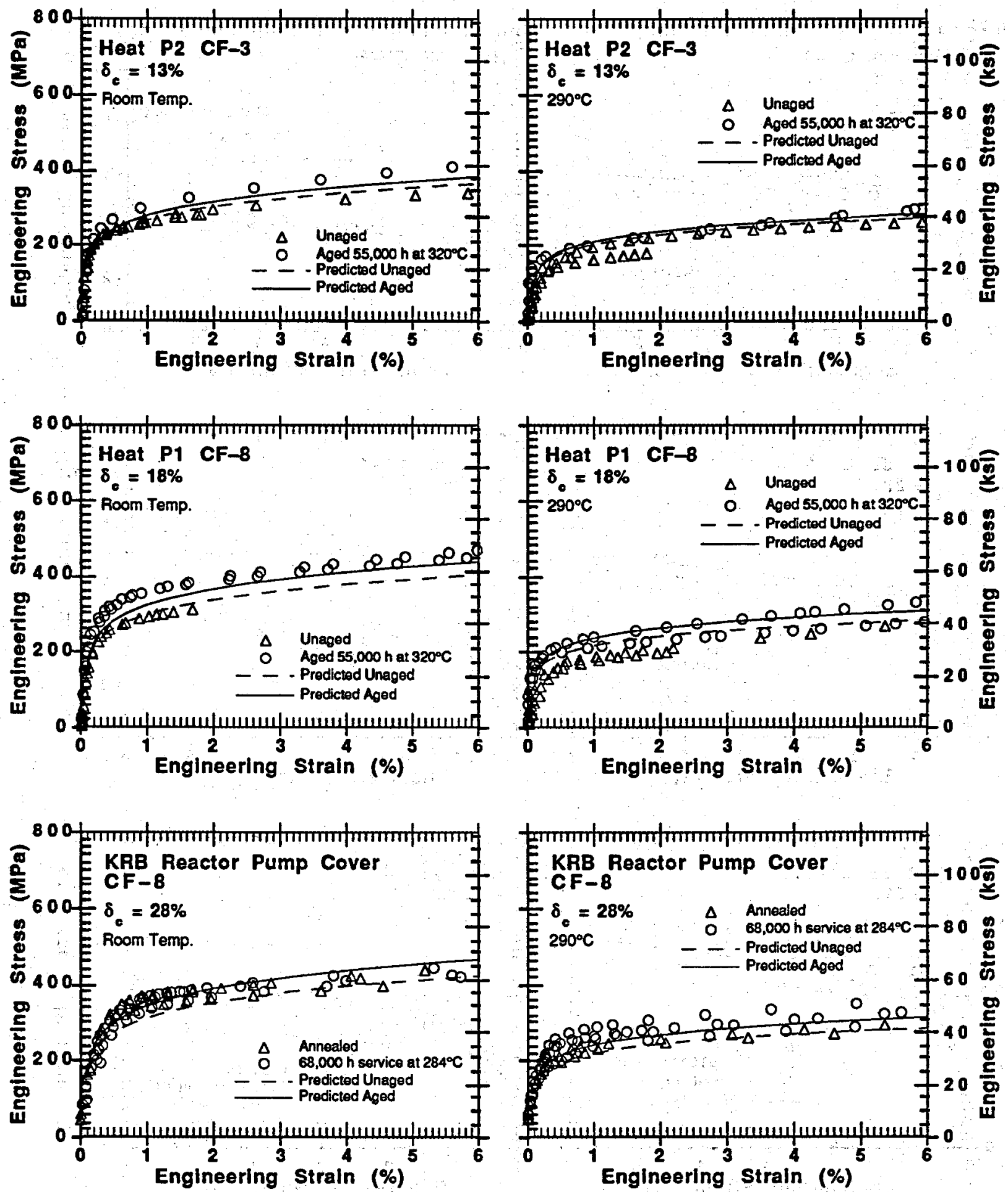

Flgure 28. (Contd.) 


\section{References}

1. O. K. Chopra and H. M. Chung, "Aging Degradation of Cast Stainless Steels: Effects on Mechanical Properties," in Environmental Degradation of Materials in Nuclear Power Systems-Water Reactors, G. J. Theus and J. R. Weeks, eds., The Metallurgical Society. Warrendale, PA, pp. 737-748 (1988).

2. O. K. Chopra and H. M. Chung. "Effect of Low-Temperature Aging on the Mechanical Properties of Cast Stainless Steels," in Propertles of Stainless Steels in ElevatedTemperature Service, M. Prager, ed., MPC Vol. 26, PVP Vol. 132, ASME, New York, pp. 79-105 (1988).

3. O. K. Chopra, "Thermal Aging of Cast Stainless Steels: Mechanisms and Predictions," in Fattgue, Degradation, and Fracture - 1990, W. H. Bamford, C. Becht, S. Bhandari, J. D. Gilman, L. A. James, and M. Prager, eds., MPC Vol. 30, PVP Vol. 195, ASME, New York. pp. 193-214 (1990).

4. O. K. Chopra and A. Sather, Inttial Assessment of the Mechanisms and Significance of LowTemperature Embrittlement of Cast Stainless Steels in LWR Systems, NUREG/CR-5385. ANL-89/17 (Aug. 1990).

5. O. K. Chopra, A. Sather, and L. Y. Bush, Long-Term Embrittlement of Cast Duplex Stainless Steels in LWR Systems: Semiannual Report. April-September 1989, NUREG/CR-4744, Vol. 4. No. 2, ANL-90/49 (June 1991).

6. O. K. Chopra, Long-Term Embrittlement of Cast Duplex Stainless Steels in LWR Systems: Semiannual Report, October 1990-March 1991, NUREG/CR-4744, Vol. 6, No. 1. ANL-91/22 (Aug. 1992).

7. O. K. Chopra, Long-Term Embrittlement of Cast Duplex Stainless Steels in LWR Systems: Semiannual Report October 1991-March 1992, NUREG/CR-4744, Vol. 7, No. 1. ANL-92/.42 (April 1993).

8. O. K. Chopra, "Evaluation of Aging Degradation of Structural Components," in Proceedings of the Aging Research Information Conference, NUREG/CP-0122, Vol. 2 , pp. 369-386 (1992).

9. O. K. Chopra, Estimation of Fracture Toughness of Cast Statnless Steels during Thermal Aging in LWR Systems, NUREG/CR-4513, ANL-90/42 (June 1991).

10. O. K. Chopra, "Thermal Aging of Cast Stainless Steels in LWR Systems: Estimation of .Mechanical Properties," in Nuclear Plant Systems/Components Aging Management and Life Extension. 1. T. KJsisel, J. Sinnappan, R. W. Carlson, and W. H. Lake, eds., PVP Vol. 228, ASME, New York, pp. 79-92 (1992).

11. O. K. Chopra, "Prediction of Aging Degradation of Cast Stainless Steel Components in LWR Systems," in Proceedings of the Aging Research Information Conference, NUREG/CP-0122, Vol. 2, pp. 324-340 (1992). 
12. H. M. Chung and O. K. Chopra. "Kinetics and Mechanism of Thermal Aging Embrittlement of Duplex Stainless Steels," in Environmental Degradation of Materlals in Nuclear Power Systems-Water Reactors, G. J. Theus and J. R. Weeks, eds., The Metallurgical Society, Warrendale, PA. pp. 359-370 (1988).

13. H. M. Chung and O. K. Chopra, "Long-Term Aging Embrittlement of Cast Austenitic Stainless Steels - Mechanism and Kinetics," in Properties of Statnless Steels in ElevatedTemperature Service, M. Prager, ed., MPC Vol. 26, PVP Vol. 132, ASME, New York, pp. 17-34 (1988).

14. H. M. Chung and T. R. Leax, "Embrittlement of Laboratory- and Reactor-Aged CF3, CF8, and CF8M Duplex Stainless Steels," Mater. ScL. Technol., 6, 249-262 (1990).

15. A. Trautweln and W. Gysel, "Influence of Long Time Aging of CF-8 and CF-8M Cast Steel at Temperatures Between 300 and $500^{\circ} \mathrm{C}$ on the Impact Toughness and the Structure Properties," in Spectrum, Technische Mittellungen aus dem+GF+Konzern. No. 5 (May 1981): also in Stainless Steel Castings, V. G. Behal and A. S. Melill, eds., STP 756, ASTM, Philadelphia, PA, pp. 165-189 (1982).

16. E. I. Landerman and W. H. Bamford, "Fracture Toughness and Fatigue Characteristics of Centrifugally Cast Type 316 Stainless Steel Pipe after Simulated Thermal Service Conditions," in Ductility and Toughness Considerations in Elevated-Temperature Service, MPC 8, ASME, New York, pp. 99-127 (1978).

17. S. Bonnet, J. Bourgoin. J. Champredonde, D. Guttmann, and M. Guttíann, "Relationship between Evolution of Mechanical Properties of Various Cast Duplex Stainless Steels and Metallurgical and Aging Parameters: An Outline of Current EDF Programmes," Mater. Sct. Technol, 6, 221-229 (1990).

18. P. H. Pumphrey and K. N. Akhurst. "Aging Kinetics of CF3 Cast Stainless Steel in Temperature Range $300-400^{\circ} \mathrm{C}, "$ Mater. Sct. Technol, 6, 211-219 (1990).

19. G. Slama, P. Petrequin, and T. Mager, "Effect of Aging on Mechanical Properties of Austenitic Stainless Steel Castings and Welds," presented at SMIRT Post-Conference Seminar 6, Assuring Structural Integrity of Steel Reactor Pressure Boundary Components, Aug. 29-30, 1983, Monterey, CA.

20. Y. Meyzaud, P. Ould, P. Balladon, M. Bethmont, and P. Soulat, "Tearing Resistance of Aged Cast Austenitic Stainless Steel," Int. Conf. on Thermal Reactor Safety (NUCSAFE 88), Oct. 1988, Avignon, France.

21. P. McConnell and J. W. Sheckherd, Fracture Toughness Characterization of Thermally Embrittled Cast Duplex Stainless Steel, Report NP-5439, Electric Power Research Institute, Palo Alto, CA (September 1987).

22. G. E. Hale and S. J. Garwood, "The Effect of Aging on the Fracture Behaviour of Cast Stainless Steel and Weldments," Mater. Sct. Technol., 6, 230-235 (1990). 
23. W. F. Michaud, P. T. Toben, W. K. Soppet, and O. K. Chopra, Tenstle-Property Characterization of Thermally Aged Cast Statnless Steels, NUREG/CR-6142, ANL-93/35 (February 1994).

24. P. Auger, F. Danolx, A. Menand, S. Bonnet, J. Bourgoin, and M. Guttmann, "Atom Probe and Transmission Electron Microscopy Study of Aging of Cast Duplex Stainless Steels," Mater. ScL. Technol., 6, 301-313 (1990).

25. M. Vrinat, P. Cozar, and Y. Meyzaud, "Precipitated Phases in the Ferrite of Aged Cast Duplex Stainless Steels," Scrtpta Metall., 20, 1101-1 106 (1986).

26. P. Joly, R. Cozar, and A. Pineau, "Effect of Crystallographic Orientation of Austenite on the Formation of Cleavage Cracks in Ferrite in an Aged Duplex Stalnless Steel," Scripta Metall. 24, 2235-2240 (1990).

27. J. M. Sassen, M. G. Hetherington, T. J. Godfrey, and G. D. W. Smith. "Kinetics of Spinodal Reaction in the Ferrite Phase of a Duplex Stainless Steel," in Properties of Stainless Steels in Elevated Temperature Servtce, M. Prager, ed., MPC Vol. 26, PVP Vol. 132, ASME. New York, pp. 65-78 (1988).

28. J. E. Brown, A. Cerezo, T. J. Godfrey, M. G. Hetherington, and G. D. W. Smith, "Quantitative Atom Probe Analysis of Spinodal Reaction in Ferrite Phase of Duplex Stainless Steel," Mater. Sci. Technol, 6, 293-300 (1990).

29. M. K. Miller, and J. Bentley, "Characterization of Fine-Scale Microstructures in Aged Primary Coolant Pipe Steels," in Environmental Degradation of Materials in Nuclear Power Systems-Water Reactors, G. J. Theus and J. R. Weeks, eds., The Metallurgical Society, Warrendale, PA, pp. 341-349 (1988).

30. O. K. Chopra and L. Y. Bush, Long-Term Embrittlement of Cast Duplex Statnless Steels in LWR Systems: Semiannual Report October 1989-March 1990. NUREG/CR-4744, Vol. 5 , No. 1, ANL-91/7 (July 1991).

31. A. W. Bowen and G. M. Leak, "Diffusion in BCC Iron Base Alloys," Metall. Trans., 1, 2767 (1970).

32. L. S. Aubrey, P. F. Wieser, W. J. Pollard, and E. A. Schoefer, "Ferrite Measurement and Control in Cast Duplex Stainless Steel," in Statnless Steel Castings, V. G. Behal and A. S. Melilli, eds., STP 756, ASTM, Philadelphia, PA, pp. 126-164 (1982).

33. Standard Practice for Steel Casting. Austenttic Alloy. Estimating Ferrite Content Thereof. ASTM Designation A 800/A 800M-84, American Society for Testing and Materials, Philadelphia. PA (1984).

34. A. L. Hiser, Fracture Toughness Characterization of Nuclear Piping Steels, NUREG/CR5118, MEA-2325, Materials Engineering Associates, Inc. (Nov. 1989).

35. G. M. Wilkowski, et al., Degraded Piping Program - Phase II, Semiannual Report, NUREG/CR-4082, Vol. 2 (June 1985). 
36. W. J. Mills, "Heat-to-Heat Variations in the Fracture Toughness of Austenitic Stainless Steels," Eng. Fracture Mech, 30, 469-492 (1988).

37. M. G. Vassilaros, R. A. Hays, and J. P. Gudas, "Investigation of the Ductile Fracture Properties of Type 304 Stainless Steel Plate, Welds, and 4-Inch Pipe," in Proc. 12th Water Reactor Safety Information Meeting, U.S. Nuclear Regulatory Commission, NUREG/CP0058, Vol. 4, p. 176 (Jan. 1985).

38. P. Balladon, J. Heritier, and P. Rabbe. "Influence of Microstructure on the Ductile Rupture Mechanisms of a 316L Steel at Room and Elevated Temperatures, " in Fracture Mechanics: Fourteenth Symposium. STP 791, ASTM, Philadelphia, PA., pp. II496-II513 (1983).

39. W. H. Bamford and A. J. Bush, "Fracture Behavior of Stainless Steel," Elastic-Plastic Fracture, STP 668, ASTM, Philadelphia, PA, pp. 553-577 (1979). 


\section{Appendix}

\section{Estimation of Fracture Properties of Cast SSs}

The correlations described in this report can be used for assessing thermal embrittlement of cast SS components. The procedure involves a few simple steps. First, available information about the material and service condition is obtained from the CMTR; 1.e., If known, determine the chemical composition, grade of steel, casting method, Charpy-impact properties, and time and temperature of service. Then, on the basis of avallable information, various schemes are used to estimate the fracture toughness $J-R$ curve and Charpy-impact energy of the aged material. Typical examples for estimating fracture properties of cast SS components during reactor service are presented.

Example 1. A centrifugally cast $\mathrm{CF}-8$ ptpe, $0.51 \mathrm{~m}$ nominal diameter, in service at $302^{\circ} \mathrm{C}$ $\left(575^{\circ} \mathrm{F}\right)$ for 18 effective full power years (efpys). The following material information is also known.

\section{Measured Ferrite Content (\%): 14.2}

Only the lower-bound fracture toughness J-R curve can be estimated for this steel, because only the grade and ferrite content are known" and the chemical composition of the material is not known. The estimation scheme for this example involves one step and is shown in Fig. A-1. The lower-bound fracture toughness represents the minimum toughness that can be achieved after long-term aging by centrifugally cast CF-8 steels containing $10-15 \%$ ferrite.

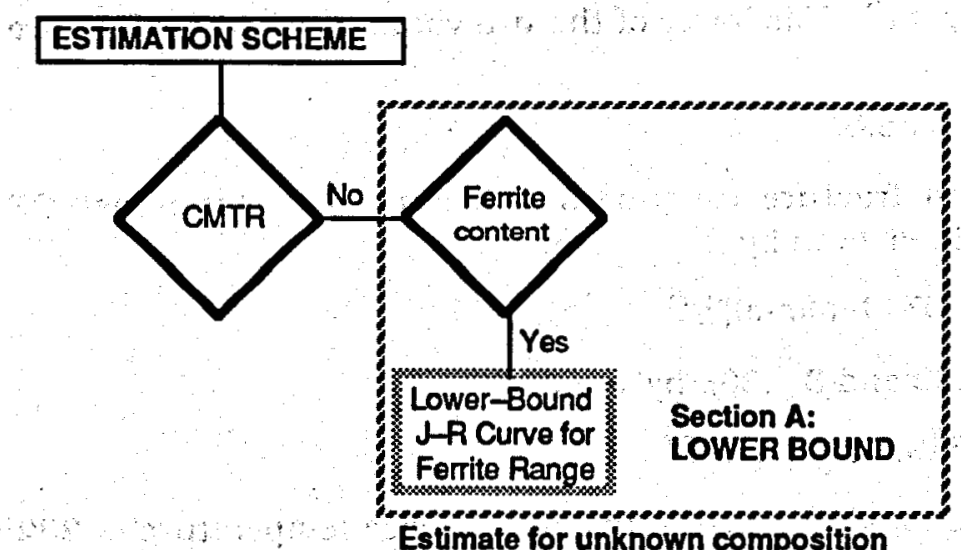

Figure A-1. Estimation scherne for Example 1

Step 1. From Eqs. 3.1.20 and 3.1.23 the predicted lower-bound fracture toughness J-R curve for centrifugally cast CF- 8 steel with $10-15 \%$ ferrite, at RT, is given by

$$
\mathrm{J}_{\mathrm{d}}\left(\mathrm{kJ} / \mathrm{m}^{2}\right)=357\left[\left.\Delta \mathrm{a}(\mathrm{mm})\right|^{0.38}\right.
$$

\footnotetext{
CF-8M steel and $>15 \%$ ferrite are assumed if the grade and ferrite content of the steel are not known.
} 
and at $290^{\circ} \mathrm{C}\left(554^{\circ} \mathrm{F}\right)$ by

$$
\mathrm{J}_{\mathrm{d}}\left(\mathrm{kJ} / \mathrm{m}^{2}\right)=360[\Delta \mathrm{a}(\mathrm{mm})]^{0.35} \text {. }
$$

The J-R curve at a service temperature of $302^{\circ} \mathrm{C}$ can be linearly extrapolated from Eqs. A-1.1 and $\mathrm{A}-1.2$. The curve at $302^{\circ} \mathrm{C}$ is not significantly different from that at $290^{\circ} \mathrm{C}$ and can be approximated as

$$
J_{d}\left(\mathrm{~kJ} / \mathrm{m}^{2}\right)=360[\Delta \mathrm{a}(\mathrm{mm})]^{0.35}
$$

Example 2. A static-cast CF-8 check value in service at $282^{\circ} \mathrm{C}\left(540^{\circ} \mathrm{F}\right)$. The following matertal information is also known.

Chem. Comp. (wt.\%): Cr, 20.26; Mo, 0.01; SL, 1.45; NL, 8.84; Mn. 1.10; C, 0.056; N. 0.041 Measured Ferrtte Content (\%): 10.4

RT Charpy-Impact Energy ( $): 150.4$

Only the saturation fracture properties can be estimated in this case, because the time of service is not known. The estimation scheme for this example is shown in Fig. A-2. The saturation fracture toughness represents the minimum toughness that can be achieved by this specific cast stainless steel after long-term aging.

Step 1. The calculated ferrite content (Eqs. 3.2.1-3.2.3) is

$$
\delta_{c}(\%)=10.8 \text {. }
$$

Step 2. The material parameter $\Phi$ (Eq. 3.2.5) 1s 16.94. Saturation RT Charpy-impact energy in terms of the material parameter (Eq. 3.2.4) is $79.8 \mathrm{~J} / \mathrm{cm}^{2}$, and in terms of composition (Eq. 3.2.6), it is $58.8 \mathrm{~J} / \mathrm{cm}^{2}$. The lower of the two values is used for fracture toughness estimations; thus

$$
\text { CVsat }\left(\mathrm{J} / \mathrm{cm}^{2}\right)=58.8 \text {. }
$$

Step 3. The saturation fracture toughness J-R curve for static-cast CF-8 steel, at RT (Eqs. 3.2.13 and 3.2.16), is given by

$$
J_{d}\left(\mathrm{~kJ} / \mathrm{m}^{2}\right)=407.8[\Delta \mathrm{a}(\mathrm{mm})]^{0.41}
$$

and at $290^{\circ} \mathrm{C}$ (Eqs. 3.2.20 and 3.2.23), by

$$
\mathrm{J}_{\mathrm{d}}\left(\mathrm{kJ} / \mathrm{m}^{2}\right)=319.2[\Delta \mathrm{a}(\mathrm{mm})]^{0.37} \text {. }
$$

The saturation fracture toughness $\mathrm{J}-\mathrm{R}$ curve at a service temperature of $282^{\circ} \mathrm{C}$ is linearly interpolated from Eqs. A-2.1 and A-2.2. The curve at $282^{\circ} \mathrm{C}$ is not significantly different from that at $290^{\circ} \mathrm{C}$ and can be approxdmated as

$$
\mathrm{Jd}_{\mathrm{d}}\left(\mathrm{kJ} / \mathrm{m}^{2}\right)=319.2[\Delta \mathrm{a}(\mathrm{mm})]^{0.37} \text {. }
$$

This corresponds to a $\mathrm{J}_{d}$ value of $579 \mathrm{~kJ} / \mathrm{m}^{2}\left(3306 \mathrm{in} .1 \mathrm{~b} / \mathrm{mn} .{ }^{2}\right)$ at 5 - $\mathrm{mm}$ crack extension. 


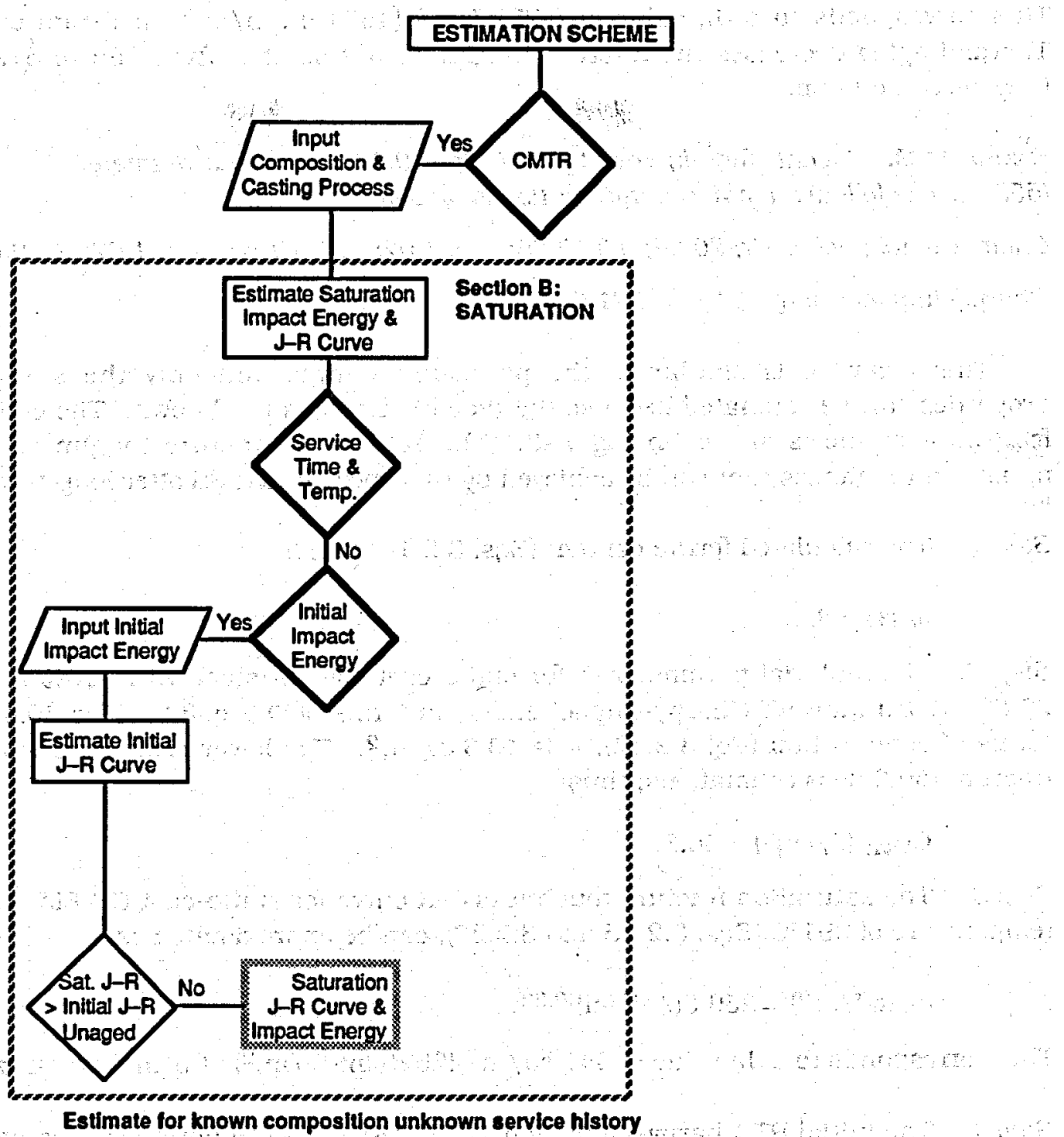

Fgure A-2. Estimation scheme for Example 2

Step 4. The initial RT Charpy-impact energy* is $150.4 \mathrm{~J}$. The normalized value is obtained by dividing this value by the cross-sectional area of the Charpy-impact specimen, $1 . e ., 0.8 \mathrm{~cm}^{2}$.

$$
\text { CVint }\left(\mathrm{J} / \mathrm{cm}^{2}\right)=188.0 \text {. }
$$

Step 5. The initial J-R curve for the unaged material is the higher of either Eq. 3.2.27 or the $\mathrm{J}-\mathrm{R}$ curve determined from Eqs. 3.2.13, 3.2.16, 3.2.20, and 3.2.23 using CVint instead of CVsat. In this example, the initial $\mathrm{J}-\mathrm{R}$ curve, at $282^{\circ} \mathrm{C}$, is obtained from Eqs. 3.2 .20 and 3.2 .23 as

$$
\mathrm{J}_{\mathrm{d}}\left(\mathrm{kJ} / \mathrm{m}^{2}\right)=441.9[\Delta \mathrm{a}(\mathrm{mm})]^{0.41} \text {. }
$$

This corresponds to a $\mathrm{J}_{\mathrm{d}}$ value of $855 \mathrm{~kJ} / \mathrm{m}^{2}\left(4881 \mathrm{in} .1 \mathrm{~b} / \mathrm{ln} .{ }^{2}\right)$ at $5-\mathrm{mm}$ crack extension. Thermal aging decreases the fracture toughness of this steel from 855 to $579 \mathrm{~kJ} / \mathrm{m}^{2}$ in the fully aged condition.

\footnotetext{
* In this report, all values of Impact energy are considered to be for a standard Charpy-V-notch specimen (ASTM Specification E 23), 1.e., $10 \times 10-\mathrm{mm}$ cross section and 2-mm $\mathrm{V}$ notch.
} 
This corresponds to a $\mathrm{J}_{\mathrm{d}}$ value of $855 \mathrm{~kJ} / \mathrm{m}^{2}\left(4881 \mathrm{ln} . \cdot \mathrm{lb} / \mathrm{in} .{ }^{2}\right)$ at $5-\mathrm{mm}$ crack extension. Thermal aging decreases the fracture toughness of this steel from 855 to $579 \mathrm{~kJ} / \mathrm{m}^{2}$ in the fully aged condition.

Example 3. A centrifugally cast $C F-8 M$ pipe, $0.51 \mathrm{~m}$ nominal diameter, in service at $291^{\circ} \mathrm{C}$ $\left(555^{\circ} \mathrm{F}\right)$. The following material information is also known.

Chem. Comp. (wt.\%): Cr, 20.64; Mo, 2.05; St, 1.02; Nh, 10.00; Mn. 1.07; C, 0.040; N, 0.151 Charpy-Impact Energy (J): $\quad 181.6$

This example is simllar to the previous example and only the saturation fracture properties can be estimated because the time of service is not known. The estimation scheme for this example is shown in Fig. A-3. The saturation fracture toughness represents the minimum toughness that can be achieved by this specific cast SS after long-term aging.

Step 1. The calculated ferrite content (Eqs. 3.2.1-3.2.3) is

$$
\delta_{\mathrm{c}}(\%)=8.8 \text {. }
$$

Step 2. The material parameter $\Phi$ for static-cast $C F-8 M$ steel with $>10 \%$ Ni (Eq. 3.2 .11 ) is 25.80. Saturation RT Charpy-impact energy in terms of $\Phi$ (Eq. 3.2.10) is $40.4 \mathrm{~J} / \mathrm{cm}^{2}$, and in terms of composition (Eq. 3.2.12), it is $40.3 \mathrm{~J} / \mathrm{cm}^{2}$. The lower of the two values is used for fracture toughness estimations; thus

$$
C_{V s a t}\left(J / \mathrm{cm}^{2}\right)=40.3 \text {. }
$$

Step 3. The saturation fracture toughness J-R curve for static-cast CF-8M steel, at a service temperature of $291^{\circ} \mathrm{C}$ (Eqs. 3.2.25 and 3.2.26), can be approximated as

$$
\mathrm{J}_{\mathrm{d}}\left(\mathrm{kJ} / \mathrm{m}^{2}\right)=259.5[\Delta \mathrm{a}(\mathrm{mm})]^{0.33} \text {. }
$$

This corresponds to a $\mathrm{Jd}_{\mathrm{d}}$ value of $441 \mathrm{~kJ} / \mathrm{m}^{2}\left(2520 \mathrm{in} .1 \mathrm{lb} / \mathrm{in} .^{2}\right)$ at 5 -mm crack extension.

Step 4. The initial RT Charpy-impact energy is $181.6 \mathrm{~J}$. The normalized value is obtained by dividing this value by $0.8 \mathrm{~cm}^{2}$, the cross-sectional area of the Charpy-impact specimen.

$$
\text { CVint }\left(\mathrm{J} / \mathrm{cm}^{2}\right)=227.0
$$

Step 5. The initial J-R curve for the unaged material is the higher of either Eq. 3.2.28 or the

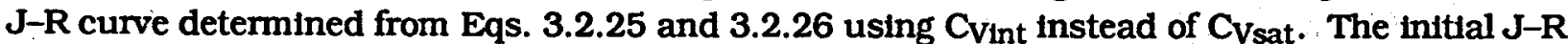
curve, at $291^{\circ} \mathrm{C}$ is essentially the same as that at $290^{\circ} \mathrm{C}$

$$
\mathrm{J}_{\mathrm{d}}\left(\mathrm{kJ} / \mathrm{m}^{2}\right)=527.0[\Delta \mathrm{a}(\mathrm{mm})]^{0.37}
$$

This corresponds to a $\mathrm{J}_{\mathrm{d}}$ value of $956 \mathrm{~kJ} / \mathrm{m}^{2}\left(5459 \mathrm{in} . \mathrm{lb} / \mathrm{ln} .{ }^{2}\right)$ at $5-\mathrm{mm}$ crack extension. Thermal aging decreases the fracture toughness of this steel from 956 to $441 \mathrm{~kJ} / \mathrm{m}^{2}$ in the fully aged condition. 


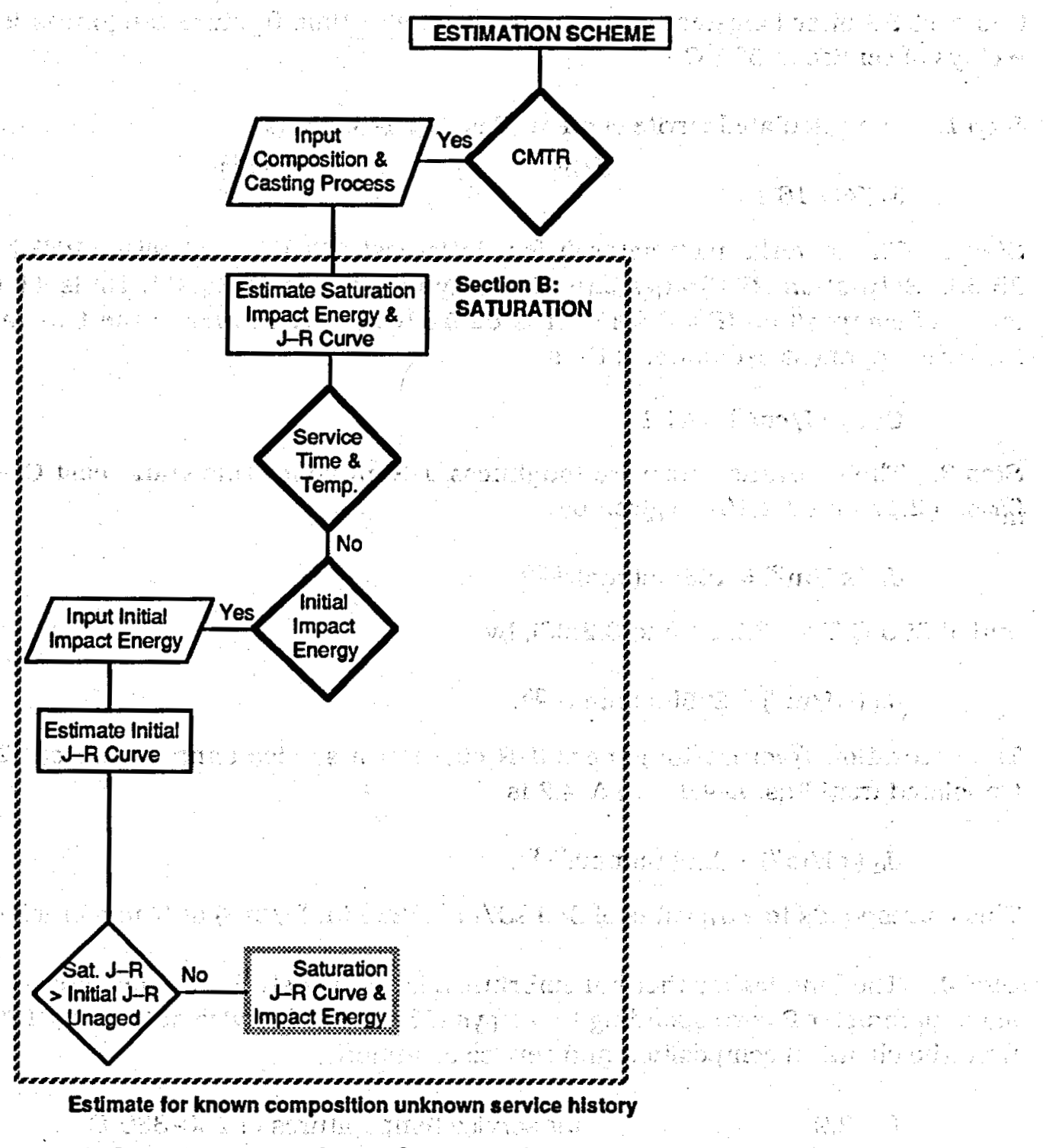

Figure A-3. Estimation scheme for Example 3

Example 4. A static-cast CF-8M elbow, $0.66 \mathrm{~m}$ nominal size, in service at $325^{\circ} \mathrm{C}\left(617^{\circ} \mathrm{F}\right)$ for 9 efpys. The following material information is also known.

Chem Comp. (wt.\%): $\mathrm{Cr}, 20.21 ; \mathrm{Mo}, 2.09 ; \mathrm{St}, 1.03 ; \mathrm{NL}, 10.24 ; \mathrm{Mn}, 0.77 ; \mathrm{C}, 0.037 ; \mathrm{N}, 0.044$ Charpy-Impact Energy (J): $\quad 209.6$
$0.2 \%$ Yield Stress (MPa):
RT
272
$325^{\circ} \mathrm{C}$
Ultimate Stress (MPa):
526
167
387

Service time, as well as saturation fracture properties, can be estimated in this case, because both chemical composition and service conditions for the material are known. The change in tensile properties can also be estimated, because the initial tensile strengths at $\mathrm{RT}$ and at $325^{\circ} \mathrm{C}$ are also available. The estimation scheme for this example is shown in Fig. A-4. The saturation fracture toughness represents the minimum toughness that can be achieved by 
this cast SS after long-term aging and the service time fracture toughness is the value after 9 efpys of service at $325^{\circ} \mathrm{C}$.

Step 1. The calculated ferrite content (Eqs. 3.2.1-3.2.3) is

$$
\delta_{c}(\%)=16.1 \text {. }
$$

Step 2. The material parameter $\Phi$ for static-cast $\mathrm{CF}-8 \mathrm{M}$ steel with $>10 \% \mathrm{Ni}$ (Eq. 3.2.11) is 25.56. Saturation RT Charpy-impact energy in terms of $\Phi$ (Eq. 3.2.10) is $41.1 \mathrm{~J} / \mathrm{cm}^{2}$, and in terms of composition (Eq. 3.2.12), it is $62.9 \mathrm{~J} / \mathrm{cm}^{2}$. The lower of the two values is used for fracture toughness estimations; thus

$$
\text { CVsat }\left(\mathrm{J} / \mathrm{cm}^{2}\right)=41.1 \text {. }
$$

Step 3. The saturation fracture toughness J-R curve for this static-cast CF-8M steel, at RT (Eqs. 3.2.17 and 3.2.19), is given by

$$
\mathrm{J}_{\mathrm{d}}\left(\mathrm{kJ} / \mathrm{m}^{2}\right)=193[\Delta \mathrm{a}(\mathrm{mm})]^{0.36}
$$

and at $290^{\circ} \mathrm{C}$ (Eqs. 3.2.24 and 3.2.26), by

$$
J_{d}\left(k J / m^{2}\right)=225[\Delta a(m m)]^{0.33} \text {. }
$$

The saturation-fracture-toughness $J-R$ curve at a service temperature of $325^{\circ} \mathrm{C}$ linearly extrapolated from Eqs. $A-4.1$ and $A-4.2$ is

$$
\mathrm{J}_{\mathrm{d}}\left(\mathrm{kJ} / \mathrm{m}^{2}\right)=229[\Delta \mathrm{a}(\mathrm{mm})]^{0.33} \text {. }
$$

This corresponds to a $J_{d}$ value of $389 \mathrm{~kJ} / \mathrm{m}^{2}\left(2224 \mathrm{ln} . \cdot \mathrm{lb} / \mathrm{mn} .{ }^{2}\right)$ at $5-\mathrm{mm}$ crack extension.

Step 4. The kinetics for thermal embrittlement of this steel, 1.e.. the activation energy $\mathrm{Q}$, and aging parameter $P$ corresponding to 9 efpys $(78840 \mathrm{~h})$ of service at $325^{\circ} \mathrm{C}\left(617^{\circ} \mathrm{F}\right)$ are estimated from the chemical composition and service conditions.

$$
\begin{array}{ll}
\theta=2.9 & \text { for service temperatures of } 280-330^{\circ} \mathrm{C} . \\
Q(\mathrm{~kJ} / \mathrm{mole})=117.6 & \text { from Eq. } 3.3 .5\left(\text { with } I_{1}=1 \text { and } I_{2}=0\right) . \\
P=3.752 & \text { from Eq. } 3.3 .2 .
\end{array}
$$

Step 5. The initial RT Charpy-impact energy is $209.6 \mathrm{~J}$. The normalized value is obtained by dividing by the cross-sectional area of the Charpy-impact specimen, $1 . e ., 0.8 \mathrm{~cm}^{2}$.

$$
C_{\text {Vint }}\left(\mathrm{J} / \mathrm{cm}^{2}\right)=262.0 \text {. }
$$

Step 6. The initial J-R curve for the unaged material is the higher of either Eq. 3.2.27 or the

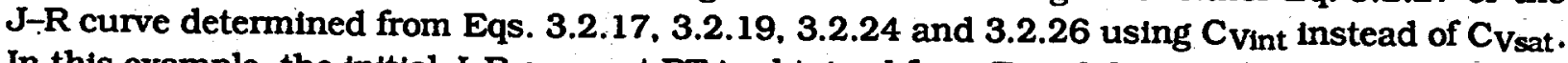
In this example, the initial $J-R$ curve at $R T$ is obtained from Eqs. 3.2.17 and 3.2.19 as

$$
\mathrm{J}_{\mathrm{d}}\left(\mathrm{kJ} / \mathrm{m}^{2}\right)=667[\Delta \mathrm{a}(\mathrm{mm})]^{0.42} \text {; }
$$

and at $290^{\circ} \mathrm{C}$ is obtained from Eqs. 3.2.24 and 3.2.26 as

$$
J_{d}\left(k J / m^{2}\right)=481[\Delta a(m m)]^{0.38}
$$




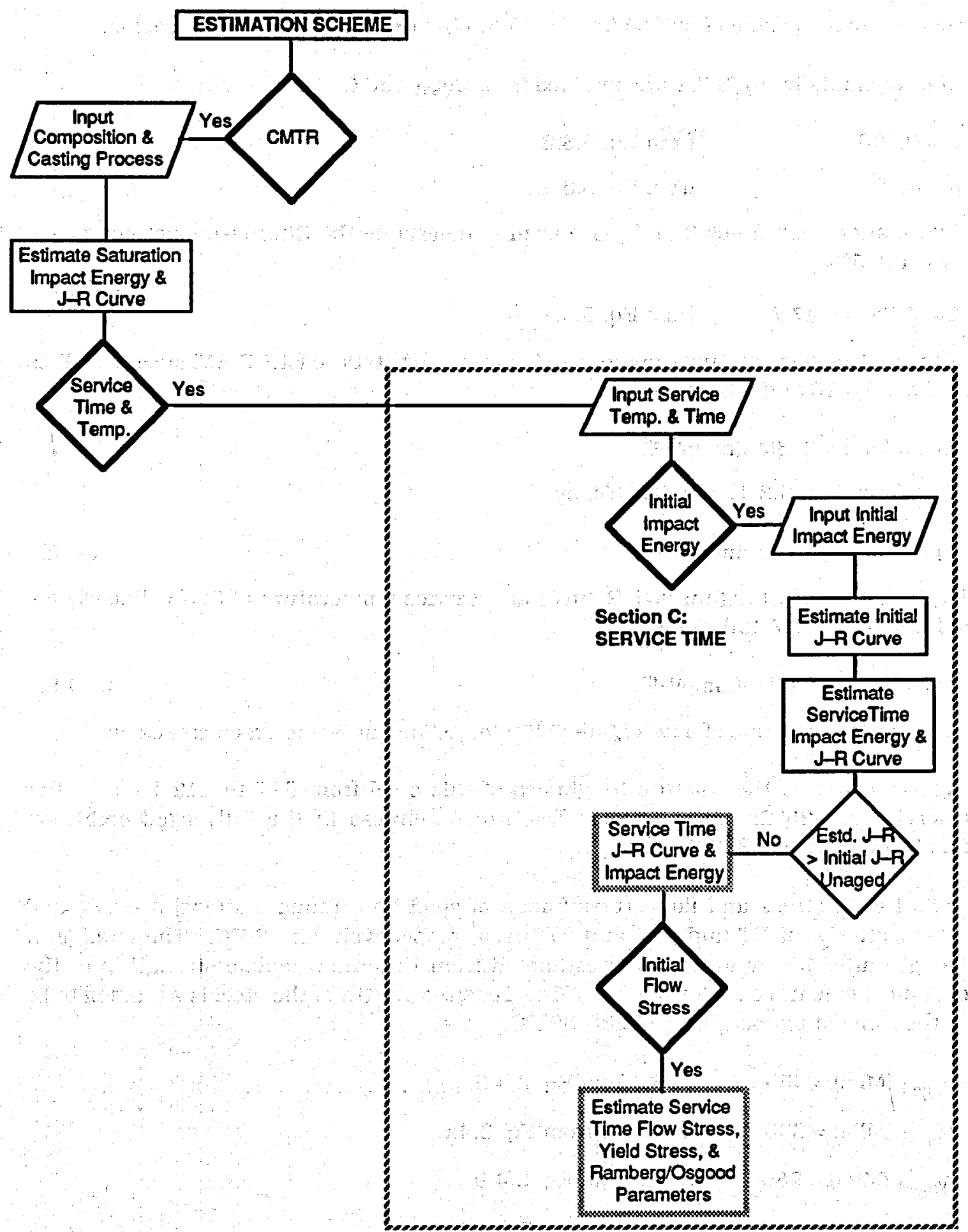

Figure A-4. Estimation scheme for Example 4

The initial-fracture-toughness $\mathrm{J}-\mathrm{R}$ curve at a service temperature of $325^{\circ} \mathrm{C}$ linearly extrapolated from Eqs. A-4.4 and A-4.5 is

$$
\mathrm{Jd}_{\mathrm{d}}\left(\mathrm{kJ} / \mathrm{m}^{2}\right)=456[\Delta \mathrm{a}(\mathrm{mm})]^{0.37} \text {. }
$$


This corresponds to a $\mathrm{J}_{\mathrm{d}}$ value of $827 \mathrm{~kJ} / \mathrm{m}^{2}\left(4723 \mathrm{ln} .1 \mathrm{~b} / \mathrm{ln} .{ }^{2}\right)$ at $5-\mathrm{mm}$ crack extension.

Step 7. The constants in Eq. 3.3.1 are obtained from CVsat and CVint.

$$
\begin{array}{ll}
\alpha=0.698 & \text { from Eq. 3.3.3. } \\
\beta=0.402 & \text { from Eq. 3.3.4. }
\end{array}
$$

Step 8. Information from Steps 2 and 7 are used to determine the Charpy-impact energy $\mathrm{CV}$ after 9 efpys at $325^{\circ} \mathrm{C}$.

$$
\mathrm{C}_{\mathrm{v}}\left(\mathrm{J} / \mathrm{cm}^{2}\right)=47.7 \quad \text { from Eq. 3.3.1. }
$$

Step 9. The service-time-fracture-toughness J-R curve for static-cast CF-8M steel, at RT, is given (from Eqs. 3.3.10 and 3.3.12) by

$$
\mathrm{J}_{\mathrm{d}}\left(\mathrm{kJ} / \mathrm{m}^{2}\right)=213[\Delta \mathrm{a}(\mathrm{mm})]^{0.36}
$$

and at $290^{\circ} \mathrm{C}$ (from Eqs. 3.3.17 and 3.3.19), by

$$
\mathrm{J}_{\mathrm{d}}\left(\mathrm{kJ} / \mathrm{m}^{2}\right)=239[\Delta \mathrm{a}(\mathrm{mm})]^{0.33} \text {. }
$$

The service-time-fracture-toughness $\mathrm{J}-\mathrm{R}$ curve at a service temperature of $325^{\circ} \mathrm{C}$ linearly extrapolated from Eqs. $A-4.7$ and $A-4.8$ is

$$
\mathrm{J}_{\mathrm{d}}\left(\mathrm{kJ} / \mathrm{m}^{2}\right)=242[\Delta \mathrm{a}(\mathrm{mm})]^{0.33} \text {. }
$$

This corresponds to a $J_{d}$ value of $412 \mathrm{~kJ} / \mathrm{m}^{2}\left(2350 \mathrm{ln} .1 \mathrm{lb} / \mathrm{in} .{ }^{2}\right)$ at 5 -mm crack extension.

Thermal aging decreases the fracture toughness of this steel from 827 to $412 \mathrm{~kJ} / \mathrm{m}^{2}$ after 9 efpy of service at $325^{\circ} \mathrm{C}$; the saturation fracture toughness in the fully aged condition corresponds to a $J_{d}$ value of $389 \mathrm{~kJ} / \mathrm{m}^{2}$.

Step 10. Initial yield stress and flow stress (mean of yield and ultimate stress) are 272 and $399 \mathrm{MPa}$, respectively, at RT and 167 and $277 \mathrm{MPa}$, respectively, at $325^{\circ} \mathrm{C}$. The change in tensile strength after 9 efpy at $325^{\circ} \mathrm{C}$ is estimated from the initial tensile strength and the kinetics of embrittlement, 1.e., a P value of 3.714. Tensile strength of the steel is assumed to be essentially the same at temperatures of $280-325^{\circ} \mathrm{C}$.

$$
\begin{array}{ll}
\sigma_{\text {aged }}(\mathrm{MPa})=455 & \text { at RT from Eq. 3.4.3. } \\
\sigma_{\text {faged }}(\mathrm{MPa})=335 & \text { at } 325^{\circ} \mathrm{C} \text { from Eq. 3.4.6. } \\
\sigma_{\text {yaged }}(\mathrm{MPa})=286 & \text { at RT from Eq. 3.4.9. } \\
\sigma_{\text {yaged }}(\mathrm{MPa})=186 & \text { at } 325^{\circ} \mathrm{C} \text { from Eq. 3.4.12. }
\end{array}
$$

Step 11. The engineering stress vs. strain behavior of the steel, up to $5 \%$ strain, can be obtained from Eqs. 3.4.16 and 3.4.19. At RT it is expressed as

$$
\frac{200,000 \varepsilon-\sigma}{455}=17.96\left(\frac{\sigma}{455}\right)^{5.6}
$$


and at $290^{\circ} \mathrm{C}$ as

$$
\frac{180.000 \varepsilon-\sigma}{335}=40.71\left(\frac{\sigma}{335}\right)^{6.6}
$$

In this example, the value of fracture toughness $\mathrm{J}_{1 \mathrm{C}}$ and tearing modulus of the aged material can also be determined from the estimated $J-R$ curve and tenstle flow stress. Furthermore. this information and the estimated Ramberg/Osgood equation may be used for elastic-plastic fracture mechanics analysis of nuclear power plant piping.

Example 6. A centrfugally cast $C F-8 M$ ptpe in service at $291^{\circ} \mathrm{C}\left(555^{\circ} \mathrm{F}\right)$ for 17 efpys. The following material information is also known.

Chem. Comp. (wt.\%): Cr, 19.64; Mo, 2.05; St. 1.02; Ni. 10.00; Mn. 1.07; C, 0.040; N, 0.151

$\begin{array}{lc} & R T \\ 0.2 \% \text { Yteld Stress (MPa): } & 242 \\ \text { Ultmate Stress (MPa): } & 495\end{array}$

Similar to Example 4, both service time and saturation fracture properties can be estimated in this case. The change in RT tensile strength can also be estimated from the avallable information. The inttial RT Charpy-Impact energy is assumed to be $160 \mathrm{~J}$, because the value is not known. The estimation scheme for this example is shown in Fig. A-5. The saturation fracture toughness represents the minimum toughness that can be achieved by this cast stainless steel after long-term aging and the service time fracture toughness is the value after 17 efpys of service at $291^{\circ} \mathrm{C}$.

Step 1. The calculated ferrite content (Eqs. $3.2 .1-3.2 .3$ ) is

$$
\delta_{c}(\%)=5.9 \text {. }
$$

Step 2. The material parameter $\Phi$ for static-cast CF-8M steel with $>10 \%$ nickel (Eq. 3.2.11) is 17.37. The saturation RT Charpy-impact energy in terms of the material parameter (Eq. 3.2.10) is $93.0 \mathrm{~J} / \mathrm{cm}^{2}$; in terms of chemical composition (Eq. 3.2.12), it is $66.4 \mathrm{~J} / \mathrm{cm}^{2}$. The lower of the two values is used for fracture toughness estimations; thus

$$
\text { CVsat }\left(\mathrm{J} / \mathrm{cm}^{2}\right)=66.4 \text {. }
$$

Step 3. The saturation fracture toughness $\mathrm{J}-\mathrm{R}$ curve for this centrifugally cast CF-8M steel, at $291^{\circ} \mathrm{C}$ (Eqs. 3.2.25 and 3.2.26), is gtven by

$$
J_{d}\left(\mathrm{~kJ} / \mathrm{m}^{2}\right)=318[\Delta \mathrm{a}(\mathrm{mm})]^{0.34}
$$

This corresponds to a $\mathrm{J}_{\mathrm{d}}$ value of $550 \mathrm{~kJ} / \mathrm{m}^{2}\left(3139 \mathrm{~m} . \cdot \mathrm{lb} / \mathrm{ln} .^{2}\right)$ at 5-mm crack extension.

Step 4. The knetics for thermal embrittlement of this steel, 1.e., the activation energy 8 , and aging parameter $P$ corresponding to 17 efpys $(148,920 \mathrm{~h})$ of service at $291^{\circ} \mathrm{C}$ are estimated from chemical composition and service conditions.

$$
\begin{array}{ll}
\theta=2.9 & \text { for service temperatures of } 280-330^{\circ} \mathrm{C} \\
Q(\mathrm{~kJ} / \mathrm{mole})=139.7 & \text { from Eq. 3.3.5 }\left(\text { with } I_{1}=1 \text { and } I_{2}=0\right) \\
P=3.077 & \text { from Eq. 3.3.2. }
\end{array}
$$




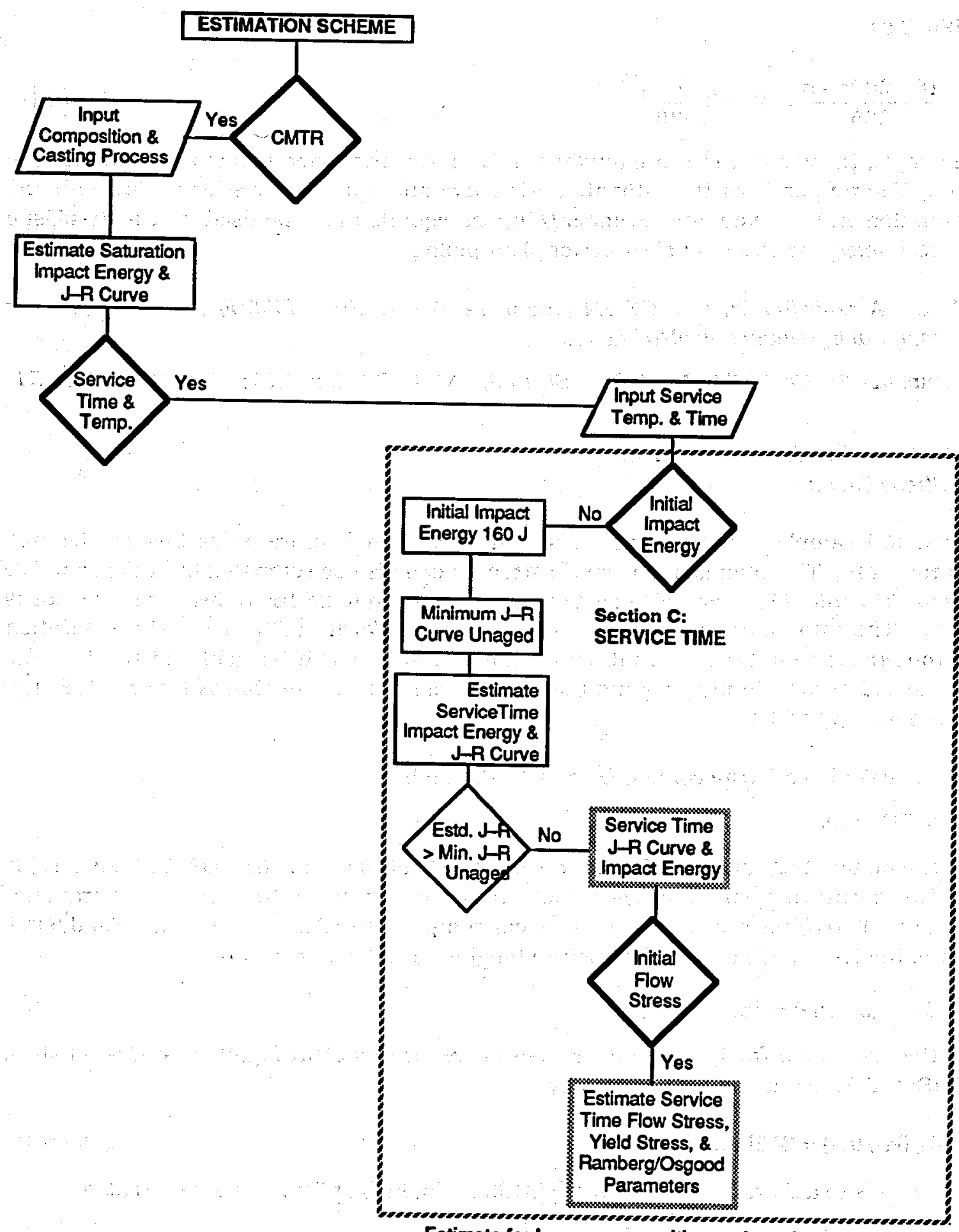

Estimate for known composition and service history

Figure A-5. Estimation scheme for Example 5

Step 5. The initial RT Charpy-impact energy is $160.0 \mathrm{~J}$. The normalized value is obtained by dividing by the cross-sectional area of the Charpy-impact specimen, $1 . e ., 0.8 \mathrm{~cm}^{2}$.

$C_{\text {Vint }}\left(\mathrm{J} / \mathrm{cm}^{2}\right)=200.0$. 
Step 6. In this example, fracture toughness of the unaged material cannot be estimated from the inttial RT Charpy-impact energy, because it is not known. The J-R curve for the unaged material given by Eq. 3.2 .28 is

$$
\mathrm{J}_{\mathrm{d}}\left(\mathrm{kJ} / \mathrm{m}^{2}\right)=650[\Delta \mathrm{a}(\mathrm{mm})]^{0.43} \text {. }
$$

Step 7. The constants in Eq. 3.3.1 are obtained from $\mathrm{CV}_{\text {sat }}$ and $\mathrm{CVInt}_{\text {. }}$

$$
\begin{array}{ll}
\alpha=0.864 & \text { from Eq. 3.3.3. } \\
\beta=0.239 & \text { from Eq. 3.3.4. }
\end{array}
$$

Step 8. Information from Steps 2 and 7 are used to determine the Charpy-impact energy $\mathrm{Cv}$ after 17 efpy at $291^{\circ} \mathrm{C}$.

$$
\mathrm{C}_{\mathrm{v}}\left(\mathrm{J} / \mathrm{cm}^{2}\right)=103.1 \quad \text { from Eq. 3.3.1. }
$$

Step 9. The service-time-fracture-toughness J-R curve for static-cast CF-8M steel, at $291^{\circ} \mathrm{C}$ (Eqs. 3.3.18 and 3.3.19), is given by

$$
\mathrm{J}_{\mathrm{d}}\left(\mathrm{kJ} / \mathrm{m}^{2}\right)=381[\Delta \mathrm{a}(\mathrm{mm})]^{0.35} \text {. }
$$

This corresponds to a $\mathrm{J}_{\mathrm{d}}$ value of $669 \mathrm{~kJ} / \mathrm{m}^{2}\left(3821 \mathrm{ln} . \cdot \mathrm{lb} / \mathrm{in} .{ }^{2}\right)$ at 5-mm crack extension.

The estimated fracture toughness of this steel after 17 efpy of service at $291{ }^{\circ} \mathrm{C}$ is $669 \mathrm{~kJ} / \mathrm{m}^{2}$; the saturation fracture toughness in the fully aged condition corresponds to a $J_{d}$ value of $550 \mathrm{~kJ} / \mathrm{m}^{2}$.

Step 10. Only RT tensile properties can be estimated in this example. Initial yield stress and flow stress (mean of yield and ultimate stress) are 242 and $369 \mathrm{MPa}$, respectively, at RT. The change in tensile strength after 17 efpys at $291^{\circ} \mathrm{C}$ is estimated from the initial tensile strength and the kinetics of embrittlement, 1.e., a $P$ value of 3.077 .

$$
\begin{array}{ll}
\sigma_{\text {aged }}(\mathrm{MPa})=398 & \text { at RT from Eq. 3.4.3. } \\
\sigma_{\text {yaged }}(\mathrm{MPa})=242 & \text { at RT from Eq. 3.4.9. }
\end{array}
$$

Step 11. The engineering stress vs. strain behavior of the steel, up to $5 \%$ strain, can be obtained from Eq. 3.4.16. At $\mathrm{RT}$ it is expressed as

$$
\frac{200,000 \varepsilon-\sigma}{398}=22.08\left(\frac{\sigma}{398}\right)^{5.6}
$$

In this example, the value of fracture toughness $\mathrm{J}_{\mathrm{IC}}$ and tearing modulus of the aged material can also be determined from the estimated $J-R$ curve and tensile flow stress. Furthermore, this information and the estimated Ramberg/Osgood equation may be used for elastic-plastic fracture mechanics analysis of nuclear power plant piping. 
P. H. Pumphrey, National Power, Technology and Environment Center, Leatherhead, Surrey, UK

D. Quiñones, Robert Cloud \& Associates, Berkeley, CA

C. Y. Rieg, Electricité de France, Villeurbanne Cedex, France

V. N. Shah, EG\&G Idaho, Inc., Idaho Falls, Idaho

V. K. Sikka, Oak Ridge National Laboratory

A. Singh, Unical Science \& Technology Division, Brea, CA

G. Slama, Framatome, Paris La Defense, France

G. D. W. Smith, Oxford University, Oxford, UK

H. D. Solomon, General Electric Co., Schenectady, NY

D. M. Stevens, Lynchburg Research Center, Babcock \& Wilcox Co., Lynchburg, VA

L. Taylor, Nuclear Electric plc., Chelsford Rd., Knutsford, Cheshire, UK

J. C. Van Duysen, Electricité de France, Moret-Sur-Loing, France

J. M. Vitek, Oak Ridge National Laboratory

J. Wilks, AMOCO, Naperville, IL 


\begin{tabular}{|c|c|c|}
\hline 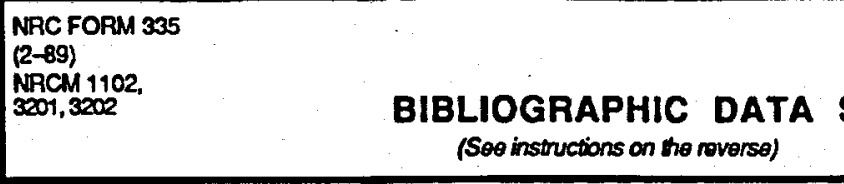 & $\begin{array}{l}\text { U. S. MUCLEAR REGULATORY COMMISSION } \\
\text { SHEET }\end{array}$ & $\begin{array}{l}\text { 1. REPORT NUMBER } \\
\text { (Assignod by NRC. Aod Vol, supp., Rov., } \\
\text { andAddondum Numbers, if any.) } \\
\text { NUREG/CR-4513 } \\
\text { ANL-93/22 } \\
\text { ReV. } 1\end{array}$ \\
\hline \multirow{4}{*}{\multicolumn{2}{|c|}{$\begin{array}{l}\text { 2. TITLE AND SUBTILE } \\
\text { Estimation of Fracture Toughness of Cast Stainless Steels } \\
\text { during Thermal Aging in LWR Systems }\end{array}$}} & Rev. 1 \\
\hline & & 3. DATE REPORT PUBLISHED \\
\hline & & \begin{tabular}{|c|c|} 
MONTH & YEAR \\
August & 1994 \\
\end{tabular} \\
\hline & & $\begin{array}{l}\text { 4. FIN OR GRANT NUMBER } \\
\text { A2243 }\end{array}$ \\
\hline $\begin{array}{l}\text { 5. AUTHOR(S) } \\
\text { O. K. Chopra }\end{array}$ & & $\begin{array}{l}\text { 6. TYPE OF REPORT } \\
\text { Technical }\end{array}$ \\
\hline 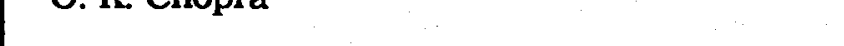 & & 7. PERIOO COVERED (hctusive Detos) \\
\hline
\end{tabular}

Argonne National Laboratory

9700 South Cass Avenue

Argonne, IL 60439

9. SPONSORING ORGANIZATION - NAME AND ADDRESS (IF NRC, type "Same as above": if contractor, provide NRC Division, Office or Region, U.S. Nuclear Regulatory Commission, and maling addrass.)

Division of Engineering

Office of Nuclear Regulatory Research

U. S. Nuclear Regulatory Commission

Washington, DC 20555 -0001

10. SUPPLEMENTAPY NOTES

11. ABSTRACT (200 words or less)

This report presents a revision of the procedure and correlations presented earlier in NUREG/CR4513. ANL-90/42 (June 1991) for predicting the change in mechanical properties of cast stainless steel components due to thermal aging during service in light water reactors at $280-330^{\circ} \mathrm{C}(535-$ $625^{\circ} \mathrm{F}$. The correlations presented in this report are based on an expanded database and have been optimized with mechanical-property data on cast stainless steels aged up to $=58,000 \mathrm{~h}$ at $290-350^{\circ} \mathrm{C}$ $\left(554-633^{\circ} \mathrm{F}\right)$. The correlations for estimating the change in tensile stress, including the Ramberg/Osgood parameters for strain hardening, are also described. The fracture toughness J-R curve, tensile stress, and Charpy-impact energy of aged cast stainless steels are estimated from known material information. Mechanical properties of a specific cast stainless steel are estimated from the extent and kinetics of thermal embrittlement. Embrittlement of cast stainless steels is characterized in terms of room-temperature Charpy-impact energy. The extent or degree of thermal embrittlement at "saturation," 1.e., the minimum impact energy that can be achieved for a material after long-term aging, is determined from the chemical composition of the steel. Charpy-impact energy as a function of time and temperature of reactor service is estimated from the kinetics of thermal embrittlement, which are also determined from the chemical composition. The Initial impact energy of the unaged steel is required for these estimations.

12. KEY WORDSTOESCRIPTORS (List wonds or phrases that will assist rosearchers in bcating this report.)

Cast duplex stainless steel

Cast stainless steel

Embrittlement

Fracture toughness

Impact strength

J-R curve

Thermal aging

\begin{tabular}{|c|}
\hline $\begin{array}{l}\text { 13. AVALABLLITYSTATEMENT } \\
\text { Unlimited }\end{array}$ \\
\hline 14. SECURITY CLASSIFICATION \\
\hline $\begin{array}{l}\text { (This Page) } \\
\text { Unclassified }\end{array}$ \\
\hline $\begin{array}{l}\text { (This Roport) } \\
\text { Unclassified }\end{array}$ \\
\hline 15. NUMBER OF PAGES \\
\hline 18. PRICE \\
\hline
\end{tabular}


Printed

on recycled

paper

Federal Recycling Program 